\title{
Cholinergic Receptor Modulation as a Target for Preventing Dementia in Parkinson's Disease
}

\author{
Alexandre larkov ${ }^{1 *}$, Cristhian Mendoza ${ }^{1}$ and Valentina Echeverria ${ }^{1,2 *}$ \\ 1 Laboratorio de Neurobiología, Facultad de Ciencias de la Salud, Universidad San Sebastián, Concepción, Chile, ${ }^{2}$ Research \\ \& Development Service, Bay Pines VA Healthcare System, Bay Pines, FL, United States
}

\section{OPEN ACCESS}

Edited by:

Kathleen A. Maguire-Zeiss, Georgetown University, United States

Reviewed by:

Andreas Wree,

University of Rostock, Germany

Roberto Cilia,

Carlo Besta Neurological Institute

(IRCCS), Italy

${ }^{*}$ Correspondence:

Alexandre larkov

alexandre.iarkov@uss.cl

Valentina Echeverria

valentina.echeverria@uss.cl

Specialty section:

This article was submitted to Neurodegeneration,

a section of the journal

Frontiers in Neuroscience

Received: 09 February 2021

Accepted: 26 August 2021

Published: 20 September 2021

Citation:

larkov A, Mendoza C and Echeverria V (2021) Cholinergic Receptor Modulation as a Target for Preventing Dementia

in Parkinson's Disease.

Front. Neurosci. 15:665820. doi: 10.3389/fnins.2021.665820
Parkinson's disease (PD) is a neurodegenerative condition characterized by the loss of dopaminergic neurons in the substantia nigra pars compacta (SNpc) in the midbrain resulting in progressive impairment in cognitive and motor abilities. The physiological and molecular mechanisms triggering dopaminergic neuronal loss are not entirely defined. $\mathrm{PD}$ occurrence is associated with various genetic and environmental factors causing inflammation and mitochondrial dysfunction in the brain, leading to oxidative stress, proteinopathy, and reduced viability of dopaminergic neurons. Oxidative stress affects the conformation and function of ions, proteins, and lipids, provoking mitochondrial DNA (mtDNA) mutation and dysfunction. The disruption of protein homeostasis induces the aggregation of alpha-synuclein $(\alpha-S Y N)$ and parkin and a deficit in proteasome degradation. Also, oxidative stress affects dopamine release by activating ATP-sensitive potassium channels. The cholinergic system is essential in modulating the striatal cells regulating cognitive and motor functions. Several muscarinic acetylcholine receptors (mAChR) and nicotinic acetylcholine receptors (nAChRs) are expressed in the striatum. The nAChRs signaling reduces neuroinflammation and facilitates neuronal survival, neurotransmitter release, and synaptic plasticity. Since there is a deficit in the nAChRs in $\mathrm{PD}$, inhibiting $\mathrm{nAChRs}$ loss in the striatum may help prevent dopaminergic neurons loss in the striatum and its pathological consequences. The nAChRs can also stimulate other brain cells supporting cognitive and motor functions. This review discusses the cholinergic system as a therapeutic target of cotinine to prevent cognitive symptoms and transition to dementia in PD.

Keywords: cotinine, dementia, Parkinson's disease, cholinergic interneurons, medium spiny neurons, striatum

Abbreviations: MPTP, 1-methyl-4-phenyl-1,2,3,6-tetrahydropyridine; 6-OHDA, 6-hydroxydopamine; ATP, adenosine 5'triphosphate; $\alpha$-SYN, Alpha synuclein; A $\beta$, Amyloid beta peptide; APP, A $\beta$ precursor protein; AChEI, acetylcholinesterase inhibitors; AD, Alzheimer's disease; BDNF, brain-derived neurotrophic factor; CREB, cAMP response element-binding protein; ChI, cholinergic interneurons; COX-2, cyclooxygenase 2; DA, dopamine; D1R, dopamine receptor 1; D2R, dopamine receptor; EGFR, epidermal growth factor receptor; ERK, extracellular signal-regulated protein kinase; GFAP, glial fibrillar acidic protein; GSK3, $\beta$ glycogen synthase kinase $3 \beta$; GPi, Globus pallidus internal; GST, glutathione S-transferase activity; HIF-1, hypoxia-inducible factor-1; IL, Interleukin; JAK2, Janus kinase 2; MRI, Magnetic resonance imaging; MCI, Mild cognitive impairment; MAOIs, monoamine oxidase inhibitors; NFKB, neurotrophic factor kappa B; nAChRs, nicotinic acetylcholine receptors; mAChRs, muscarinic acetylcholine receptors; NOS, nitric oxide synthase; NMDA, N-methyl-Daspartate; PAM, positive allosteric modulator; PD, Parkinson's disease; PARK2, Parkinson disease-2; PARK8, Parkinson disease-8; PDD, Parkinson's disease dementia; PDGF, platelet-derived growth factor; PDGFR, PDGF receptor; PI3K, phosphatidylinositol 3-kinase; Akt, Protein kinase B; PPN, pedunculopontine; PPNd, PPN pars dissipatus; PPNpc, PPN pars compacta; PSD95, postsynaptic density protein 95; STAT, signal transducer and activator of transcription; SN, substantia nigra; SNpc, SN pars compacta; STN, subthalamic nucleus; TNF, tumor necrosis factor; VEGF, vascular endothelial growth factor; VEGFR, vascular endothelial growth factor receptor; VTA, ventral tegmental area. 


\section{INTRODUCTION}

Parkinson's disease (PD) is a severe neurodegenerative condition characterized by the death of dopaminergic motor and nonmotor symptoms leading to locomotor impairment, loss of cognitive function, dementia, psychiatric disorders, and premature death (Gelb et al., 1999; Leverenz et al., 2009; Subramaniam and Chesselet, 2013; Grover et al., 2015; Aarsland et al., 2017; Martin-Jimenez et al., 2017; Poewe et al., 2017; Walker et al., 2019; Wichmann, 2019; Hussein et al., 2021).

More than a century of studies in PD achieved breakthrough discoveries in the etiology of this disease and the role of cholinergic neurons (Quik et al., 2015b; Jurado-Coronel et al., 2016; Rizzi and Tan, 2017; Tanimura et al., 2018; Ztaou and Amalric, 2019; Iarkov et al., 2020; Liu, 2020). These studies indicated that the etiology of PD is not entirely clear and has a complex and multifactorial nature (Olanow and Tatton, 1999; Takahashi and Yamada, 1999; Thomas and Beal, 2007; Guttuso et al., 2019b; O'Callaghan and Miller, 2019; Hasan et al., 2020). Etiological risk factors are considered a combination of age, gender, genetic background, and environmental factors (Carvey et al., 2003; Thomas and Beal, 2007; Pavlou and Outeiro, 2017; Videira and Castro-Caldas, 2018; Guo et al., 2019; Mehra et al., 2019; Delic et al., 2020; Kline et al., 2020). Nevertheless, less than $15 \%$ of PD cases have a family history, and most of them are sporadic and seemingly caused by deleterious environmental factors acting synergically with susceptibility genes to affect the striatum activity (Foltynie et al., 2002a,b; Ferrer et al., 2011; Wirdefeldt et al., 2011; Deng et al., 2018; Guo et al., 2019). However, much remains unclear, and effective treatments have yet to be developed based on innovative new strategies (Liu et al., 2010; Campos et al., 2011; Schapira, 2011; Irwin et al., 2016; Wang et al., 2017; Shimohama and Kawamata, 2018; Iarkov et al., 2020). A decline of the flow of information from midbrain dopaminergic neurons to the striatum, limbic, and cortical regions and a deficiency of dopamine (DA) in these structures are central events triggering PD (Alexander, 2004; Cerasa et al., 2016; Anderkova et al., 2017; Galantucci et al., 2017). The decrease of incoming dopaminergic input disrupts complex regulatory mechanisms in the overlying structures (Gale et al., 2008; Schapira and Jenner, 2011; Singh et al., 2017). Deficiency of DA can arise due to the neuronal death or synaptic dysfunction of dopaminergic neurons in the midbrain (Schulz-Schaeffer, 2010, 2015; George et al., 2013). The striatum contains mainly GABAergic medium spiny neurons (MSN) and large aspiny choline interneurons ChIs (Alexander et al., 1986; Conti et al., 2018; Tanimura et al., 2018; Martel and Apicella, 2021). At the cellular level, DA deficiency induces an imbalance of the activity of different MSN populations resulting in motor and behavioral disturbances (Alexander, 2004; Taverna et al., 2008; Tozzi et al., 2011; Gallo, 2019; Iarkov et al., 2020). MSNs expressing the DA receptor 2 (D2R) will decrease their activity, while neurons expressing the DA receptor 1 (D1R) will increase it (Taverna et al., 2008; Tozzi et al., 2011; Gallo, 2019). Alteration of the indirect and direct pathways to globus pallidus internal (GPi)/Substantia nigra pars reticulata (SNpr) impairs the communication of the thalamus with the motor cortex resulting in motor dysfunction
(Alexander et al., 1986; Bjorklund and Dunnett, 2007; RodriguezSabate et al., 2021). In other words, an enhanced excitatory output from the subthalamic nucleus (STN) increases the activity of the GP that induces an anomalous inhibitory outflow to the thalamus and brain stem areas (Braak and Braak, 2000; Cerasa et al., 2016; Iarkov et al., 2020; van Nuland et al., 2020). The inhibition of the thalamus affects the thalamocortical communication triggering movement abnormalities characteristic of $\mathrm{PD}$, such as bradykinesia (DeLong, 2000; Poewe et al., 2017; Wichmann, 2018; Reich and Savitt, 2019).

Though PD is a progressive neurodegenerative disease that is mainly considered a clinically dominant movement disorder, it also has noticeable non-motor symptoms such as psychiatric signs of depression, anxiety, and cognitive impairment, some of which may appear even before the motor ones (Hemmerle et al., 2012; Lindqvist et al., 2012; Lohle et al., 2019; Mendonca et al., 2020; Carey et al., 2021; Hussein et al., 2021; Kwon et al., 2021).

Many research groups have investigated the prevalence, sex differences, morphological and functional changes, and biomarkers to predict the progression from cognitive impairment to dementia in PD (Braak et al., 2005; Anang et al., 2017; Hoogland et al., 2017; Ye et al., 2017; Cholerton et al., 2018; Friedman, 2018; Hussain and Camicioli, 2018; Lanskey et al., 2018; Renouf et al., 2018; Zou et al., 2018; Agelink van Rentergem et al., 2019; Berman and Miller-Patterson, 2019; Chondrogiorgi et al., 2019; Chung et al., 2019; Palermo et al., 2019a,b; Yoo et al., 2019; Byeon, 2020).

Almost two decades ago, Braak et al. (2005) found an association between cognitive status and the neuropathologic stages of PD in patients with the sporadic form of the disease. The authors assessed Lewy bodies (LBs) immunoreactive for $\alpha$-SYN and neuropathological markers for comorbidities such as Alzheimer's disease $(\mathrm{AD})$ that could be contributing to cognitive decline. The authors divided the patients into groups from marginally impaired cognition to severe dementia according to the Mini-Mental State Examination (MMSE) scores. The results showed that MMSE scores positively and linearly correlated with ascending neuropathologic stages (Braak et al., 2005). Cognitively impaired patients showed higher levels of $\mathrm{AD}$ like neuropathology, including beta-amyloid $(A \beta)$ deposition than cognitively intact patients. MMSE scores did not correlate significantly with disease duration, age at disease onset, or death. The authors concluded that a decrease in MMSE scores between the disease stages 3 to 6 raises the risk of developing dementia during PD progression (Ross et al., 1996; Braak et al., 2005). However, in some patients, cognitive decline develops in the absence of substantial PD-related cortical pathology and, on the contrary, in other patients, extensive cortical neuropathology does not unavoidably lead to cognitive decline and dementia (Green et al., 2002; Braak et al., 2005; Leverenz et al., 2009). Further studies have given more insight into the mechanisms and morphological correlations of cognitive impairment progression to dementia (Aybek et al., 2009; Foster et al., 2013; Aarsland et al., 2017; Lanskey et al., 2018).

On the other hand, other non-motor symptoms, including anxiety and depression, and impulse control disorder, and psychosis, affect many patients, with a prevalence of $50-80 \%$, 
often appearing at the early stages of the disease is only partially treated by conventional treatments such as L-DOPA and new treatments have been tested (Bonito-Oliva et al., 2014; Titova and Chaudhuri, 2018; Eisinger et al., 2019; Hussein et al., 2021). Experimentally, non-motor symptoms can be induced in mice by bilateral injection of the toxin 6-hydroxydopamine (6-OHDA) in the dorsal striatum. This mouse model of PDlike pathology shows only slight gait modifications, with no horizontal motor activity changes as tested in the open-field test. However, The treated mice showed depressive-like behavior such as increased immobility in the forced swim and tail suspension tests.

Additionally, mice showed anxiety, expressed as a reduced time spent in the open arms in the classic anxiety test elevated plus maze test and increased thigmotaxis in the open-field test. L-DOPA did not decrease depressive- and anxiety-like behaviors. Reboxetine, a noradrenaline reuptake inhibitor, reverted the depressive and anxiogenic effects. However, desipramine used to preserve noradrenaline neurons, when administered before injection of 6-OHDA, did not modify the resultant depressiveand anxiety behaviors. The authors concluded that mood-related disorders were not due to a decrease in noradrenaline (BonitoOliva et al., 2014). Last decade studies have indicated the involvement of alteration of the serotoninergic system and its components, such as the serotonin receptors, with the appearance of depression in PD (Ballanger et al., 2012; Bonito-Oliva et al., 2014; Maillet et al., 2016). One of these studies used positron emission tomography (PET) and (18)F (Roselli et al., 2010) MPPF, a selective serotonin $1 \mathrm{~A}$ receptor antagonist, to investigate whether changes in this receptor activity at the postsynaptic site were involved in the pathophysiology of depression. Compared with non-depressed parkinsonian patients, depressed patients showed a lower tracer uptake in the left hippocampus, the right insula, the left superior temporal cortex, and the orbitofrontal cortex. Compared with controls, non-depressed parkinsonian patients presented a reduced F-18 MPPF uptake bilaterally in the frontal cortex and the right ventral striatum and insula. Compared with controls, F-18 MPPF uptake was decreased in depressed parkinsonian patients in the left dorsal anterior cingulate and orbitofrontal cortices, in the right hippocampal region, and the temporal cortex. The imaging data suggest that serotonin $1 \mathrm{~A}$ receptor dysfunction in the limbic system may underly depression in patients with PD (Ballanger et al., 2012; Bonito-Oliva et al., 2014; Maillet et al., 2016). The mechanism of action of various neuroprotective strategies to prevent PD is under investigation; however, efficacious new therapeutic approaches still need to be discovered (Guo et al., 2019; JuradoCoronel et al., 2019; Iarkov et al., 2020).

\section{THE ROLE OF LEWY BODIES IN PD}

The progressive appearance of protein deposits called Lewy bodies often accompanies the loss of dopaminergic neurons in various brain regions (Schulz-Schaeffer, 2010; Mehra et al., 2019). These deposits contain elevated misfolded $\alpha$-synuclein $(\alpha-$ SYN) oligomers and aggregates, neurofilaments, and ubiquitin inside neurons and glia (Braak et al., 1998; Martin et al., 2012). Although the role of Lewy bodies in the development of PD is still unknown, the neuropathological diagnosis of PD was base on its detection and quantification (Beach et al., 2008, 2009). Intriguingly, not always neurodegeneration of dopaminergic neurons is accompanied by Lewy bodies (Tompkins et al., 1997; Burke and O'Malley, 2013). Patients with mutations in $\alpha$-SYN present [Parkinson disease (PARK)1, PARK3/4/5] or not present (PARK2 and PARK8) Lewy bodies associated with nigral degeneration (Foltynie et al., 2002b; Duce et al., 2017). Mutations such as PARK1 lead to amino acid changes such as A53T that increase $\alpha$-SYN aggregation to form oligomers and fibrils (Duce et al., 2017). DA inhibits the transition of the protein oligomers neurotoxic to filaments, a property that may clarify the higher vulnerability of dopaminergic cells to neurodegeneration in PD (Foltynie et al., 2002b). Moreover, neurons in the $\mathrm{SN}$, regardless of whether they contain Lewy bodies or not, present morphological dendritic abnormalities or biochemical changes, indicating that all neurons are involved in the disease process (Patt et al., 1991; Bergeron et al., 1996; Hill, 1996; Devi et al., 2008). Due to its structure, $\alpha$-SYN can interact with anionic lipids, which leads to conformational changes that facilitate its aggregation into toxic species (Schapira and Jenner, 2011; Bose and Beal, 2016; Shamoto-Nagai et al., 2018; Zeng et al., 2018; Gilmozzi et al., 2020). For instance, the accumulation of mutant forms of $\alpha$-SYN in the inner mitochondrial membrane disrupts complex I, increasing the production of reactive oxygen species (ROS) and contributing to neuronal apoptosis (Devi et al., 2008). ROS influence cellular self-defenses by promoting the cytoprotective effects of DJ-1 and PTEN-induced putative kinase 1 (PINK1) while inducing Akt dysregulation (Zhao et al., 2017).

\section{WHY ARE DOPAMINERGIC NEURONS IN THE MIDBRAIN SO VULNERABLE?}

Dopaminergic neurons in the midbrain have unique morphological characteristics that may contribute to their enhanced vulnerability (Carlsson and Fornstedt, 1991; Chung et al., 2005; Alavian et al., 2008; Hegarty et al., 2013). For example, DA neurons have long unmyelinated axons and massive dendrites that branch out into SNpr, with their somas being less than $1 \%$ of the total volume of these cells (Iarkov et al., 2020). Due to this morphology, a relatively small number of neurons provide massive dopaminergic innervation of the striatum (Sulzer, 2007). It has been calculated that each neuron in the SN may have up to 150,000 presynaptic terminals in the striatum (Oorschot, 1996; Sulzer and Schmitz, 2007). The normal functioning of such neurons requires highly active axonal transport through microtubules to support metabolic and reparative processes, synaptogenesis, removal of cellular waste, and communication with other brain cells (Prots et al., 2013, 2018; Lu et al., 2014). These cellular process demands high levels of ATP, turning DA neurons in the SN exceptionally susceptible to mitochondrial dysfunction during the development of PD (Horowitz et al., 2011; Venkateshappa et al., 2012; 
Vanhauwaert and Verstreken, 2015; Course and Wang, 2016; Burbulla et al., 2017).

\section{MOLECULAR MECHANISMS ASSOCIATED WITH PD}

It is reasonable to postulate that an accumulation of risk factors above the repair capacity of DA neurons triggers mitochondrial dysfunction, abnormal accumulation of misfolded proteins, oxidative stress, and tau hyperphosphorylation in the PD brain (Alexander, 2004; Perier and Vila, 2012; Franco-Iborra et al., 2016; Jiang and Dickson, 2018). Tau dysfunction disrupts the potential of the mitochondrial membrane, impairs the activity of respiratory enzymes, resulting in a decreased ATP production and energy supply as well as increased reactive oxygen species (ROS) production $\left(\mathrm{O}^{2-}\right.$ and $\mathrm{H}_{2} \mathrm{O}_{2}$ ) (Bose et al., 2011; Keane et al., 2011; Sutachan et al., 2012). Oxidative stress damages cellular organelles and the DNA, an event that is particularly dangerous for mitochondrial DNA that does not have protective histones and therefore is more vulnerable to ROS damage than nuclear DNA (Dexter and Jenner, 2013). Once started, the disease develops on the principle of positive feedback; oxidative stress can potentiate different risk factors, such as age and unfavorable environmental conditions to induce mutations in both cellular and mitochondrial DNA (Bandy and Davison, 1990). Although mitochondria contain the genetic information to produce proteins, most mitochondrial proteins, including those involved in DNA transcription, translation, and repair, are encoded by nuclear DNA and transported to mitochondria from the cytosol (Lenka et al., 1998; Lee et al., 2005). DNA mutations affecting genes involved in mitochondrial electron transport, glucose utilization, and glucose sensing may correlate with PD occurrence (Blanch et al., 2016; Requejo-Aguilar and Bolanos, 2016; Grunewald et al., 2019). It has been found that 28 sets of genes are linked to $\mathrm{PD}$, likely playing a pathogenic role at the early stages of the disease (Anderson and Becker, 1981; Zheng et al., 2010; Keane et al., 2011). Currently, a more extensive list of genes is associated with the onset of PD, supporting the multifactorial etiology of both familial and sporadic cases of PD (Scott et al., 2017; Lu et al., 2018; Zeng et al., 2018; Kline et al., 2020; Wang et al., 2020b; Allende et al., 2021; Martinez-Banaclocha, 2021).

An early study investigating changes in the binding of the $\alpha 4 \beta 2$ nAChR tracer 5- (125)I-A-85380 in PD found a loss of striatal 5-(125)I-A-85380 binding that correlated with the loss of nigrostriatal dopaminergic markers (Pimlott et al., 2004). Similar changes were observed in subjects with dementia with Lewy bodies (DLB) that showed a reduced striatal 5-(125)I-A85380 binding density, which the authors interpreted as an early degeneration in nigrostriatal inputs. These results suggest the involvement of the nAChRs on PD etiology (Pimlott et al., 2004). In agreement with this idea, multiple epidemiological studies have shown that active smokers have a lower risk of developing PD (Fratiglioni and Wang, 2000; Quik, 2004; Chapman, 2009; Chen et al., 2010; Greenbaum et al., 2013; Gallo et al., 2019; Cheng and Wang, 2020; Kim et al., 2020; Mappin-Kasirer et al., 2020) encouraging the investigation of the potential neuroprotective effects of alkaloids such as nicotine and other nicotinoids from tobacco plants with positive results (Maggio et al., 1998; Linert et al., 1999; Court et al., 2000; Mihailescu and Drucker-Colin, 2000; Quik and Kulak, 2002; Soto-Otero et al., 2002; Quik et al., 2006; Park et al., 2007; Bordia et al., 2008; Huang et al., 2009). This effect has been attributed mainly to nicotine or its metabolites acting on the AChRs (Bordia et al., 2008; Huang et al., 2009). On the other hand, nAChRs are expressed on every cell of the dopaminergic system and exert many neuroprotective effects. For this reason, modulators of the nAChRs may act as preventative drugs against PD deserve more in-depth consideration (Parain et al., 2001, 2003; Soto-Otero et al., 2002; Bordia et al., 2008; O'Leary et al., 2008; Riveles et al., 2008; Hong et al., 2009; Huang et al., 2009, 2011b; Bordia et al., 2010; Quik et al., 2012, 2013a; Barreto et al., 2014; Iarkov et al., 2020).

On the other hand, other authors have attributed these potential positive effects of tobacco consumption in decreasing the risk for PD to the content of lithium in the cigarettes (Guttuso, 2019; Guttuso et al., 2019a,b). These effects have been linked to changes in the activity of beta-Catenin, a transcriptional cofactor that upregulates the expression of canonical Wnt target genes, that it has been found reduced in sporadic PD and cell carrying Leucine-rich repeat serine/threonine-protein kinase (LRPK) 2 and beta-glucosidase PD-linked mutations (Marchetti, 2018). Also, smokers' brains have significantly lower alphasynuclein levels. Tobacco contains very high lithium levels compared to other plants. Lithium has a broad array of neuroprotective actions, including enhancing autophagy and reducing intracellular alpha-synuclein levels, and is effective in neurotoxin and transgenic preclinical PD models (Guttuso, 2019; Guttuso et al., 2019a,b; Vallee et al., 2021). One of the lithium's neuroprotective actions is the enhancement of betacatenin-mediated activity, leading to increased Nurr1 expression through its ability to inhibit glycogen synthase kinase-3 beta (GSK3B) (Zhu et al., 2014; Guttuso, 2019; Guttuso et al., 2019b; Vallee et al., 2021). The authors hypothesized that inhaled lithium from smoking might account for the associated reduced rates of PD, a beneficial effect mediated by the inhibition of GSK $3 \beta$ and activation of beta-catenin, two factors that could be effective therapeutic targets against $\mathrm{PD}$, for neuroprotective drugs, including the ones modulating the $\alpha 7 \mathrm{nAChRs}$ (L'Episcopo et al., 2014; Liu et al., 2017; Guttuso, 2019; Guttuso et al., 2019b; Vallee et al., 2021).

\section{NEUROTRANSMITTER SYSTEMS IN THE STRIATUM ALTERED BY PD}

The striatum receives many synaptic inputs from all cortical regions and the thalamus providing excitatory glutamatergic afferents (Aosaki et al., 2010; Ferre et al., 2010; Huang et al., 2011a,b). At the same time, the nigrostriatal pathway delivers modulatory neurotransmitters such as DA, ACh, GABA, nitric oxide, and adenosine (Calabresi et al., 2000a; Morelli et al., 2010; Parent et al., 2011; Tripathy et al., 2015; Sanjari Moghaddam et al., 2017; Lopes et al., 2019). All these neurotransmitter systems modulate the efficacy of the synaptic transmission in the striatum, 
which processes excitatory glutamatergic signals from cortical and thalamic afferents and modulates signals from dopaminergic neurons of the midbrain, aspiny GABAergic, and cholinergic interneurons (Bolam et al., 2000; Kreitzer and Malenka, 2008; Gerfen and Surmeier, 2011). These signals are received and processed by the dorsal striatum MSN, which make up 9095\% of the striatum neuron population (Tepper et al., 2007). The remaining $5-10 \%$ of striatum neurons are interneurons, including the GABA and ACh interneuron (ChI) populations, which are significant regulators of both MSN and striatal afferents (Durieux et al., 2011; Munoz-Manchado et al., 2018). Among them, the most important are ChIs, which closely interact with DA afferents of the midbrain (Kim et al., 2019; Dautan et al., 2020). The glutamatergic, serotonergic, cholinergic, GABAergic, noradrenergic systems are involved in modulating the striatum's output signals (Calabresi et al., 2000a; Do et al., 2012; Zhai et al., 2019). In addition, opioids, neuropeptides, steroids, and adenosine receptors families are present in the dorsal striatum (Aosaki et al., 2010; Ferre et al., 2010; Huang et al., 2011b; Moreno et al., 2011; Quik et al., 2012, 2013a; Almey et al., 2015; Iarkov et al., 2020). Due to the presence of such a variety of modulators, DA deficiency could be surmounted by modulating these receptors (Quik and McIntosh, 2006; Quik et al., 2007; Livingstone and Wonnacott, 2009; Avena and Rada, 2012; Goldberg et al., 2012; Mathur and Lovinger, 2012; Myslivecek et al., 2017; Ferre and Ciruela, 2019; Ztaou and Amalric, 2019; Liu, 2020).

\section{INTERACTION OF THE CHOLINERGIC AND DOPAMINERGIC SYSTEMS IN THE STRIATUM}

Both the dopaminergic and cholinergic systems belong to the regulatory systems of the brain, the neurons of which are actively involved in maintaining the body's homeostasis (Picciotto et al., 2012; Rizzi and Tan, 2017). They have a similar anatomical structure with the neuronal bodies of both systems located in the brain stem, midbrain, and subcortical structures of the forebrain, and they send their axons throughout the forebrain toward the cortex hippocampus, and limbic structures (see Figure 1). Both express several different types of receptors that can generate a wide range of cellular responses (Rizzi and Tan, 2017). It is essential to keep in mind that during the development of PD, the brain loses not only dopaminergic neurons but also cholinergic and serotonergic neurons (Reader and Dewar, 1999; Roselli et al., 2010; Ferrer et al., 2012; Myslivecek, 2021).

There are four primary sources of cholinergic projections in the mammalian brain: the pedunculopontine (PPN) and laterodorsal tegmental nuclei, the thalamic nuclei, the striatum, where a small number of giant cholinergic neurons play the role of local interneurons, and the basal forebrain nuclei, that collectively serve as crucial sources of cholinergic neurons projecting toward the neocortex, hippocampus, and amygdala (Figure 1; Garcia-Rill, 1986; Charara and Parent, 1994; Bohnen et al., 2011; Stein and Aziz, 2012; Dautan et al., 2014). The PPN can be divided into two subnuclei, the pars compacta (PPNc) and pars dissipatus (PPNd), and it is involved in starting and modulating stereotyped movements, including gait (Garcia-Rill, 1986; Snijders et al., 2016; Dos Santos et al., 2021). Glutamatergic neurons of the PPNd (pars dissipatus) regulates the basal ganglia and spinal cord. In contrast, the cholinergic pars compacta (PPNc) is part of the loop connecting the spinal cord and limbic areas with the basal ganglia and thalamus (Bohnen et al., 2011; French and Muthusamy, 2018; Bertino et al., 2020). Non-bursting cholinergic PPNc neurons are considered key to sustaining steady-state locomotion (Brimblecombe et al., 2018; Sharma et al., 2020; Huerta-Ocampo et al., 2021). Additionally, small cholinergic neurons are present in the reticular formation, the medial habenula, and the cortex (Mesulam et al., 1983, 1992; Terenzi et al., 1992; Ballinger et al., 2016).

The cholinergic neurons in the striatum play one of the most critical roles in developing symptoms in $\mathrm{PD}$, and their stimulation decrease PD symptomatology (Bohnen et al., 2009; Dautan et al., 2014; Kucinski and Sarter, 2015; Osada and Iwasaki, 2017; Chambers et al., 2019; Lieberman et al., 2019). As mentioned above, the striatum contains giant aspiny ChIs, connecting to medium spiny neurons. Although giants ChIs account for only $1-3 \%$ of striatal neurons, they have highly dense axonal arbors that overlap with those of dopaminergic neurons projecting from the SNpc (Dautan et al., 2014, 2020; Mallet et al., 2019; Martel and Apicella, 2021). Thus, the high density of striatal cholinergic markers reveals the vital role of the cholinergic neurotransmission in modulating striatal function (Phelps et al., 1985; Calabresi et al., 2000a,b; Mallet et al., 2019; Martel and Apicella, 2021).

Research over the past decade shows that striatal ChIs maintain synaptic plasticity and are involved in memory and other cognitive functions mediated by the posterior striatum, such as attention and motivation (Bennett et al., 2000; Bohnen et al., 2011; Havekes et al., 2011; Deffains and Bergman, 2015). ChIs display a constant spiking activity in the absence of synaptic inputs (Bennett et al., 2000; Goldberg and Reynolds, 2011). Changes in ChI activity occur during associative conditioned learning (Robinson et al., 2011; Jiang et al., 2016). For example, in classical conditioning studies, the temporal pattern of ChIs activity has been investigated. In these experiments, animals learned to associate a conditioned stimulus (CS) (a tone) with an unconditioned stimulus (US) (a food reward) (Wilson and Fadel, 2017; Kellis et al., 2020). The results showed that during conditioning, shortly after the presentation of the CS, ChIs typically responded with a pause in firing that lasted approximately $200 \mathrm{~ms}$. This pause was preceded or followed by an excitatory burst response (Mallet et al., 2019). This evidence supports the view that ChIs are involved in acquiring contextual information during conditioning learning (Aosaki et al., 1994a,b; Apicella, 2017). ChIs modulation with a cholinergic agonist mimicked the electrical oscillations in the striatum of PD brains (McCarthy et al., 2011). Furthermore, Opto-excitation of ChIs in healthy animals resulted in PD-like motor deficits (Kondabolu et al., 2016), while ChIs Opto-inhibition decreased them in PD mice (Maurice et al., 2015). Other scientists have investigated how the temporality of ChIs activity shapes striatal function using optogenetics coupled to the direct infusion of cholinergic 


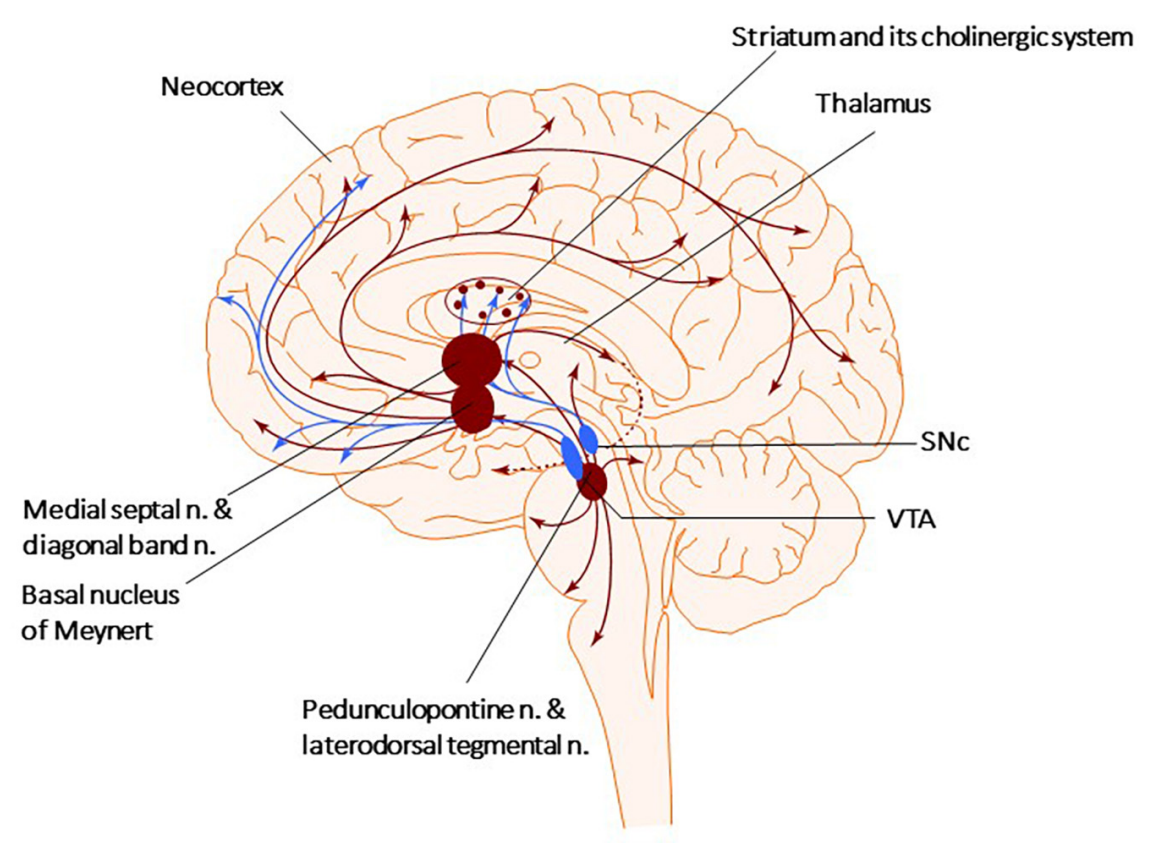

FIGURE 1 | Cholinergic and Dopaminergic systems. The diagram describes the Cholinergic (brown) and Dopaminergic (blue) systems. There are four primary sources of cholinergic projections in the mammalian brain. These include pedunculopontine nucleus and laterodorsal tegmental nuclei; a set of thalamic nuclei; striatum, where few cholinergic neurons are local interneurons; and the basal forebrain nuclei, which collectively serve as the primary sources of cholinergic projection neurons in the neocortex, hippocampus, and amygdala. SNc-Substantia nigra pars compacta, VTA, ventral tegmental area.

modulators in the striatum (Mallet et al., 2019). Overall, this evidence suggests that both $\mathrm{ChI}$ and dopaminergic neurons work together to regulate some motor and cognitive functions and represent promising targets for alleviating the symptoms in $\mathrm{PD}$ (Iarkov et al., 2020).

\section{THE DEVELOPMENT OF AN IMBALANCE BETWEEN DIFFERENT SYSTEMS IN THE STRIATUM AS THE MAIN CONTRIBUTING FACTOR IN PD}

Dopamine deficiency in the striatum causes an imbalance of activity between two MSN populations, each expressing only one type of receptor (D1R or D2R). Each of both MSN groups has a unique path to the GPi/SNpr neurons. MSNs expressing D1R form a direct pathway, while those expressing D2R form an indirect pathway via the GPe and the subthalamic nucleus (STN) (Alexander, 2004; Tozzi et al., 2011; Lu et al., 2021). DA deficiency causes a decrease in the activity of MSN expressing $\mathrm{D} 1 \mathrm{R}$ and increases the activity of neurons expressing D2R, thereby causing motor and cognitive dysfunctions (Alexander, 2004; Tozzi et al., 2011; Wang et al., 2019). The balance between the dopaminergic and cholinergic systems is vital for the correct functioning of the striatum (Aosaki et al., 2010; Lester et al., 2010; Crans and Ciruela, 2021). PD symptoms such as tremor and rigidity are ameliorated by L-DOPA and anticholinergic drugs, suggesting that $\mathrm{PD}$ is a hypercholinergic disorder induced by a dysbalance between Dopaminergic and cholinergic systems (Bohnen and Albin, 2011; Tata et al., 2014; McKinley et al., 2019).

Parkinson's disease develops as an imbalance between dopaminergic inputs and cholinergic interneurons as well as between the serotoninergic and histaminergic systems, increasing the histaminergic tone and decreasing the serotoninergic and dopaminergic activities (Fahn, 1989; Przuntek and Muller, 1999; Aquino-Miranda et al., 2012; Johnston et al., 2019). This hypothesis is coherent because PD symptoms can be successfully relieved by anticholinergics and anti-histamine drugs such as Benadryl (Barbeau, 1962). However, the prescription of anticholinergic drugs stopped due to their undesired side effects, including the impairment of cognitive abilities (Cooper et al., 1992; Herzallah et al., 2010; Crispo et al., 2016). These results suggest that a deterioration of the ascending cholinergic neurons observed post-mortem in PD brains might underly the behavioral deficits in tasks depending on the subcortical frontal cortex. After the work of Alexander and DeLong (Alexander et al., 1986; DeLong, 2000), the concept changed, but now many researchers are again paying attention to it, and, considering that an imbalance between the ChIs activity and DA input signals contributes to the development of PD (Threlfell et al., 2012; Ztaou and Amalric, 2019). Fortunately, over the last decade, results obtained with new research methods have clarified the main aspects of the complex relationship between these two systems, clarifying that ChIs is modulated mainly by dopaminergic neurons located in the SN and the VTA (Threlfell and Cragg, 2011; Gonzales and Smith, 2015). 
Direct pathway MSNs are activated by dopaminergic signals via D1R and inhibited by ChIs signals via M4 mAChRs in these cells expressing D1R (Bonsi et al., 2011; Gerfen and Surmeier, 2011; Oldenburg and Ding, 2011). The MSNs forming the indirect pathway are inhibited by inputs from dopaminergic neurons through D2R but activated by inputs coming from ChIs stimulating the M1 mAChRs (expressed in both MSNs expressing D1R and D2R) (Bonsi et al., 2011; Gerfen and Surmeier, 2011; Oldenburg and Ding, 2011; Goldberg et al., 2012; Rizzi and Tan, 2017). Thus, the dopaminergic system of the midbrain and striatal ChIs modulate each other to maintain the functional balance between the direct and indirect pathways, precisely controlling the movement (Liu, 2020). At the same time, dopaminergic control of ACh release depends on dopaminergic neurons on ChIs expressing D2Rs that decrease ACh release (Stoof et al., 1992; Consolo et al., 1993; Yan et al., 1997; Pisani et al., 2000). Only a tiny fraction of ChI expresses D1Rs, which increases ACh release (Damsma et al., 1991; Di Chiara et al., 1994; Steinberg et al., 1998; Acquas and Di Chiara, 1999; Lim et al., 2014; Gonzales and Smith, 2015). On the other hand, the control by the cholinergic system of DA release depends on the activation of presynaptic nAChRs and the modulation by mAChRs (Acquas and Di Chiara, 1999; Aosaki et al., 2010; Goldberg et al., 2012). Thus, the initial view of an antagonistic relationship between these two systems has evolved. New studies have shown an even higher complexity in their mutual influence that depends on an organism's physiological state (Ztaou and Amalric, 2019; Liu, 2020). The interaction of these two systems in the striatum is perceived instead not as enmity but as a dynamic interplay in a virtual "neurotransmitter dance" (Surmeier and Graybiel, 2012).

\section{THE NICOTINIC RECEPTORS IN THE STRIATUM}

In vertebrate species, 17 different subunits of the nAChRs have been identified $(\alpha 1-10, \beta 1-4, \delta, \varepsilon, \gamma)$ (Millar, 2003; Dineley et al., 2015; Papke and Lindstrom, 2020). The subunits form homo-and heteropentameric receptors, and the different combinations change their specific pharmacological properties (Wu and Lukas, 2011; Dani, 2015). The nAChRs are composed of $\alpha 4, \alpha 6, \alpha 7, \beta 2$, and $\beta 3$ subunits, with preferential expression of the $\alpha 4 \beta 2$ and $\alpha 6 \beta 2$ receptors (Marchi et al., 2002; Millar and Gotti, 2009; Quik and Wonnacott, 2011; Siciliano et al., 2017). Under basal conditions, binding of ligands to the $\alpha 7 \mathrm{nAChR}$ induces a conformational change of the receptor that opens the central channel permitting the influx of sodium and calcium ions and the efflux of potassium ions (Albuquerque et al., 2009). The $\alpha 7 \mathrm{nAChRs}$ are detectable in cortical glutamatergic terminals, potentially directly modulating corticostriatal transmission (Howe et al., 2016). In the striatum, the nAChRs are not expressed in the MSN; however, they are extensively distributed on GABAergic interneurons and dopaminergic and glutamatergic terminals, thereby having the physiological mechanism for a fine-tuned modulation of the striatum (Marshall et al., 1997; Kaiser and Wonnacott, 2000; Howe et al., 2016; Siciliano et al., 2017). Additional studies showed that activation of nAChRs, stimulated the GABAergic interneurons (English et al., 2011; Luo et al., 2013), indirectly affecting the striatal dopaminergic activity (Adermark et al., 2011; Clarke and Adermark, 2015).

\section{WHAT ARE THE MECHANISMS INVOLVED IN THE PUTATIVE NEUROPROTECTIVE EFFECTS OF TOBACCO CONSUMPTION?}

The nAChRs have attracted particular interest among researchers after numerous epidemiological studies have confirmed the low incidence of PD in active smokers (Chen et al., 2010; Gallo et al., 2019). The activation of the cholinergic system is the best target to induce neuroprotection by nicotine-derived compounds in PD (Quik et al., 2011, 2015a,b; Zhang et al., 2013; Bordia et al., 2015; Jurado-Coronel et al., 2019; Iarkov et al., 2020). ACh and other ligands acting on the AChRs stimulate the release of DA in the striatum, reduce neuroinflammation and gliosis, and promote neuronal survival and synaptic plasticity in the brain (Zhou et al., 2003; Quik et al., 2007; Goldberg et al., 2012; Jurado-Coronel et al., 2016; Abudukeyoumu et al., 2019; Bordia and Perez, 2019; Liu, 2020). Distinctively, mAChRs are expressed exclusively in the MSNs (Zhou et al., 2003; Goldberg et al., 2012).

The nAChRs are present in dopaminergic neurons, glutamatergic neurons, cholinergic interneurons (ChIs), and GABAergic interneurons in the striatum (Tanaka et al., 2010; Searles Nielsen et al., 2012; Mappin-Kasirer et al., 2020).

Since tobacco smoke contains nicotine, an agonist of the nAChRs, its protective effect has been related to the activity of nicotine on these receptors (Quik and McIntosh, 2006; Quik et al., 2007, 2009, 2012, 2013a,b; O’Leary et al., 2008; Riveles et al., 2008; Hong et al., 2009; Huang et al., 2009, 2011b; Kyaw et al., 2013; Barreto et al., 2014; Tiwari et al., 2015). In the last decades, new evidence highlights cotinine's neuroprotective actions, a derivative of nicotine that is a positive modulator of the $\alpha 7 n$ AChRs (Soto-Otero et al., 2002; Buccafusco and Terry, 2003; Terry et al., 2005; Echeverria and Zeitlin, 2012; Barreto et al., 2014; Gao et al., 2014; Boiangiu et al., 2020; Iarkov et al., 2020). Cotinine, acting on the $\alpha 7 n$ AChRs, stimulates mechanisms of neuroprotection acting on glial cells (Morioka et al., 2018; Oliveros-Matus et al., 2020). The actual evidence suggests that activated microglia (M1 microglia) contributes to PD development (Bayarsaikhan et al., 2015; Saitgareeva et al., 2020). Thus, decreasing microglial activation could be an excellent therapeutic strategy for preventing or treating PD.

$\alpha 7 \mathrm{nAChRs}$ are unique targets to diminish the synthesis of proinflammatory molecules and neuroinflammation due to their ability to inhibit microglial activation (Kim et al., 2015; Lee et al., 2015). Also, in microglia, the glutamate transporter (GLAST) is upregulated by $\alpha 7 \mathrm{nAChRs}$ stimulation through the activation of both inositol triphosphate- $\mathrm{Ca}^{2+/}$ calmodulin-dependent protein kinase II (CaMKII) and fibroblast growth factor-2 (FGF2) pathways (Morioka et al., 2014). The activation of microglial $\alpha 7 \mathrm{nAChRs}$ is neuroprotective by inhibiting the expression of 
proinflammatory molecules and preventing excitotoxicity by promoting glutamate clearance (Morioka et al., 2018).

\section{THE NEUROPROTECTIVE ROLE OF THE nAChRs}

The cholinergic system plays a vital role in controlling the release of neurotransmitters, decreasing neuroinflammation, promoting synaptic plasticity, and neuronal survival in the brain (Van Beek and Claassen, 2011; Hampel et al., 2018). In addition, the cholinergic system modulates both innate and adaptive immune responses (Bosmans et al., 2017; Halder and Lal, 2021; Pohanka, 2021). The cholinergic system affects immune cell proliferation, T-helper differentiation, antigen presentation, and cytokine production (Fujii et al., 2017; Halder and Lal, 2021; Lu and $\mathrm{Wu}, 2021)$. In agreement with these functions, the $\alpha 7 \mathrm{nAChRs}$ are expressed in basophils, dendritic cells, macrophages, mast cells, and T and B lymphocytes (Sato et al., 1999; Skok et al., 2003; Sudheer et al., 2006; de Jonge and Ulloa, 2007; Mashimo et al., 2020). In addition, in neurons, presynaptic nAChRs modulate neurotransmitter release, while postsynaptic nAChRs increase neuronal firing rate, promoting long-term potentiation, considered a cellular mechanism of memory formation (Wayner et al., 1996; Fujii et al., 1999; Chen et al., 2006; Huang et al., 2008; Albuquerque et al., 2009; Kroker et al., 2011; Srivareerat et al., 2011; Nees, 2015; Echeverria et al., 2016b).

Epidemiological studies have shown a lower rate of development of PD in people who use tobacco products, suggesting that one or more tobacco-derived compounds may have neuroprotective effects (Fratiglioni and Wang, 2000; Parain et al., 2003; Hong et al., 2009). Various studies have shown that nicotine reduces the damage of cultured dopaminergic neurons (Riveles et al., 2008; Toulorge et al., 2011; Getachew et al., 2019). Other studies have shown that nicotine and its major metabolite, cotinine, have neuroprotective effects against 6-hydroxydopamine (6-OHDA) toxicity in cultured SH-SY5Y neuroblastoma cells expressing nAChRs (Pogocki et al., 2007; Riveles et al., 2008). Nicotine also showed neuroprotective effects in animal models of PD when administered before nigrostriatal damage occurs (Linert et al., 1999; Salminen et al., 1999; Huang et al., 2009; Quik et al., 2009, 2015a). The neuroprotective effects of other $\mathrm{nAChR}$ modulators have also been investigated with promising results (Pogocki et al., 2007; Tiwari et al., 2013; Jurado-Coronel et al., 2019).

\section{THE NICOTINIC RECEPTORS AND NEURONAL SURVIVAL IN THE PD BRAIN}

Numerous studies in this area have shown that these pathways promote neuronal survival, proliferation, and neurite growth as well as neurotransmitter release in the brain and other tissues (Eneroth et al., 1977; Fuxe et al., 1979; Aizenman et al., 1991; Sastry, 1995; Parain et al., 2001; Buccafusco and Terry, 2003; Koh et al., 2003; de Aguiar et al., 2013; Gao et al., 2014; Tiwari et al., 2015; Majdi et al., 2018).
The two main subtypes of $\mathrm{nAChRs}$ are the heteropentameric $\alpha 4 \beta 2, \alpha 3 \beta 2, \alpha 7 \beta 2$ receptors, and homopentameric $\alpha 7$ receptor, all of which are channels with high permeability to $\mathrm{Ca}^{2+}$ (Akaike and Izumi, 2018). An increase in the intracellular $\mathrm{Ca}^{2+}$ activates critical signaling pathways, linking input signals from the extracellular environment to a cellular response to maintain homeostasis (Gotti et al., 2009; Wang et al., 2012). Some studies have shown that activation of the nicotinic receptors can be neuroprotective by activating signaling pathways stimulated by $\mathrm{Ca}^{2+}$ (Kihara et al., 2001; Dajas-Bailador and Wonnacott, 2004; Rehani et al., 2008; Shimohama and Kawamata, 2018; Takahashi, 2020). For example, nicotine induces neuroprotection throughout the $\alpha 7$ - and $\alpha 4 \beta 2$ receptors that, when activated, stimulate the expression of pro-survival genes that inhibit apoptosis and support synaptic function (Mudo et al., 2007; Buckingham et al., 2009; Shimohama and Kawamata, 2018; Papke and Lindstrom, 2020). For example, the increase in $\mathrm{Ca}^{2+}$ ion levels induced by ligands of the $\alpha 7 \mathrm{nAChRs}$ activates the phosphatidylinositol-3-kinase (PI3K) signaling pathway (Kihara et al., 2001; Dajas-Bailador and Wonnacott, 2004; Rehani et al., 2008; Shimohama and Kawamata, 2018). For instance, downstream of the $\alpha 7 \mathrm{nAChR}$ the protein kinase Fyn, a member of the Src family, stimulates the PI3K (Gergalova et al., 2014). PI3K phosphorylates Akt, which activates by phosphorylation the transcription factor cAMP response element-binding protein (CREB) (Leinninger et al., 2004; Wang et al., 2020a; Liu et al., 2021). This transcription, in turn, increases the expression of the cell survival factor Bcl-2 (Rehani et al., 2008). Also, Akt inhibits the proapoptotic factor GSK3 $\beta$ and, therefore, the phosphorylation of the microtubule-associated protein Tau (Rajmohan and Reddy, 2017; Sayas and Avila, 2021). These actions are relevant to preventing dementia because hyperphosphorylated Tau inhibits axonal transport and induces energy deficits in the brain leading to oxidative stress, synaptic deficits, and neuronal cell death (Perez et al., 2018; Compta and Revesz, 2021; Koziorowski et al., 2021). Coherent with this idea, the positive modulation of the $\alpha 7 \mathrm{nAChR}$ by cotinine is neuroprotective against amyloid- $\beta$ peptide $(A \beta)$ toxicity in vivo, inhibiting GSK3 $\beta$-mediated Tau phosphorylation, and activating the transcription factor CREB (required for long-term memory storage), improved memory abilities in mouse models of $\mathrm{AD}$ (Echeverria et al., 2011; Echeverria and Zeitlin, 2012; Patel et al., 2014; Grizzell and Echeverria, 2015; Grizzell et al., 2017). Other mechanisms of nAChRmediated neuroprotection include activating the extracellular signal-regulated protein kinase/mitogen-activated protein kinase (ERK/MAPK) pathway (Grizzell and Echeverria, 2015). The $\alpha 7 n A C h R s$ activate neuroprotective factors stimulated by $\mathrm{Ca}^{2+}$, including the protein kinase $\mathrm{C}$ (PKC) and the $\mathrm{Ca}^{2+} /$ calmodulindependent protein kinase (CaMK), both of which activate CREB (Kawamata and Shimohama, 2011; Kawamata et al., 2011, 2012; Sutachan et al., 2012; Albert-Gasco et al., 2020).

Evidence obtained using agents inducing PD-like pathologies such as Rotenone, 6-OHDA, and 1-methyl-4-phenyl-1,2,3,6tetrahydropyridine (MPTP), enlightened potential mechanisms of nAChRs-mediated neuroprotection (Kawamata et al., 2011). 
These mechanisms involve activating the signal transducer and activator of transcription (STAT) $1 / 3 / 5$, and the Fyn/PI3K/Akt/Bcl2, Janus kinase 2 (JAK2)/PI3K/Akt (Bharadwaj et al., 2020). Besides, the stimulation of the $\alpha 4 \beta 2$ and $\alpha 7 \mathrm{nAChRs}$ triggers other neuroprotective signaling cascades without the direct involvement of the PI3K system, such as the ERK/MAPK and JAK2/STAT3 pathways, PKC/Raf/MEK/ERK/STAT3, and Ras-Raf-ERK signaling pathways (Figure 2; Buckingham et al., 2009; Zdanowski et al., 2015).

The $\alpha 7 n$ AChRs also stimulate the expression and activity of various growth factors and their receptors, such as the vascular endothelial factor (VEGF) and the VEGF receptor 2 (VEGFR2), the platelet-derived growth factor (PDGF) and the PDGF receptor (PDGFR), and the epidermal growth factor receptor (EGFR) (Pillai and Chellappan, 2012). EGFR activates the Akt pathway and its downstream effectors, X-linked inhibitor of apoptosis protein-survivin and the nuclear factor kappa B (NFkB) (Zdanowski et al., 2015). In general, the nAChRs can activate neuroprotective signaling cascades in neurons, astroglia, and microglia to promote cell survival, synaptic plasticity and maintain brain homeostasis (Picciotto et al., 2000; Echeverria and Zeitlin, 2012; Kawamata et al., 2012). For example $\alpha 7 \mathrm{nAChRs}$ upregulate the transcription factors hypoxiainducible factor-1 (HIF-1), GATA-3, NFkB, and signal transducer and activator of transcription (STAT) 1 (Picciotto et al., 2000;

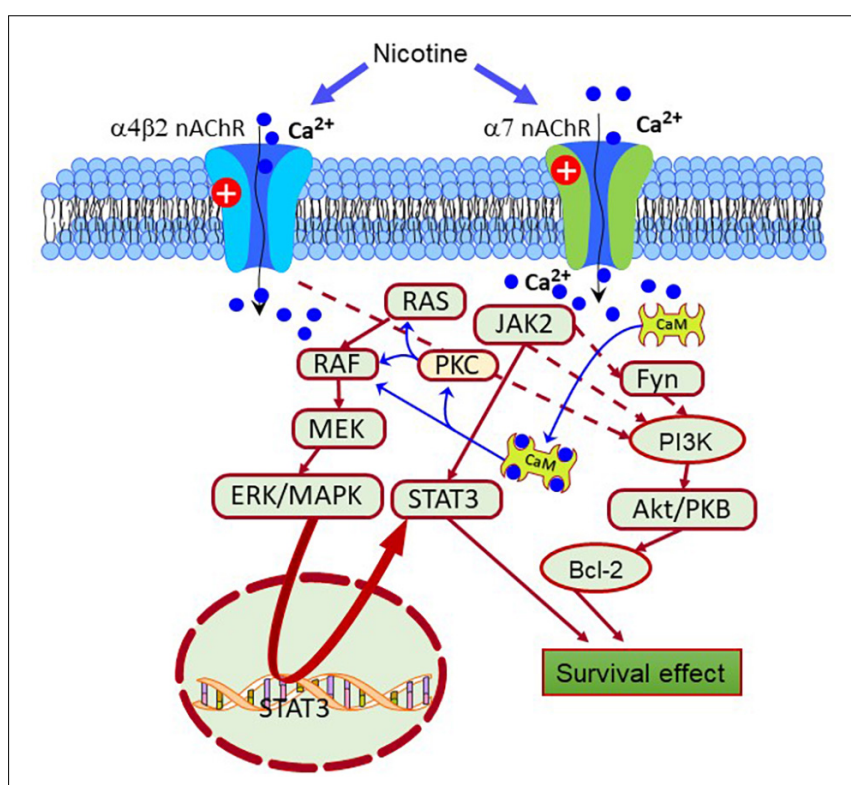

FIGURE 2 | Scheme depicting different pro-survival signaling pathways activated by the nAChRs. Nicotine-induced neuroprotection is mediated by receptors, primarily through the $\alpha 7$ and $\alpha 4 \beta 2$ receptors. Also, the nAChRs can activate intracellular pathways that enhance the expression of pro-survival proteins that inhibit apoptosis. From them, Janus kinase 2 (JAK2), Fyn, protein kinase $\mathrm{C}(\mathrm{PKC})$, and calcium-calmodulin kinase (CaMK) are crucial protein factors triggering the activation of the extracellular signal-regulated protein kinase (ERK), JAK2/signal transducer, and activator of transcription 3 (STAT3), and phosphatidylinositol 3-kinase (PI3K)-Akt pathways. In turn, these pathways enhance the expression of antiapoptotic factors such as Bcl-2.
Echeverria and Zeitlin, 2012; Kawamata et al., 2012; Pillai and Chellappan, 2012; Echeverria et al., 2016a,b).

\section{THE MUSCARINIC RECEPTORS IN THE STRIATUM}

In the striatum, every type of neuron expresses different subtypes of both mAChR and nAChRs (Threlfell et al., 2010; Lim et al., 2014). The $\mathrm{mAChRs}$ are metabotropic receptors that indirectly control the activity of membrane ion channels through heterotrimeric G-proteins (Kruse et al., 2014; Roth,

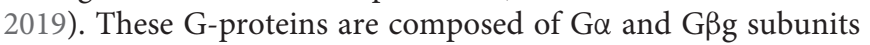
classified according to the type of $\alpha$ subunit, which determines their association to specific G-protein coupled receptors (GPCR) (Huang and Thathiah, 2015; Roth, 2019).

In the CNS, the mAChRs are categorized into five subtypes groups (M1 to M5) (Lim et al., 2014; Mallet et al., 2019). These receptors show significant differences in expression M1 > M2 > M4 > M3 and M5 (Zhou et al., 2003; Graef et al., 2011).

A study using atropine to inhibit M2 and M3 mAChRs present on the glutamatergic terminals revealed a small but significant increase in corticostriatal transmission, suggesting the existence of tonic cholinergic presynaptic inhibition of this excitatory afferents inputs (Pakhotin and Bracci, 2007; Mallet et al., 2019). At different, the M1 mAChR blocker pirenzepine decreased corticostriatal transmission (Tozzi et al., 2011).

In $\mathrm{PD}$, anti-muscarinic receptor drugs were the first symptomatic PD treatment before discovering L-DOPA (Fahn, 1989). mAChR antagonists were used as early treatments and are still under use in PD (Langmead et al., 2008a,b; Thomas et al., 2009). The muscarinic antagonists decrease the hyperactivity of ChIs and corticostriatal glutamatergic neurotransmission after nigrostriatal denervation (Lim et al., 2014). However, while they provide some benefits, these drugs are not without side effects, including cognitive impairment (Drachman and Leavitt, 1974; Yamamoto et al., 2011). Therefore, there is a need for more selective cholinergic modulators with improved therapeutic properties. In addition, therapies with more selective modulators of the cholinergic receptors may permit more target specificity and improved pharmacokinetics compared to ACh.

\section{THE MUSCARINIC AChRs SIGNALING AND THEIR ROLE IN MAINTAINING BRAIN HOMEOSTASIS}

The M1, M3, and M5 mAChRs are associated with G-proteins' Gq/11 subfamily (Sil'kis, 2003; Tobin and Budd, 2003; Santiago and Abrol, 2019). When activated by these receptors, Gq interchanges GTP for GDP and dissociates in their constituent subunits that become free to activate downstream effectors such as the phospholipase C (PLC) (Falkenburger et al., 2010). PLC activity results in the release of inositol-triphosphate 3 (IP3) and diacylglycerol (DG) (Berridge, 2016). IP3 binds to the IP3R 
in the endoplasmic reticulum (ER), triggering the release of $\mathrm{Ca}^{2+}$ from intracellular stores, and DG stimulates the PKC (Rehman and Dimri, 2020).

The activation of M2 and M4 receptors activates the Gi/o subfamily of $G$ proteins, increasing the opening time of potassium channels and decreasing cAMP production (Santiago and Abrol, 2019). Since this second messenger activates the prosurvival PKA/CREB pathway, this decrease inhibits cell survival and synaptic plasticity in the brain (Resende and Adhikari, 2009). The M2 mAChRs also weakly bind to Gs and Gq, acting as a negative autoreceptor leading to decreased ACh release (Quirion et al., 1990; Wess et al., 2007; Santiago and Abrol, 2019).

On the other hand, the activation of the M1 mAChRs increases the non-amyloidogenic processing of the amyloid precursor protein (APP) to generate $\mathrm{APP} \alpha$, a proteolytic product that promotes neuroprotection by stimulating neuritogenesis, neurogenesis, synaptic plasticity, and memory formation while reducing $A \beta$ and Tau pathology in the brain (Deng et al., 2015; Habib et al., 2017).

Some drugs, including non-steroidal anti-inflammatory compounds, have neuroprotective effects by shaping APP processing (Avramovich et al., 2002; Yogev-Falach et al., 2003; Kalaitzakis et al., 2008; Miklossy et al., 2008; Shimohama and Kawamata, 2018). Also, other kinases such as PKC and ERK1/2 stimulate the non-amyloidogenic processing of APP by $\alpha$-secretase (Wang et al., 2016; Zhang et al., 2019).

Also, M1 mAChR activation upregulates the expression of $\beta$-secretase 1 (BACE1) through a mechanism involving the activation of MEK/ERK, by a mechanism prevented by M2 mAChRs activation (Zuchner et al., 2004). Besides, the stimulation of M1 mAChRs counteracted the A $\beta$-induced inhibition of Wnt signaling by GSK3 $\beta$, resulting in the stabilization of $\beta$-catenin and increased expression of survival genes (Farias et al., 2004; Jiang et al., 2014b; Wysocka et al., 2020). Additionally, the M1 mAChRs, by inhibiting the tau kinase GSK3 $\beta$ also prevented tau hyperphosphorylation and toxicity (Jiang et al., 2014b). Figure 3 represents a possible mAChR signaling mechanism that protects brain cells from mitochondrial dysfunction, caspase activation, oxidative stress, and DNA damage in PD.

In agreement with this effect, cell studies indicate that Wnt/ $\beta$-catenin pathway inhibition mediates manganese-induced neurotoxicity (Jiang et al., 2014a). In AD, increased levels of aggregated forms of $A \beta$ seem to interfere with the function of M1 mAChRs by uncoupling the receptor-G protein complex (Janickova et al., 2013).

On the other hand, the cellular localization of these cholinergic receptors also may play a key role in their function and cellular effects (Anisuzzaman et al., 2013; Uwada et al., 2014; Uspenska et al., 2017; Jong et al., 2018; Muramatsu et al., 2018). Although most cholinergic receptors are located in the plasma membrane to convert extracellular signals into intracellular ones, several studies have reported nAChRs in other neuronal organelles like mitochondria (Skok and Lykhmus, 2016). The current evidence suggests that intracellular $\alpha 7 \beta 2$ receptors mainly stimulate the PI3K/Akt pathway, while $\alpha 3 \beta 2$ and $\alpha 4 \beta 2$ receptors inhibit Akt signaling and $\mathrm{Ca}^{2+} /$ calmodulin-dependent pathways, consequently promoting mitochondrial apoptosis (Gergalova et al., 2014; Lykhmus et al., 2014; Muramatsu et al., 2018). New studies indicate that the mAChRs, the cannabinoid receptor, and the metabotropic glutamate receptor 5 (mGluR5) also localize intracellularly in the membranes of various organelles (Jong et al., 2018). In these intracellular locations, they can transmit signals from structures such as endosomes, Golgi apparatus, endoplasmic reticulum, mitochondria, and nucleus (Boivin et al., 2008; Jong et al., 2009; Benard et al., 2012; Gergalova et al., 2014; Lykhmus et al., 2014). Recent studies have shown that approximately half of the M1 mAChRs are in the intracellular part of the membrane in neuronal cells (Anisuzzaman et al., 2013; Uwada et al., 2014). Expression studies using immunohistochemistry methods indicated that the $\mathrm{mAChRs}$ could also localize in the Golgi apparatus (Muramatsu et al., 2018). Interestingly, the intracellular localization of the mAChRs requires a C-terminal tryptophan motif that is only present in the M1 subtype. The M1 mAChRs are also present in postsynaptic neurons (Anisuzzaman et al., 2013; Morishima et al., 2013; Uwada et al., 2014; Muramatsu et al., 2018). Figure 4 shows a simplified schematic view of the plasma membrane and intracellular M1 mAChRs in the pre-and postsynaptic neurons, their predicted signal transduction pathways, and the elicited physiological responses. Studies with the GABAA receptor's competitive antagonist bicuculline suggested that M3 and M4 receptors modulate DA release via facilitation or inhibition of striatal GABA release.

\section{EFFECT OF COTININE PREVENTING AMYLOID- $\beta$ PEPTIDES ACCUMULATION AND PROMOTING SYNAPTIC PLASTICITY IN THE BRAIN}

Despite their structural similarities, nicotine, and cotinine, differ in their mechanism of action, properties, behavioral effects, and toxicity profile (nicotine is one hundred times more toxic than cotinine) (Buccafusco and Terry, 2003; Grizzell and Echeverria, 2015; Majdi et al., 2018). The last decade of research has shown that cotinine has unique pharmacokinetic and pharmacodynamic properties, acting as a very weak $\mathrm{nAChR}$ agonist but a positive modulator of the $\alpha 7 n A C h R s$ (Moran, 2012; Grizzell et al., 2014; Sadigh-Eteghad et al., 2020). Different from nicotine, cotinine is safe and does not elicit addictive behaviors in mammals, including humans (Yim and Hee, 1995; Hatsukami et al., 1997; Vainio et al., 1998; Zevin et al., 2000; Echeverria and Zeitlin, 2012; Thomopoulos et al., 2013). Cotinine has shown to protect astrocytes from the toxic effects of chronic and acute stress in vivo (Alvarez-Ricartes et al., 2018; Mendoza et al., 2018; Oliveros-Matus et al., 2020) and to prevent the loss of presynaptic proteins such as synaptophysin in the PFC and hippocampus of mice subjected to chronic stress (Grizzell et al., 2014; Grizzell and Echeverria, 2015). In addition, cotinine has shown to reduce the activation of macrophages (Rehani et al., 2008) and be neuroprotective, reducing plaque deposition, tau hyperphosphorylation, and cognitive impairment 


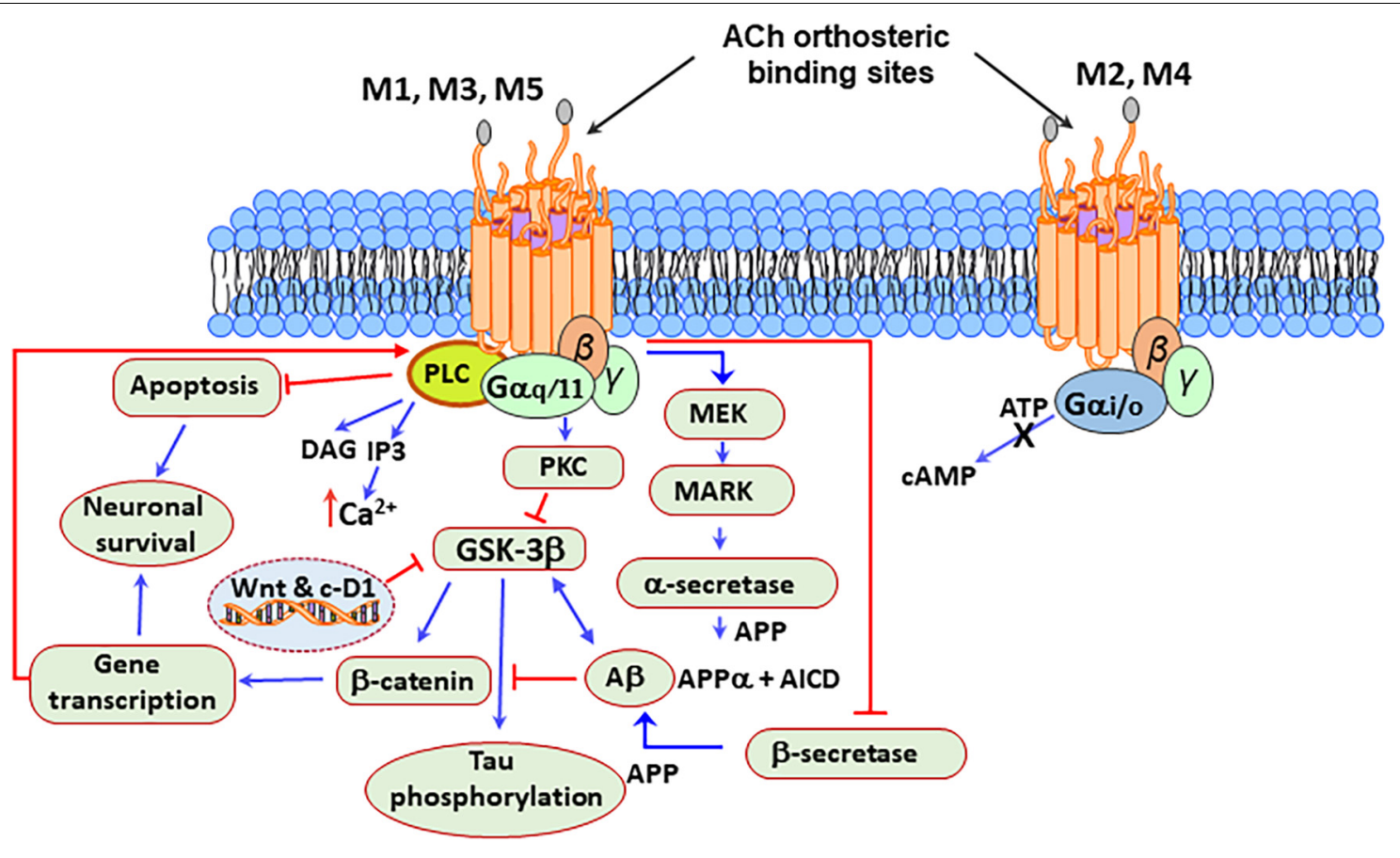

FIGURE 3 | Neuroprotective signaling pathways stimulated by the mAChRs. M1, M3, and M5 mAChRs are associated with the Gq/11 subfamily of G proteins, which are responsible for the increase of cytosolic $\mathrm{Ca}^{2+}$, activation of phospholipase $\mathrm{C}(\mathrm{PLC})$ and protein kinase $\mathrm{C}(\mathrm{PKC})$, which leads to the production of signaling molecules inositol triphosphate (IP3) and diacylglycerol (DAG). Acetylcholine (ACh) activation of the M2 and M4 receptors, which are associated with the Gi/o subfamily of $\mathrm{G}$ proteins, increases the opening time of potassium channels and decreases the production of adenosine- $3^{\prime}, 5^{\prime}$-cyclic monophosphate (cAMP). Besides, the stimulation of the M1 mAChRs by agonists or ACh increases the production of SAPP $\alpha$ and decreases the production of amyloid A $\beta$ peptide. Protein kinase C (PKC) and the extracellular signal-regulated protein kinase (ERK)1/2 are involved in this process by activating $\alpha$-secretases. The activation of the M1 mAChRs counteracts $A \beta$-induced neurotoxicity via the Wnt signaling pathway, as $A \beta$ inhibits this pathway through the destabilization of $\beta$-catenin. In contrast, stimulation of M1 mAChR inactivates glycogen synthase kinase 3 (GSK3 $\beta$ ) via PKC activation, thus stabilizing $\beta$-catenin and inducing the expression of the Wnt-targeting and cyclin-D1 genes for neuronal survival.

while increasing the expression of the postsynaptic density protein 95 (PSD95) in transgenic AD mice overexpressing human A $\beta$ peptides (Terry et al., 2005, 2012, 2015; Echeverria et al., 2011; Echeverria and Zeitlin, 2012; Patel et al., 2014; Grizzell et al., 2017).

In addition, there is evidence suggesting that the activation of the nicotinic receptors by cotinine modulates the stoichiometry and expression of the nAChRs (Lester et al., 2009). A study using neuronal cells and Xenopus oocytes expressing nAChRs (Terry et al., 2015) showed that, like nicotine, cotinine increased the expression of $\alpha 4 \beta 2$ receptors on the plasma membrane and induced a change in the intracellular distribution of these receptors. Furthermore, cotinine altered the assembly of $\alpha 4 \beta 2$ receptors to favor the assembly of $(\alpha 4)_{2}(\beta 2)_{3}$ receptor's stoichiometry that has higher sensitivity to the agonists than $(\alpha 4)_{3}(\beta 2)_{2}$ stoichiometry (Srinivasan et al., 2011). Cotinine also decreased the expression of the $\alpha 6 \beta 2 \beta 3$ receptors (Moran, 2012). In contrast, cotinine did not change the trafficking or expression of $\alpha 6 \beta 2, \alpha 4 \beta 2 \alpha 5$, or $\alpha 3 \beta 4$ receptors (Fox et al., 2015). A previous study compared ACh alone or plus cotinine on the channel activity of the $\alpha 7 \mathrm{nAChR}$. The results revealed an enhanced channel activity induced by ACh plus cotinine than the receptors treated with ACh alone (Terry et al., 2015). They also found that exposure to cotinine for 2 days, at doses found in heavy smokers, induced a moderate down-regulation of $\alpha 4 \beta 2$ receptors expressed in Xenopus laevis oocyte (Terry et al., 2015). A contemporary study, using a combination of fluorescence imaging and single-molecule measurements, showed evidence that cotinine at concentrations higher than $5 \mu \mathrm{M}$ did not increase the receptor expression on the plasma membrane, but lower concentrations of cotinine change both the assembly and trafficking of the nAChRs (Fox et al., 2015). No doubt that these changes affect their affinity for the ligands and their function in the brain. New studies are required to define these differences in more detail.

Many studies have shown that modulators of the nicotinic receptors such as nicotine and Cotinine control the release of neurotransmitters such as serotonin (O'Leary et al., 2008) and DA (Fuxe et al., 1986) in the brain (Fuxe et al., 1979), GABA and glutamate (Yan et al., 2019) affecting brain connectivity and its function.

\section{PREDICTING THE DEVELOPMENT OF PD DEMENTIA}

In addition to motor deficits, $\mathrm{PD}$ presents with non-motor alterations, including cognitive decline, symptoms of depression, 


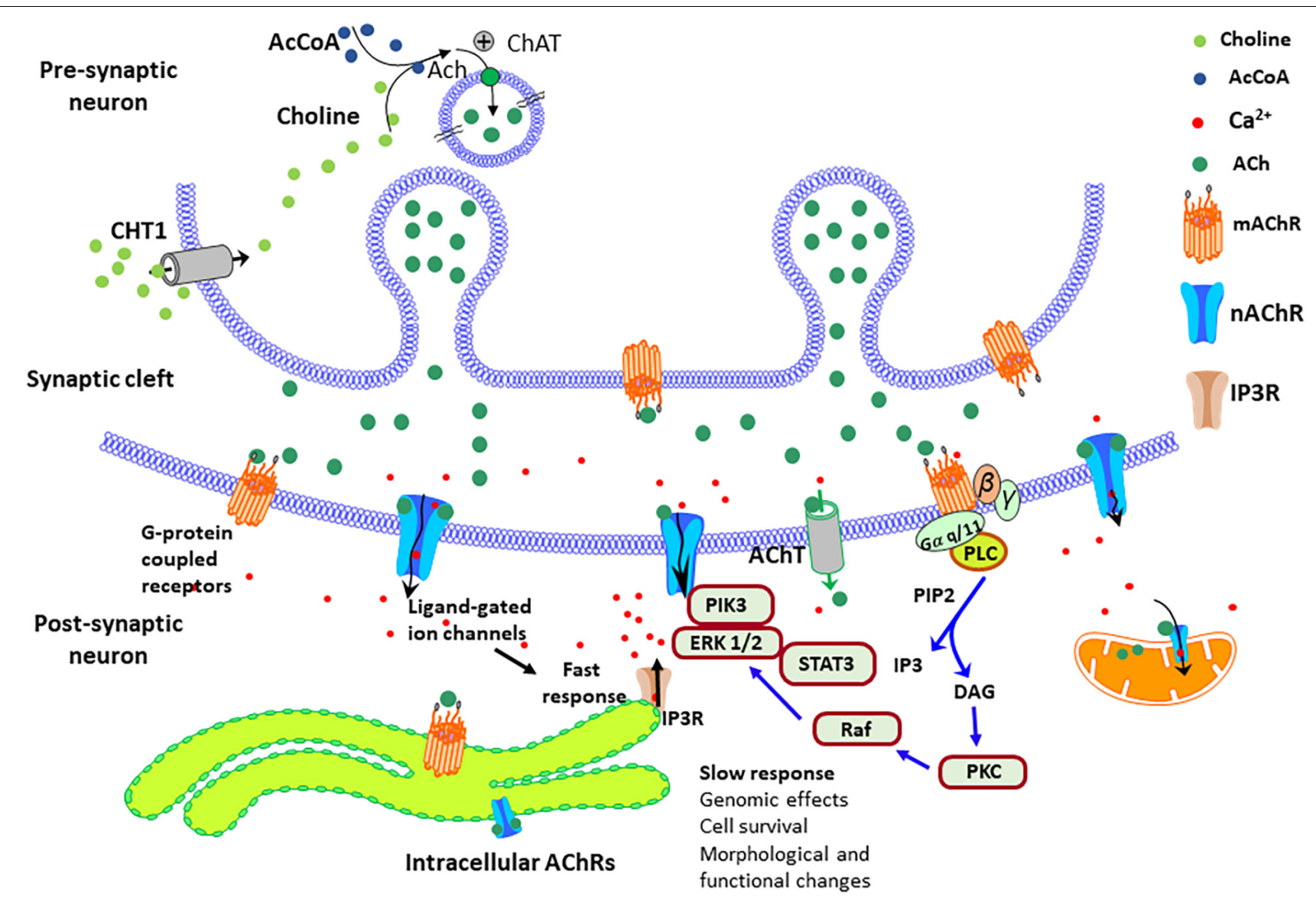

FIGURE 4 | Simplified diagram of the AChRs signal transduction pathways in the pre-and post-synaptic sites. In brain cells, intracellular AChRs - both mAChRs and $\mathrm{nAChRs}$ are located on both the surface of the plasma membrane and intracellular membranes of various organelles, such as endosomes, Golgi apparatus, endoplasmic reticulum, mitochondria, and nuclear membranes. The choline transporter-like protein1 (CHT1) uptake choline at the presynaptic, and the acetylcholine (ACh) transporter (AChT) uptake ACh at the post-synaptic site. The entrance of calcium throughout the nAChRs stimulates signaling factors, such as the enzymes phosphatidylinositol 3-kinase (PI3K)/ extracellular signal-regulated protein kinase (ERK)1/2/ signal transducer and activator of transcription 3 (STAT3). These factors prevent apoptosis and stimulate the expression of prosurvival genes, The signaling cascades elicited by the mAChRs stimulate the release of calcium from intracellular stores via the activation of PLC that generates the Inositol trisphosphate (IP3) that activates the IP3 receptors (IP3Rs) and the second messenger diacylglycerol (DAG) that stimulates the protein kinase C (PKC)/ Raf/ ERK pathway.

abnormal autonomic nervous system function (dysautonomia), and psychosis (Hemmerle et al., 2012; Lindqvist et al., 2012; Grover et al., 2015; Maillet et al., 2016; Samudra et al., 2016; Hussein et al., 2021). Although memory and language dysfunctions are less evident than the observed in $\mathrm{AD}, \mathrm{PDD}$ is $600 \%$ higher than in the general population. One prospective 8 year study found a cumulative prevalence of dementia of $78 \%$ among PD patients (Emre et al., 2007). In another study to a 5 -year prospective study in more than 400 patients with $\mathrm{PD}$, the risk factors for dementia included older age, longer disease duration, later age-at-onset, and higher daily levodopa (1-dopa) dosage (Aarsland et al., 2003). PDD, like AD, shows cognitive symptoms such as a diminution of attention and executive and visuospatial abilities (Fitts et al., 2015; Ho et al., 2020; Hussein et al., 2021). PDD seems to result from a combination of ADlike, cortical Lewy-bodies and vascular pathology induced by high homocysteine level (hyperhomocysteinemia), and dysautonomia with abnormal blood pressure (BP), breathing and digestive problems, and loss of bladder control (Zoccolella et al., 2006; Byeon, 2020; Kwon et al., 2021).

In $\mathrm{PD}$, it is challenging to assess the progression to dementia. Structural changes in the PD brain could predict motor and cognitive outcomes (Byeon, 2020; Chung et al., 2021; OwensWalton et al., 2021; Shin et al., 2021). For example, previous studies have found a correlation between cortical thinning and PD dementia (PDD) (Chung et al., 2021). The methodological advances in structural and functional brain analysis could permit the prediction of PDD development in clinical settings (Oldan et al., 2021; Owens-Walton et al., 2021; Shin et al., 2021). A recent retrospective study explored whether the assessment of cortical thickness by MRI combined with other clinical symptoms using a machine learning-based model could predict the transition from mild cognitive impairment (MCI) to dementia in PD. The study involved patients diagnosed with PD and MCI and evaluated with MRI for 8 years. Features were chosen from clinical and cortical thickness variables to support vector machine 
models (Shin et al., 2021). From all participants, 42 patients advanced to PDD (converters), and 75 patients did not advance to PDD (non-converters). Models exhibited fair to good predictive outcomes; however, their performances increased when models included both clinical and structural variables (AUC range, 0.80-0.88). In pair-wise comparisons, models trained with both variables obtained better achievements. The authors concluded that Cortical thickness from MRI could help forecast transition from MCI to dementia in PD with improved accuracy when combined with other clinical variables (Shin et al., 2021).

Another recent study used structural and functional MRI to elucidate pathophysiological mechanisms associated with cognitive impairment and dementia in PD (Owens-Walton et al., 2021). They specifically investigated resting-state functional connectivity and morphology of the caudate nucleus, putamen, and thalamus, in PD brains. The results revealed enhanced functional connectivity of the dorsal caudate, anterior putamen, and mediodorsal thalamic subdivisions with the frontal lobe and lower functional connectivity of the dorsal caudate with posterior cortical, and cerebellar regions. Compared to cognitively unimpaired subjects, those with mild cognitive impairment ( $n=22$ ) demonstrated reduced functional connectivity of the mediodorsal thalamus with the paracingulate cortex while also demonstrating increased functional connectivity of the mediodorsal thalamus with the posterior cingulate cortex, compared to subjects with dementia $(n=17)$. The patients with PDD showed a significant reduction in volume in those regions compared to controls or PD participants without dementia. The authors concluded that abnormalities in the functional connectivity of the basal ganglia-thalamocortical circuits, mainly between the mediodorsal thalamus with the cingulate regions, are involved in the appearance of dementia in PD (Owens-Walton et al., 2021). Changes in connectivity can predict the severity of the disease, with the pattern of connectivity considered a form to predict the response to L-DOPA and cognitive status in the PD patients (Amboni et al., 2015; Akram et al., 2017; Anderkova et al., 2017; Chung et al., 2021).

\section{REFERENCES}

Aarsland, D., Andersen, K., Larsen, J. P., Lolk, A., and Kragh-Sorensen, P. (2003). Prevalence and characteristics of dementia in Parkinson disease: an 8year prospective study. Arch. Neurol. 60, 387-392. doi: 10.1001/archneur.60. 3.387

Aarsland, D., Creese, B., Politis, M., Chaudhuri, K. R., Ffytche, D. H., Weintraub, D., et al. (2017). Cognitive decline in Parkinson disease. Nat. Rev. Neurol. 13, 217-231. doi: 10.1038/nrneurol.2017.27

Abudukeyoumu, N., Hernandez-Flores, T., Garcia-Munoz, M., and Arbuthnott, G. W. (2019). Cholinergic modulation of striatal microcircuits. Eur. J. Neurosci. 49, 604-622. doi: 10.1111/ejn.13949

Acquas, E., and Di Chiara, G. (1999). Dopamine D(1) receptor-mediated control of striatal acetylcholine release by endogenous dopamine. Eur. J. Pharmacol. 383, 121-127. doi: 10.1016/s0014-2999(99)00570-1

Adermark, L., Clarke, R. B., Soderpalm, B., and Ericson, M. (2011). Ethanolinduced modulation of synaptic output from the dorsolateral striatum in rat is regulated by cholinergic interneurons. Neurochem. Int. 58, 693-699. doi: 10.1016/j.neuint.2011.02.009

\section{CONCLUSION}

The cholinergic system has a powerful influence over the striatum function by controlling the dopaminergic activity and promoting the survival of neurons to mitochondrial dysfunction, oxidative stress, and neuroinflammation. The dopamine-centric view of $\mathrm{PD}$ has failed to control the pathology, and new and more integral approaches considering the disbalance of other neurotransmitters such as serotonin, histamine, and ACh need to be addressed to prevent the loss of dopaminergic neurons in PD. Cotinine positively modulates the nAChRs, and affects the release of serotonin, DA, GABA and glutamate receptors in the brain facilitating brain connectivity and function (Stone, 2021). Based on this evidence, it is reasonable to postulate that cotinine could be a critical factor delaying cognitive impairment in PD or PDD in tobacco users. Further preclinical and clinical studies are required to fully unmask the potential beneficial effects of cotinine in PD.

\section{AUTHOR CONTRIBUTIONS}

All authors listed have made a substantial, direct and intellectual contribution to the work, and approved it for publication.

\section{FUNDING}

This work was supported by the National Commission for Scientific and Technological Research in Chile (ANID) (grant FONDECYT 1190264) and the Universidad San Sebastián, Chile.

\section{ACKNOWLEDGMENTS}

The result of this work was supported by the resources and facilities from the Universidad San Sebastián (Chile). The contents do not necessarily represent the views of the Department of Veterans Affairs or the United States Government.

Agelink van Rentergem, J. A., de Vent, N. R., Huizenga, H. M., Murre, J. M. J., Consortium, A., and Schmand, B. A. (2019). Predicting progression to parkinson's disease dementia using multivariate normative comparisons. J. Int. Neuropsychol. Soc. 25, 678-687. doi: 10.1017/S13556177190 00298

Aizenman, E., Tang, L. H., and Reynolds, I. J. (1991). Effects of nicotinic agonists on the NMDA receptor. Brain Res. 551, 355-357.

Akaike, A., and Izumi, Y. (2018). "Overview," in Nicotinic Acetylcholine Receptor Signaling in Neuroprotection, eds A. Akaike, S. Shimohama, and Y. Misu (Singapore: Springer), 1-15.

Akram, H., Wu, C., Hyam, J., Foltynie, T., Limousin, P., De Vita, E., et al. (2017). 1-Dopa responsiveness is associated with distinctive connectivity patterns in advanced Parkinson's disease. Mov. Disord. 32, 874-883. doi: 10.1002/mds. 27017

Alavian, K. N., Scholz, C., and Simon, H. H. (2008). Transcriptional regulation of mesencephalic dopaminergic neurons: the full circle of life and death. Mov. Disord. 23, 319-328. doi: 10.1002/mds.21640

Albert-Gasco, H., Ros-Bernal, F., Castillo-Gomez, E., and Olucha-Bordonau, F. E. (2020). MAP/ERK Signaling in developing cognitive and emotional function 
and its effect on pathological and neurodegenerative processes. Int. J. Mol. Sci. 21:21124471. doi: 10.3390/ijms21124471

Albuquerque, E. X., Pereira, E. F., Alkondon, M., and Rogers, S. W. (2009). Mammalian nicotinic acetylcholine receptors: from structure to function. Physiol. Rev. 89, 73-120. doi: 10.1152/physrev.00015.2008

Alexander, G. E. (2004). Biology of Parkinson's disease: pathogenesis and pathophysiology of a multisystem neurodegenerative disorder. Dialogues Clin. Neurosci. 6, 259-280.

Alexander, G. E., DeLong, M. R., and Strick, P. L. (1986). Parallel organization of functionally segregated circuits linking basal ganglia and cortex. Annu. Rev. Neurosci. 9, 357-381.

Allende, M. L., Zhu, H., Kono, M., Hoachlander-Hobby, L. E., Huso, V. L., and Proia, R. L. (2021). Genetic defects in the sphingolipid degradation pathway and their effects on microglia in neurodegenerative disease. Cell Signal 78:109879. doi: 10.1016/j.cellsig.2020.109879

Almey, A., Milner, T. A., and Brake, W. G. (2015). Estrogen receptors in the central nervous system and their implication for dopamine-dependent cognition in females. Horm. Behav. 74, 125-138. doi: 10.1016/j.yhbeh.2015.06.010

Alvarez-Ricartes, N., Oliveros-Matus, P., Mendoza, C., Perez-Urrutia, N., Echeverria, F., Iarkov, A., et al. (2018). Intranasal cotinine plus krill oil facilitates fear extinction, decreases depressive-like behavior, and increases hippocampal calcineurin a levels in mice. Mole. Neurobiol. 55, 7961-7961. doi: 10.1007/ s12035-018-1095-8

Amboni, M., Tessitore, A., Esposito, F., Santangelo, G., Picillo, M., Vitale, C., et al. (2015). Resting-state functional connectivity associated with mild cognitive impairment in Parkinson's disease. J. Neurol. 262, 425-434. doi: 10.1007/ s00415-014-7591-5

Anang, J. B., Nomura, T., Romenets, S. R., Nakashima, K., Gagnon, J. F., and Postuma, R. B. (2017). Dementia predictors in parkinson disease: a validation study. J. Parkinsons. Dis. 7, 159-162. doi: 10.3233/JPD- 160925

Anderkova, L., Barton, M., and Rektorova, I. (2017). Striato-cortical connections in Parkinson's and Alzheimer's diseases: Relation to cognition. Mov. Disord. 32, 917-922. doi: 10.1002/mds.26956

Anderson, R. H., and Becker, A. E. (1981). Stanley Kent and accessory atrioventricular connections. J. Thorac. Cardiovasc. Surg. 81, 649-658.

Anisuzzaman, A. S., Uwada, J., Masuoka, T., Yoshiki, H., Nishio, M., Ikegaya, Y., et al. (2013). Novel contribution of cell surface and intracellular M1-muscarinic acetylcholine receptors to synaptic plasticity in hippocampus. J. Neurochem. 126, 360-371. doi: 10.1111/jnc.12306

Aosaki, T., Graybiel, A. M., and Kimura, M. (1994a). Effect of the nigrostriatal dopamine system on acquired neural responses in the striatum of behaving monkeys. Science 265, 412-415. doi: 10.1126/science.8023166

Aosaki, T., Miura, M., Suzuki, T., Nishimura, K., and Masuda, M. (2010). Acetylcholine-dopamine balance hypothesis in the striatum: an update. Geriatr. Gerontol. Int. 10(Suppl. 1), S148-S157. doi: 10.1111/j.1447-0594.2010.00588.x

Aosaki, T., Tsubokawa, H., Ishida, A., Watanabe, K., Graybiel, A. M., and Kimura, M. (1994b). Responses of tonically active neurons in the primate's striatum undergo systematic changes during behavioral sensorimotor conditioning. J. Neurosci. 14, 3969-3984.

Apicella, P. (2017). The role of the intrinsic cholinergic system of the striatum: What have we learned from TAN recordings in behaving animals? Neuroscience 360, 81-94. doi: 10.1016/j.neuroscience.2017.07.060

Aquino-Miranda, G., Molina-Hernandez, A., and Arias-Montano, J. A. (2012). Regulation by histamine $\mathrm{H} 3$ receptors of neurotransmitter release in the basal ganglia: implications for Parkinson's disease pathophysiology. Gac. Med. Mex. 148, 467-475.

Avena, N. M., and Rada, P. V. (2012). Cholinergic modulation of food and drug satiety and withdrawal. Physiol. Behav. 106, 332-336. doi: 10.1016/j.physbeh. 2012.03.020

Avramovich, Y., Amit, T., and Youdim, M. B. (2002). Non-steroidal antiinflammatory drugs stimulate secretion of non-amyloidogenic precursor protein. J. Biol. Chem. 277, 31466-31473. doi: 10.1074/jbc.M201308200

Aybek, S., Lazeyras, F., Gronchi-Perrin, A., Burkhard, P. R., Villemure, J. G., and Vingerhoets, F. J. (2009). Hippocampal atrophy predicts conversion to dementia after STN-DBS in Parkinson's disease. Parkinsonism. Relat. Disord. 15, 521-524. doi: 10.1016/j.parkreldis.2009.01.003

Ballanger, B., Klinger, H., Eche, J., Lerond, J., Vallet, A. E., Le Bars, D., et al. (2012). Role of serotonergic 1A receptor dysfunction in depression associated with Parkinson's disease. Mov. Disord. 27, 84-89. doi: 10.1002/mds. 23895

Ballinger, E. C., Ananth, M., Talmage, D. A., and Role, L. W. (2016). Basal forebrain cholinergic circuits and signaling in cognition and cognitive decline. Neuron 91 , 1199-1218. doi: 10.1016/j.neuron.2016.09.006

Bandy, B., and Davison, A. J. (1990). Mitochondrial mutations may increase oxidative stress: implications for carcinogenesis and aging? Free Radic. Biol. Med. 8, 523-539. doi: 10.1016/0891-5849(90)90152-9

Barbeau, A. (1962). The pathogenesis of Parkinson's disease: a new hypothesis. Can. Med. Assoc. J. 87, 802-807.

Barreto, G. E., Iarkov, A., and Moran, V. E. (2014). Beneficial effects of nicotine, cotinine and its metabolites as potential agents for Parkinson's disease. Front. Aging Neurosci. 6:340. doi: 10.3389/fnagi.2014.00340

Bayarsaikhan, E., Bayarsaikhan, D., Lee, J., Son, M., Oh, S., Moon, J., et al. (2015). Microglial AGE-albumin is critical for neuronal death in Parkinson's disease: a possible implication for theranostics. Int. J. Nanomed. 10, 281-292. doi: 10. 2147/IJN.S95077

Beach, T. G., Adler, C. H., Sue, L. I., Peirce, J. B., Bachalakuri, J., DalsingHernandez, J. E., et al. (2008). Reduced striatal tyrosine hydroxylase in incidental Lewy body disease. Acta Neuropathol. 115, 445-451. doi: 10.1007/ s00401-007-0313-7

Beach, T. G., White, C. L. III, Hladik, C. L., Sabbagh, M. N., Connor, D. J., Shill, H. A., et al. (2009). Olfactory bulb alpha-synucleinopathy has high specificity and sensitivity for Lewy body disorders. Acta Neuropathol. 117, 169-174. doi: 10.1007/s00401-008-0450-7

Benard, G., Massa, F., Puente, N., Lourenco, J., Bellocchio, L., Soria-Gomez, E., et al. (2012). Mitochondrial $\mathrm{CB}(1)$ receptors regulate neuronal energy metabolism. Nat. Neurosci. 15, 558-564. doi: 10.1038/nn.3053

Bennett, B. D., Callaway, J. C., and Wilson, C. J. (2000). Intrinsic membrane properties underlying spontaneous tonic firing in neostriatal cholinergic interneurons. J. Neurosci. 20, 8493-8503.

Bergeron, C., Petrunka, C., Weyer, L., and Pollanen, M. S. (1996). Altered neurofilament expression does not contribute to Lewy body formation. Am. J. Pathol. 148, 267-272.

Berman, S. B., and Miller-Patterson, C. (2019). PD and DLB: Brain imaging in Parkinson's disease and dementia with Lewy bodies. Prog. Mol. Biol. Transl. Sci. 165, 167-185. doi: 10.1016/bs.pmbts.2019.07.009

Berridge, M. J. (2016). The Inositol Trisphosphate/calcium signaling pathway in health and disease. Physiol. Rev. 96, 1261-1296. doi: 10.1152/physrev.00006. 2016

Bertino, S., Basile, G. A., Anastasi, G., Bramanti, A., Fonti, B., Cavallaro, F., et al. (2020). Anatomical characterization of the human structural connectivity between the pedunculopontine nucleus and globus pallidus via multishell multi-tissue tractography. Medicina,2020:452. doi: 10.3390/medicina560 90452

Bharadwaj, U., Kasembeli, M. M., Robinson, P., and Tweardy, D. J. (2020). Targeting janus kinases and signal transducer and activator of transcription 3 to treat inflammation, fibrosis, and cancer: rationale, progress, and caution. Pharmacol. Rev. 72, 486-526. doi: 10.1124/pr.119.018440

Bjorklund, A., and Dunnett, S. B. (2007). Dopamine neuron systems in the brain: an update. Trends Neurosci. 30, 194-202. doi: 10.1016/j.tins.2007.03.006

Blanch, M., Mosquera, J. L., Ansoleaga, B., Ferrer, I., and Barrachina, M. (2016). Altered mitochondrial dna methylation pattern in alzheimer disease-related pathology and in parkinson disease. Am. J. Pathol. 186, 385-397. doi: 10.1016/j. ajpath.2015.10.004

Bohnen, N. I., and Albin, R. L. (2011). The cholinergic system and Parkinson disease. Behav. Brain Res. 221, 564-573. doi: 10.1016/j.bbr.2009.12.048

Bohnen, N. I., Albin, R. L., Muller, M. L., and Chou, K. (2011). Advances in therapeutic options for gait and balance in parkinson's disease. US Neurol. 7, 100-108. doi: 10.17925/usn.2011.07.02.100

Bohnen, N. I., Muller, M. L., Koeppe, R. A., Studenski, S. A., Kilbourn, M. A., Frey, K. A., et al. (2009). History of falls in Parkinson disease is associated with reduced cholinergic activity. Neurology $73,1670-1676$. doi: 10.1212/WNL. 0b013e3181c1ded6

Boiangiu, R. S., Mihasan, M., Gorgan, D. L., Stache, B. A., Petre, B. A., and Hritcu, L. (2020). Cotinine and 6-Hydroxy-L-Nicotine reverses memory deficits and reduces oxidative stress in abeta25-35-induced rat model of alzheimer's disease. Antioxidants 9:768. doi: 10.3390/antiox9080768 
Boivin, B., Vaniotis, G., Allen, B. G., and Hebert, T. E. (2008). G protein-coupled receptors in and on the cell nucleus: a new signaling paradigm? J. Recept. Signal. Transduct. Res. 28, 15-28. doi: 10.1080/10799890801941889

Bolam, J. P., Hanley, J. J., Booth, P. A., and Bevan, M. D. (2000). Synaptic organisation of the basal ganglia. J. Anat. 196(Pt 4), 527-542. doi: 10.1046/j. 1469-7580.2000.19640527.x

Bonito-Oliva, A., Masini, D., and Fisone, G. (2014). A mouse model of non-motor symptoms in Parkinson's disease: focus on pharmacological interventions targeting affective dysfunctions. Front Behav Neurosci 8:290. doi: 10.3389/fnbeh. 2014.00290

Bonsi, P., Cuomo, D., Martella, G., Madeo, G., Schirinzi, T., Puglisi, F., et al. (2011). Centrality of striatal cholinergic transmission in Basal Ganglia function. Front. Neuroanat. 5:6. doi: 10.3389/fnana.2011.00006

Bordia, T., Campos, C., Huang, L., and Quik, M. (2008). Continuous and intermittent nicotine treatment reduces L-3,4-dihydroxyphenylalanine (LDOPA)-induced dyskinesias in a rat model of Parkinson's disease. J. Pharmacol. Exp. Ther. 327, 239-247. doi: 10.1124/jpet.108.140897

Bordia, T., Campos, C., McIntosh, J. M., and Quik, M. (2010). Nicotinic receptor-mediated reduction in L-DOPA-induced dyskinesias may occur via desensitization. J. Pharmacol. Exp. Ther. 333, 929-938.

Bordia, T., McGregor, M., Papke, R. L., Decker, M. W., McIntosh, J. M., and Quik, M. (2015). The alpha7 nicotinic receptor agonist ABT-107 protects against nigrostriatal damage in rats with unilateral 6-hydroxydopamine lesions. Exp. Neurol. 263, 277-284. doi: 10.1016/j.expneurol.2014.09.015

Bordia, T., and Perez, X. A. (2019). Cholinergic control of striatal neurons to modulate L-dopa-induced dyskinesias. Eur. J. Neurosci. 49, 859-868. doi: 10. 1111/ejn. 14048

Bose, A., and Beal, M. F. (2016). Mitochondrial dysfunction in Parkinson's disease. J. Neurochem. 139(Suppl. 1), 216-231. doi: 10.1111/jnc.13731

Bose, A., Mouton-Liger, F., Paquet, C., Mazot, P., Vigny, M., Gray, F., et al. (2011). Modulation of tau phosphorylation by the kinase PKR: implications in Alzheimer's disease. Brain Pathol. 21, 189-200. doi: 10.1111/j.1750-3639.2010. 00437.x

Bosmans, G., Shimizu Bassi, G., Florens, M., Gonzalez-Dominguez, E., Matteoli, G., and Boeckxstaens, G. E. (2017). Cholinergic modulation of type 2 immune responses. Front. Immunol. 8:1873. doi: 10.3389/fimmu.2017.01873

Braak, H., and Braak, E. (2000). Pathoanatomy of Parkinson's disease. J. Neurol. 247(Suppl. 2), II3-II10.

Braak, H., de Vos, R. A., Jansen, E. N., Bratzke, H., and Braak, E. (1998). Neuropathological hallmarks of alzheimer's and parkinson's diseases. Prog. Brain Res. 117, 267-285.

Braak, H., Rub, U., Jansen Steur, E. N., Del Tredici, K., and de Vos, R. A. (2005). Cognitive status correlates with neuropathologic stage in Parkinson disease. Neurology 64, 1404-1410. doi: 10.1212/01.WNL.0000158422. 41380.82

Brimblecombe, K. R., Threlfell, S., Dautan, D., Kosillo, P., Mena-Segovia, J., and Cragg, S. J. (2018). Targeted activation of cholinergic interneurons accounts for the modulation of dopamine by striatal nicotinic receptors. eNeuro 5:2018. doi: 10.1523/ENEURO.0397-17.2018

Buccafusco, J. J., and Terry, A. V. Jr. (2003). The potential role of cotinine in the cognitive and neuroprotective actions of nicotine. Life Sci. 72, 2931-2942.

Buckingham, S. D., Jones, A. K., Brown, L. A., and Sattelle, D. B. (2009). Nicotinic acetylcholine receptor signalling: roles in Alzheimer's disease and amyloid neuroprotection. Pharmacol. Rev. 61, 39-61.

Burbulla, L. F., Song, P., Mazzulli, J. R., Zampese, E., Wong, Y. C., Jeon, S., et al. (2017). Dopamine oxidation mediates mitochondrial and lysosomal dysfunction in Parkinson's disease. Science 357, 1255-1261. doi: 10.1126/ science.aam 9080

Burke, R. E., and O'Malley, K. (2013). Axon degeneration in Parkinson's disease. Exp. Neurol. 246, 72-83. doi: 10.1016/j.expneurol.2012.01.011

Byeon, H. (2020). Best early-onset Parkinson dementia predictor using ensemble learning among Parkinson's symptoms, rapid eye movement sleep disorder, and neuropsychological profile. World J. Psychiatry 10, 245-259. doi: 10.5498/wjp. v10.i11.245

Calabresi, P., Centonze, D., Gubellini, P., Marfia, G. A., Pisani, A., Sancesario, G., et al. (2000a). Synaptic transmission in the striatum: from plasticity to neurodegeneration. Prog. Neurobiol. 61, 231-265. doi: 10.1016/s0301-0082(99) 00030- 1
Calabresi, P., Centonze, D., Gubellini, P., Pisani, A., and Bernardi, G. (2000b). Acetylcholine-mediated modulation of striatal function. Trends Neurosci. 23, 120-126. doi: 10.1016/s0166-2236(99)01501-5

Campos, H. C., da Rocha, M. D., Viegas, F. P., Nicastro, P. C., Fossaluzza, P. C., Fraga, C. A., et al. (2011). The role of natural products in the discovery of new drug candidates for the treatment of neurodegenerative disorders I: Parkinson's disease. CNS Neurol. Disord. Drug Targets 10, 239-250.

Carey, G., Gormezoglu, M., de Jong, J. J. A., Hofman, P. A. M., Backes, W. H., Dujardin, K., et al. (2021). Neuroimaging of Anxiety in Parkinson's Disease: A Systematic Review. Mov. Disord 36, 327-339. doi: 10.1002/mds.28404

Carlsson, A., and Fornstedt, B. (1991). Possible mechanisms underlying the special vulnerability of dopaminergic neurons. Acta Neurol. Scand. Suppl. 136, 16-18. doi: 10.1111/j.1600-0404.1991.tb05014.x

Carvey, P. M., Chang, Q., Lipton, J. W., and Ling, Z. (2003). Prenatal exposure to the bacteriotoxin lipopolysaccharide leads to long-term losses of dopamine neurons in offspring: a potential, new model of Parkinson's disease. Front. Biosci. 8:s826-s837.

Cerasa, A., Novellino, F., and Quattrone, A. (2016). Connectivity changes in parkinson's disease. Curr. Neurol. Neurosci. Rep. 16:91. doi: 10.1007/s11910016-0687-9

Chambers, N. E., Meadows, S. M., Taylor, A., Sheena, E., Lanza, K., Conti, M. M., et al. (2019). Effects of muscarinic acetylcholine $\mathrm{m} 1$ and $\mathrm{m} 4$ receptor blockade on dyskinesia in the hemi-parkinsonian rat. Neuroscience 409, 180-194. doi: 10.1016/j.neuroscience.2019.04.008

Chapman, M. A. (2009). Does smoking reduce the risk of Parkinson's disease through stimulation of the ubiquitin-proteasome system? Med. Hypotheses 73, 887-891. doi: 10.1016/j.mehy.2009.03.053

Charara, A., and Parent, A. (1994). Brainstem dopaminergic, cholinergic and serotoninergic afferents to the pallidum in the squirrel monkey. Brain Res. 640, 155-170. doi: 10.1016/0006-8993(94)91870-8

Chen, H., Huang, X., Guo, X., Mailman, R. B., Park, Y., Kamel, F., et al. (2010). Smoking duration, intensity, and risk of Parkinson disease. Neurology 74, 878-884. doi: 10.1212/WNL.0b013e3181d55f38

Chen, L., Yamada, K., Nabeshima, T., and Sokabe, M. (2006). alpha7 Nicotinic acetylcholine receptor as a target to rescue deficit in hippocampal LTP induction in beta-amyloid infused rats. Neuropharmacology 50, 254-268. doi: 10.1016/j. neuropharm.2005.09.018

Cheng, Y., and Wang, Y. J. (2020). Tobacco smoking and the reduced risk of Parkinson disease: A puzzle of 60 years. Neurology 94, 860-861. doi: 10.1212/ WNL.0000000000009431

Cholerton, B., Johnson, C. O., Fish, B., Quinn, J. F., Chung, K. A., Peterson-Hiller, A. L., et al. (2018). Sex differences in progression to mild cognitive impairment and dementia in Parkinson's disease. Parkinsonism Relat. Disord. 50, 29-36. doi: 10.1016/j.parkreldis.2018.02.007

Chondrogiorgi, M., Astrakas, L. G., Zikou, A. K., Weis, L., Xydis, V. G., Antonini, A., et al. (2019). Multifocal alterations of white matter accompany the transition from normal cognition to dementia in Parkinson's disease patients. Brain Imag. Behav. 13, 232-240. doi: 10.1007/s11682-018-9863-7

Chung, C. Y., Seo, H., Sonntag, K. C., Brooks, A., Lin, L., and Isacson, O. (2005). Cell type-specific gene expression of midbrain dopaminergic neurons reveals molecules involved in their vulnerability and protection. Hum. Mol. Genet. 14, 1709-1725. doi: 10.1093/hmg/ddil78

Chung, S. J., Yoo, H. S., Lee, Y. H., Lee, H. S., Ye, B. S., Sohn, Y. H., et al. (2019). Frontal atrophy as a marker for dementia conversion in Parkinson's disease with mild cognitive impairment. Hum. Brain Mapp. 40, 3784-3794. doi: 10.1002/hbm.24631

Chung, S. J., Yoo, H. S., Shin, N. Y., Park, Y. W., Lee, H. S., Hong, J. M., et al. (2021). Perivascular spaces in the basal ganglia and long-term motor prognosis in newly diagnosed parkinson disease. Neurology 96, e2121-e2131. doi: 10.1212/ WNL.0000000000011797

Clarke, R., and Adermark, L. (2015). Dopaminergic regulation of striatal interneurons in reward and addiction: focus on alcohol. Neural. Plast. 2015:814567. doi: 10.1155/2015/814567

Compta, Y., and Revesz, T. (2021). Neuropathological and biomarker findings in parkinson's disease and alzheimer's disease: from protein aggregates to synaptic dysfunction. J. Parkinsons. Dis. 11, 107-121. doi: 10.3233/JPD-202323

Consolo, S., Girotti, P., Zambelli, M., Russi, G., Benzi, M., and Bertorelli, R. (1993). D1 and D2 dopamine receptors and the regulation of striatal acetylcholine 
release in vivo. Prog. Brain Res. 98, 201-207. doi: 10.1016/s0079-6123(08) 62400-0

Conti, M. M., Chambers, N., and Bishop, C. (2018). A new outlook on cholinergic interneurons in Parkinson's disease and L-DOPA-induced dyskinesia. Neurosci. Biobehav. Rev. 92, 67-82. doi: 10.1016/j.neubiorev.2018.05.021

Cooper, J. A., Sagar, H. J., Doherty, S. M., Jordan, N., Tidswell, P., and Sullivan, E. V. (1992). Different effects of dopaminergic and anticholinergic therapies on cognitive and motor function in Parkinson's disease. A follow-up study of untreated patients. Brain 115(Pt 6), 1701-1725. doi: 10.1093/brain/115.6.1701

Course, M. M., and Wang, X. (2016). Transporting mitochondria in neurons. F1000Res 5:7864. doi: 10.12688/f1000research.7864.1

Court, J. A., Piggott, M. A., Lloyd, S., Cookson, N., Ballard, C. G., McKeith, I. G., et al. (2000). Nicotine binding in human striatum: elevation in schizophrenia and reductions in dementia with Lewy bodies, Parkinson's disease and Alzheimer's disease and in relation to neuroleptic medication. Neuroscience 98, 79-87.

Crans, R. A. J., and Ciruela, F. (2021). Dopaminergic-cholinergic imbalance in movement disorders: a role for the novel striatal dopamine D2- muscarinic acetylcholine M1 receptor heteromer. Neural. Regen. Res. 16, 1406-1408. doi: 10.4103/1673-5374.300988

Crispo, J. A., Willis, A. W., Thibault, D. P., Fortin, Y., Hays, H. D., McNair, D. S., et al. (2016). Associations between anticholinergic burden and adverse health outcomes in parkinson disease. PLoS One 11:e0150621. doi: 10.1371/journal. pone. 0150621

Dajas-Bailador, F., and Wonnacott, S. (2004). Nicotinic acetylcholine receptors and the regulation of neuronal signalling. Trends Pharmacol. Sci. 25, 317-324. doi: $10.1016 /$ j.tips.2004.04.006

Damsma, G., Robertson, G. S., Tham, C. S., and Fibiger, H. C. (1991). Dopaminergic regulation of striatal acetylcholine release: importance of D1 and N-methyl-D-aspartate receptors. J. Pharmacol. Exp. Ther. 259, 1064-1072.

Dani, J. A. (2015). Neuronal nicotinic acetylcholine receptor structure and function and response to nicotine. Int. Rev. Neurobiol. 124, 3-19. doi: 10.1016/bs.irn. 2015.07.001

Dautan, D., Huerta-Ocampo, I., Gut, N. K., Valencia, M., Kondabolu, K., Kim, Y., et al. (2020). Cholinergic midbrain afferents modulate striatal circuits and shape encoding of action strategies. Nat. Commun. 11:1739. doi: 10.1038/s41467-02015514-3

Dautan, D., Huerta-Ocampo, I., Witten, I. B., Deisseroth, K., Bolam, J. P., Gerdjikov, T., et al. (2014). A major external source of cholinergic innervation of the striatum and nucleus accumbens originates in the brainstem. J. Neurosci. 34, 4509-4518. doi: 10.1523/JNEUROSCI.5071-13.2014

de Aguiar, R. B., Parfitt, G. M., Jaboinski, J., and Barros, D. M. (2013). Neuroactive effects of cotinine on the hippocampus: behavioral and biochemical parameters. Neuropharmacology 71, 292-298.

de Jonge, W. J., and Ulloa, L. (2007). The alpha7 nicotinic acetylcholine receptor as a pharmacological target for inflammation. Br. J. Pharmacol. 151, 915-929.

Deffains, M., and Bergman, H. (2015). Striatal cholinergic interneurons and cortico-striatal synaptic plasticity in health and disease. Mov. Disord. 30, 10141025. doi: $10.1002 / \mathrm{mds} .26300$

Delic, V., Beck, K. D., Pang, K. C. H., and Citron, B. A. (2020). Biological links between traumatic brain injury and Parkinson's disease. Acta Neuropathol. Commun. 8:45. doi: 10.1186/s40478-020-00924-7

DeLong, M. (2000). Parkinson's disease. Neurobiol. Dis. 7, 559-560. doi: 10.1006/ nbdi. 2000.0355

Deng, H., Wang, P., and Jankovic, J. (2018). The genetics of Parkinson disease. Ageing Res. Rev. 42, 72-85. doi: 10.1016/j.arr.2017.12.007

Deng, J., Habib, A., Obregon, D. F., Barger, S. W., Giunta, B., Wang, Y. J., et al. (2015). Soluble amyloid precursor protein alpha inhibits tau phosphorylation through modulation of GSK3beta signaling pathway. J Neurochem 135, 630637. doi: $10.1111 /$ jnc. 13351

Devi, L., Raghavendran, V., Prabhu, B. M., Avadhani, N. G., and Anandatheerthavarada, H. K. (2008). Mitochondrial import and accumulation of alpha-synuclein impair complex I in human dopaminergic neuronal cultures and Parkinson disease brain. J. Biol. Chem. 283, 9089-9100. doi: 10.1074/jbc.M710012200

Dexter, D. T., and Jenner, P. (2013). Parkinson disease: from pathology to molecular disease mechanisms. Free Radic Biol. Med. 62, 132-144. doi: 10.1016/ j.freeradbiomed.2013.01.018
Di Chiara, G., Morelli, M., and Consolo, S. (1994). Modulatory functions of neurotransmitters in the striatum: ACh/dopamine/NMDA interactions. Trends Neurosci. 17, 228-233. doi: 10.1016/0166-2236(94)90005-1

Dineley, K. T., Pandya, A. A., and Yakel, J. L. (2015). Nicotinic ACh receptors as therapeutic targets in CNS disorders. Trends Pharmacol. Sci. 36, 96-108. doi: 10.1016/j.tips.2014.12.002

Do, J., Kim, J. I., Bakes, J., Lee, K., and Kaang, B. K. (2012). Functional roles of neurotransmitters and neuromodulators in the dorsal striatum. Learn Mem. 20, 21-28. doi: 10.1101/lm.025015.111

Dos Santos, T. F. O., de, R. S. E., Bispo, J. M. M., de Souza, M. F., de Gois, A. M., Lins, L., et al. (2021). Balance alterations and reduction of pedunculopontine cholinergic neurons in early stages of parkinsonism in middle-aged rats. Exp. Gerontol. 145:111198. doi: 10.1016/j.exger.2020.111198

Drachman, D. A., and Leavitt, J. (1974). Human memory and the cholinergic system. A relationship to aging? Arch. Neurol. 30, 113-121. doi: 10.1001/ archneur.1974.00490320001001

Duce, J. A., Wong, B. X., Durham, H., Devedjian, J. C., Smith, D. P., and Devos, D. (2017). Post translational changes to alpha-synuclein control iron and dopamine trafficking; a concept for neuron vulnerability in Parkinson's disease. Mol. Neurodegener. 12:45. doi: 10.1186/s13024-017-0186-8

Durieux, P. F., Schiffmann, S. N., de Kerchove, and d'Exaerde, A. (2011). Targeting neuronal populations of the striatum. Front. Neuroanat. 5:40. doi: 10.3389/ fnana.2011.00040

Echeverria, V., Grizzell, J. A., and Barreto, G. E. (2016a). Neuroinflammation: a therapeutic target of cotinine for the treatment of psychiatric disorders? Curr. Pharm. Des. 22, 1324-1333.

Echeverria, V., Yarkov, A., and Aliev, G. (2016b). Positive modulators of the alpha7 nicotinic receptor against neuroinflammation and cognitive impairment in Alzheimer's disease. Prog. Neurobiol. 144, 142-157. doi: 10.1016/j.pneurobio. 2016.01.002

Echeverria, V., and Zeitlin, R. (2012). Cotinine: a potential new therapeutic agent against Alzheimer's disease. CNS Neurosci. Ther. 18, 517-523. doi: 10.1111/j. 1755-5949.2012.00317.x

Echeverria, V., Zeitlin, R., Burgess, S., Patel, S., Barman, A., Thakur, G., et al. (2011). Cotinine reduces amyloid-beta aggregation and improves memory in Alzheimer's disease mice. J. Alzheimers Dis. 24, 817-835. doi: 10.3233/JAD2011-102136

Eisinger, R. S., Ramirez-Zamora, A., Carbunaru, S., Ptak, B., Peng-Chen, Z., Okun, M. S., et al. (2019). Medications, deep brain stimulation, and other factors influencing impulse control disorders in parkinson's disease. Front. Neurol. 10:86. doi: 10.3389/fneur.2019.00086

Emre, M., Aarsland, D., Brown, R., Burn, D. J., Duyckaerts, C., Mizuno, Y., et al. (2007). Clinical diagnostic criteria for dementia associated with Parkinson's disease. Mov. Disord. 22, 1689-1707. doi: 10.1002/mds.21507

Eneroth, P., Fuxe, K., Gustafsson, J. A., Hokfelt, T., Lofstrom, A., Skett, P., et al. (1977). The effect of nicotine on central catecholamine neurons and gonadotropin secretion. III. Studies on prepubertal female rats treated with pregnant mare serum gonadotropin. Med. Biol. 55, 167-176.

English, D. F., Ibanez-Sandoval, O., Stark, E., Tecuapetla, F., Buzsaki, G., Deisseroth, K., et al. (2011). GABAergic circuits mediate the reinforcementrelated signals of striatal cholinergic interneurons. Nat. Neurosci. 15, 123-130. doi: $10.1038 / \mathrm{nn} .2984$

Fahn, S. (1989). The history of parkinsonism. Mov. Disord. 4(Suppl. 1), S2-S10. doi: $10.1002 / \mathrm{mds} .870040502$

Falkenburger, B. H., Jensen, J. B., and Hille, B. (2010). Kinetics of PIP2 metabolism and KCNQ2/3 channel regulation studied with a voltage-sensitive phosphatase in living cells. J. Gen. Physiol. 135, 99-114. doi: 10.1085/jgp.200910345

Farias, G. G., Godoy, J. A., Hernandez, F., Avila, J., Fisher, A., and Inestrosa, N. C. (2004). M1 muscarinic receptor activation protects neurons from betaamyloid toxicity. A role for Wnt signaling pathway. Neurobiol. Dis. 17, 337-348. doi: 10.1016/j.nbd.2004.07.016

Ferre, S., and Ciruela, F. (2019). Functional and neuroprotective role of striatal adenosine A2A Receptor Heterotetramers. J. Caffeine Adenosine Res. 9, 89-97. doi: 10.1089/caff.2019.0008

Ferre, S., Lluis, C., Justinova, Z., Quiroz, C., Orru, M., Navarro, G., et al. (2010). Adenosine-cannabinoid receptor interactions. Implications for striatal function. Br. J. Pharmacol. 160, 443-453. doi: 10.1111/j.1476-5381.2010. 00723.x 
Ferrer, I., Lopez-Gonzalez, I., Carmona, M., Dalfo, E., Pujol, A., and Martinez, A. (2012). Neurochemistry and the non-motor aspects of PD. Neurobiol. Dis. 46, 508-526. doi: 10.1016/j.nbd.2011.10.019

Ferrer, I., Martinez, A., Blanco, R., Dalfo, E., and Carmona, M. (2011). Neuropathology of sporadic Parkinson disease before the appearance of parkinsonism: preclinical Parkinson disease. J. Neural. Transm. 118, 821-839. doi: 10.1007/s00702-010-0482-8

Fitts, W., Weintraub, D., Massimo, L., Chahine, L., Chen-Plotkin, A., Duda, J. E., et al. (2015). Caregiver report of apathy predicts dementia in Parkinson's disease. Parkinsonism. Relat. Disord. 21, 992-995. doi: 10.1016/j.parkreldis. 2015.06.009

Foltynie, T., Brayne, C., and Barker, R. A. (2002a). The heterogeneity of idiopathic Parkinson's disease. J. Neurol. 249, 138-145. doi: 10.1007/pl00007856

Foltynie, T., Sawcer, S., Brayne, C., and Barker, R. A. (2002b). The genetic basis of Parkinson's disease. J. Neurol. Neurosurg. Psychiatry 73, 363-370. doi: 10.1136/ jnnp.73.4.363

Foster, P. S., Drago, V., Mendez, K., Witt, J. C., Crucian, G. P., and Heilman, K. M. (2013). Mood disturbances and cognitive functioning in Parkinson's disease: the effects of disease duration and side of onset of motor symptoms. J. Clin. Exp. Neuropsychol. 35, 71-82. doi: 10.1080/13803395.2012.753037

Fox, A. M., Moonschi, F. H., and Richards, C. I. (2015). The nicotine metabolite, cotinine, alters the assembly and trafficking of a subset of nicotinic acetylcholine receptors. J. Biol. Chem. 290, 24403-24412. doi: 10.1074/jbc.M115.661827

Franco-Iborra, S., Vila, M., and Perier, C. (2016). The parkinson disease mitochondrial hypothesis: where are we at? Neuroscientist 22, 266-277. doi: $10.1177 / 1073858415574600$

Fratiglioni, L., and Wang, H. X. (2000). Smoking and Parkinson's and Alzheimer's disease: review of the epidemiological studies. Behav. Brain Res. 113, 117-120. doi: 10.1016/s0166-4328(00)00206-0

French, I. T., and Muthusamy, K. A. (2018). A review of the pedunculopontine nucleus in parkinson's disease. Front. Aging. Neurosci. 10:99. doi: 10.3389/fnagi. 2018.00099

Friedman, J. H. (2018). Dementia with lewy bodies and parkinson disease dementia: it is the same disease! Parkinsonism Relat. Disord. 46(Suppl. 1), S6-S9. doi: 10.1016/j.parkreldis.2017.07.013

Fujii, S., Ji, Z., Morita, N., and Sumikawa, K. (1999). Acute and chronic nicotine exposure differentially facilitate the induction of LTP. Brain Res. 846, 137-143. doi: 10.1016/s0006-8993(99)01982-4

Fujii, T., Mashimo, M., Moriwaki, Y., Misawa, H., Ono, S., Horiguchi, K., et al. (2017). Physiological functions of the cholinergic system in immune cells. J. Pharmacol. Sci. 134, 1-21. doi: 10.1016/j.jphs.2017.05.002

Fuxe, K., Andersson, K., Harfstrand, A., and Agnati, L. F. (1986). Increases in dopamine utilization in certain limbic dopamine terminal populations after a short period of intermittent exposure of male rats to cigarette smoke. J. Neural. Transm. 67, 15-29.

Fuxe, K., Everitt, B. J., and Hokfelt, T. (1979). On the action of nicotine and cotinine on central 5-hydroxytryptamine neurons. Pharmacol. Biochem. Behav. $10,671-677$.

Galantucci, S., Agosta, F., Stefanova, E., Basaia, S., van den Heuvel, M. P., Stojkovic, T., et al. (2017). Structural Brain Connectome and Cognitive Impairment in Parkinson Disease. Radiology 283, 515-525. doi: 10.1148/radiol.2016160274

Gale, J. T., Amirnovin, R., Williams, Z. M., Flaherty, A. W., and Eskandar, E. N. (2008). From symphony to cacophony: pathophysiology of the human basal ganglia in Parkinson disease. Neurosci. Biobehav. Rev. 32, 378-387. doi: 10.1016/ j.neubiorev.2006.11.005

Gallo, E. F. (2019). Disentangling the diverse roles of dopamine D2 receptors in striatal function and behavior. Neurochem. Int. 125, 35-46. doi: 10.1016/j. neuint.2019.01.022

Gallo, V., Vineis, P., Cancellieri, M., Chiodini, P., Barker, R. A., Brayne, C., et al. (2019). Exploring causality of the association between smoking and Parkinson's disease. Int. J. Epidemiol. 48, 912-925. doi: 10.1093/ije/dyy230

Gao, J., Adam, B. L., and Terry, A. V. Jr. (2014). Evaluation of nicotine and cotinine analogs as potential neuroprotective agents for Alzheimer's disease. Bioorg. Med. Chem. Lett. 24, 1472-1478. doi: 10.1016/j.bmcl.2014.02.008

Garcia-Rill, E. (1986). The basal ganglia and the locomotor regions. Brain Res. 396, 47-63.

Gelb, D. J., Oliver, E., and Gilman, S. (1999). Diagnostic criteria for Parkinson disease. Arch. Neurol. 56, 33-39.
George, S., Rey, N. L., Reichenbach, N., Steiner, J. A., and Brundin, P. (2013). alphaSynuclein: the long distance runner. Brain Pathol 23, 350-357. doi: 10.1111/bpa. 12046

Gerfen, C. R., and Surmeier, D. J. (2011). Modulation of striatal projection systems by dopamine. Annu Rev. Neurosci. 34, 441-466. doi: 10.1146/annurev-neuro061010-113641

Gergalova, G., Lykhmus, O., Komisarenko, S., and Skok, M. (2014). alpha7 nicotinic acetylcholine receptors control cytochrome $\mathrm{c}$ release from isolated mitochondria through kinase-mediated pathways. Int. J. Biochem. Cell Biol. 49, 26-31. doi: 10.1016/j.biocel.2014.01.001

Getachew, B., Csoka, A. B., Aschner, M., and Tizabi, Y. (2019). Nicotine protects against manganese and iron-induced toxicity in SH-SY5Y cells: Implication for Parkinson's disease. Neurochem. Int. 124, 19-24. doi: 10.1016/j.neuint.2018. 12.003

Gilmozzi, V., Gentile, G., Castelo Rueda, M. P., Hicks, A. A., Pramstaller, P. P., Zanon, A., et al. (2020). Interaction of alpha-synuclein with lipids: mitochondrial cardiolipin as a critical player in the pathogenesis of parkinson's disease. Front. Neurosci. 14:578993. doi: 10.3389/fnins.2020.578993

Goldberg, J. A., Ding, J. B., and Surmeier, D. J. (2012). Muscarinic modulation of striatal function and circuitry. Handb. Exp. Pharmacol. 208, 223-241. doi: 10.1007/978-3-642-23274-9_10

Goldberg, J. A., and Reynolds, J. N. (2011). Spontaneous firing and evoked pauses in the tonically active cholinergic interneurons of the striatum. Neuroscience 198, 27-43. doi: 10.1016/j.neuroscience.2011.08.067

Gonzales, K. K., and Smith, Y. (2015). Cholinergic interneurons in the dorsal and ventral striatum: anatomical and functional considerations in normal and diseased conditions. Ann. N. Y. Acad. Sci. 1349, 1-45. doi: 10.1111/nyas. 12762

Gotti, C., Clementi, F., Fornari, A., Gaimarri, A., Guiducci, S., Manfredi, I., et al. (2009). Structural and functional diversity of native brain neuronal nicotinic receptors. Biochem. Pharmacol. 78, 703-711. doi: 10.1016/j.bcp.2009.05.024

Graef, S., Schonknecht, P., Sabri, O., and Hegerl, U. (2011). Cholinergic receptor subtypes and their role in cognition, emotion, and vigilance control: an overview of preclinical and clinical findings. Psychopharmacology 215, 205-229. doi: 10.1007/s00213-010-2153-8

Green, J., McDonald, W. M., Vitek, J. L., Evatt, M., Freeman, A., Haber, M., et al. (2002). Cognitive impairments in advanced PD without dementia. Neurology 59, 1320-1324. doi: 10.1212/01.wnl.0000031426.21683.e2

Greenbaum, L., Rigbi, A., Lipshtat, N., Cilia, R., Tesei, S., Asselta, R., et al. (2013). Association of nicotine dependence susceptibility gene. CHRNA5, with Parkinson's disease age at onset: gene and smoking status interaction. Parkinsonism Relat. Disord. 19, 72-76. doi: 10.1016/j.parkreldis.2012.07.007

Grizzell, J. A., and Echeverria, V. (2015). New insights into the mechanisms of action of cotinine and its distinctive effects from nicotine. Neurochem. Res. 40, 2032-2046. doi: 10.1007/s11064-014-1359-2

Grizzell, J. A., Iarkov, A., Holmes, R., Mori, T., and Echeverria, V. (2014). Cotinine reduces depressive-like behavior, working memory deficits, and synaptic loss associated with chronic stress in mice. Behav. Brain Res. 268, 55-65. doi: 10. 1016/j.bbr.2014.03.047

Grizzell, J. A., Patel, S., Barreto, G. E., and Echeverria, V. (2017). Cotinine improves visual recognition memory and decreases cortical Tau phosphorylation in the Tg6799 mice. Prog. Neuropsychopharmacol. Biol. Psychiatry 78, 75-81. doi: 10.1016/j.pnpbp.2017.05.010

Grover, S., Somaiya, M., Kumar, S., and Avasthi, A. (2015). Psychiatric aspects of Parkinson's disease. J. Neurosci. Rural. Pract. 6, 65-76. doi: 10.4103/0976-3147. 143197

Grunewald, A., Kumar, K. R., and Sue, C. M. (2019). New insights into the complex role of mitochondria in Parkinson's disease. Prog. Neurobiol. 177, 73-93. doi: 10.1016/j.pneurobio.2018.09.003

Guo, Y., Xu, W., Liu, F. T., Li, J. Q., Cao, X. P., Tan, L., et al. (2019). Modifiable risk factors for cognitive impairment in Parkinson's disease: a systematic review and meta-analysis of prospective cohort studies. Mov. Disord. 34, 876-883. doi: $10.1002 / \mathrm{mds} .27665$

Guttuso, T. Jr. (2019). High lithium levels in tobacco may account for reduced incidences of both Parkinson's disease and melanoma in smokers through enhanced beta-catenin-mediated activity. Med. Hypotheses 131:109302. doi: 10. 1016/j.mehy.2019.109302

Guttuso, T. Jr., Andrzejewski, K. L., Lichter, D. G., and Andersen, J. K. (2019a). Targeting kinases in Parkinson's disease: a mechanism shared by LRRK2, 
neurotrophins, exenatide, urate, nilotinib and lithium. J. Neurol. Sci. 402, 121-130. doi: 10.1016/j.jns.2019.05.016

Guttuso, T. Jr., Russak, E., De Blanco, M. T., and Ramanathan, M. (2019b). Could high lithium levels in tobacco contribute to reduced risk of Parkinson's disease in smokers? J. Neurol. Sci. 397, 179-180. doi: 10.1016/j.jns.2019. 01.009

Habib, A., Sawmiller, D., and Tan, J. (2017). Restoring soluble amyloid precursor protein alpha functions as a potential treatment for alzheimer's disease. J. Neurosci. Res. 95, 973-991. doi: 10.1002/jnr.23823

Halder, N., and Lal, G. (2021). Cholinergic System and Its Therapeutic Importance in Inflammation and Autoimmunity. Front. Immunol. 12:660342. doi: 10.3389/ fimmu.2021.660342

Hampel, H., Mesulam, M. M., Cuello, A. C., Farlow, M. R., Giacobini, E., Grossberg, G. T., et al. (2018). The cholinergic system in the pathophysiology and treatment of Alzheimer's disease. Brain 141, 1917-1933. doi: 10.1093/brain/ awy132

Hasan, S., Mielke, M. M., Turcano, P., Ahlskog, J. E., Bower, J. H., and Savica, R. (2020). Traumatic brain injury preceding clinically diagnosed alphasynucleinopathies: A case-control study. Neurology 94, e764-e773. doi: 10.1212/ WNL.0000000000008995

Hatsukami, D. K., Grillo, M., Pentel, P. R., Oncken, C., and Bliss, R. (1997). Safety of cotinine in humans: physiologic, subjective, and cognitive effects. Pharmacol. Biochem. Behav. 57, 643-650.

Havekes, R., Abel, T., and Van der Zee, E. A. (2011). The cholinergic system and neostriatal memory functions. Behav. Brain Res 221, 412-423. doi: 10.1016/j. bbr.2010.11.047

Hegarty, S. V., Sullivan, A. M., and O'Keeffe, G. W. (2013). Midbrain dopaminergic neurons: a review of the molecular circuitry that regulates their development. Dev. Biol. 379, 123-138. doi: 10.1016/j.ydbio.2013.04.014

Hemmerle, A. M., Herman, J. P., and Seroogy, K. B. (2012). Stress, depression and Parkinson's disease. Exp. Neurol. 233, 79-86. doi: 10.1016/j.expneurol.2011. 09.035

Herzallah, M. M., Moustafa, A. A., Misk, A. J., Al-Dweib, L. H., Abdelrazeq, S. A., Myers, C. E., et al. (2010). Depression impairs learning whereas anticholinergics impair transfer generalization in Parkinson patients tested on dopaminergic medications. Cogn. Behav. Neurol. 23, 98-105. doi: 10.1097/ WNN.0b013e3181df3048

Hill, W. D. (1996). Altered neurofilament expression does not contribute to Lewy body formation. Am. J. Pathol. 149, 728-729.

Ho, M. W., Chien, S. H., Lu, M. K., Chen, J. C., Aoh, Y., Chen, C. M., et al. (2020). Impairments in face discrimination and emotion recognition are related to aging and cognitive dysfunctions in Parkinson's disease with dementia. Sci. Rep. 10:4367. doi: 10.1038/s41598-020-61310-w

Hong, D. P., Fink, A. L., and Uversky, V. N. (2009). Smoking and Parkinson's disease: does nicotine affect alpha-synuclein fibrillation? Biochim. Biophys. Acta 1794, 282-290. doi: 10.1016/j.bbapap.2008.09.026

Hoogland, J., Boel, J. A., de Bie, R. M. A., Geskus, R. B., Schmand, B. A., DalrympleAlford, J. C., et al. (2017). Mild cognitive impairment as a risk factor for Parkinson's disease dementia. Mov. Disord 32, 1056-1065. doi: 10.1002/mds. 27002

Horowitz, M. P., Milanese, C., Di Maio, R., Hu, X., Montero, L. M., Sanders, L. H., et al. (2011). Single-cell redox imaging demonstrates a distinctive response of dopaminergic neurons to oxidative insults. Antioxid. Redox Signal. 15, 855-871. doi: 10.1089 /ars.2010.3629

Howe, W. M., Young, D. A., Bekheet, G., and Kozak, R. (2016). Nicotinic receptor subtypes differentially modulate glutamate release in the dorsal medial striatum. Neurochem. Int. 100, 30-34. doi: 10.1016/j.neuint.2016.08.009

Huang, L. Z., Campos, C., Ly, J., Ivy Carroll, F., and Quik, M. (2011a). Nicotinic receptor agonists decrease L-dopa-induced dyskinesias most effectively in partially lesioned parkinsonian rats. Neuropharmacology 60, 861-868. doi: 10. 1016/j.neuropharm.2010.12.032

Huang, L. Z., Grady, S. R., and Quik, M. (2011b). Nicotine reduces L-DOPAinduced dyskinesias by acting at beta2* nicotinic receptors. J. Pharmacol. Exp. Ther. 338, 932-941. doi: 10.1124/jpet.111.182949

Huang, L. Z., Parameswaran, N., Bordia, T., Michael, McIntosh, J., and Quik, M. (2009). Nicotine is neuroprotective when administered before but not after nigrostriatal damage in rats and monkeys. J. Neurochem. 109, 826-837. doi: $10.1111 / j .1471-4159.2009 .06011 . x$
Huang, Y., and Thathiah, A. (2015). Regulation of neuronal communication by G protein-coupled receptors. FEBS Lett. 589, 1607-1619. doi: 10.1016/j.febslet. 2015.05.007

Huang, Y. Y., Kandel, E. R., and Levine, A. (2008). Chronic nicotine exposure induces a long-lasting and pathway-specific facilitation of LTP in the amygdala. Learn Mem. 15, 603-610. doi: 10.1101/lm.975308

Huerta-Ocampo, I., Dautan, D., Gut, N. K., Khan, B., and Mena-Segovia, J. (2021). Whole-brain mapping of monosynaptic inputs to midbrain cholinergic neurons. Sci. Rep. 11:9055. doi: 10.1038/s41598-021-88374-6

Hussain, M. W., and Camicioli, R. (2018). Nonmotor symptoms of parkinson's disease as predictors of dementia. Can. J. Neurol. Sci. 45, 97-99. doi: 10.1017/ cjn.2017.239

Hussein, A., Guevara, C. A., Del Valle, P., Gupta, S., Benson, D. L., and Huntley, G. W. (2021). Non-motor symptoms of parkinson's disease: the neurobiology of early psychiatric and cognitive dysfunction. Neuroscientist 2021:011979. doi: $10.1177 / 10738584211011979$

Iarkov, A., Barreto, G. E., Grizzell, J. A., and Echeverria, V. (2020). Strategies for the treatment of parkinson's disease: beyond dopamine. Front. Aging Neurosci. 12:4. doi: $10.3389 /$ fnagi.2020.00004

Irwin, M. H., Moos, W. H., Faller, D. V., Steliou, K., and Pinkert, C. A. (2016). Epigenetic treatment of neurodegenerative disorders: alzheimer and parkinson diseases. Drug Dev. Res. 77, 109-123. doi: 10.1002/ddr.21294

Janickova, H., Rudajev, V., Zimcik, P., Jakubik, J., Tanila, H., El-Fakahany, E. E., et al. (2013). Uncoupling of M1 muscarinic receptor/G-protein interaction by amyloid beta(1-42). Neuropharmacology 67, 272-283. doi: 10.1016/j. neuropharm.2012.11.014

Jiang, J., Shi, S., Zhou, Q., Ma, X., Nie, X., Yang, L., et al. (2014a). Downregulation of the Wnt/beta-catenin signaling pathway is involved in manganese-induced neurotoxicity in rat striatum and PC12 cells. J. Neurosci. Res. 92, 783-794. doi: $10.1002 /$ jnr. 23352

Jiang, L., Kundu, S., Lederman, J. D., Lopez-Hernandez, G. Y., Ballinger, E. C., Wang, S., et al. (2016). Cholinergic signaling controls conditioned fear behaviors and enhances plasticity of cortical-amygdala circuits. Neuron 90, 1057-1070. doi: 10.1016/j.neuron.2016.04.028

Jiang, P., and Dickson, D. W. (2018). Parkinson's disease: experimental models and reality. Acta Neuropathol. 135, 13-32. doi: 10.1007/s00401-017-1788-5

Jiang, S., Li, Y., Zhang, C., Zhao, Y., Bu, G., Xu, H., et al. (2014b). M1 muscarinic acetylcholine receptor in Alzheimer's disease. Neurosci. Bull. 30, 295-307. doi: $10.1007 / \mathrm{s} 12264-013-1406-\mathrm{z}$

Johnston, T. H., Geva, M., Steiner, L., Orbach, A., Papapetropoulos, S., Savola, J. M., et al. (2019). Pridopidine, a clinic-ready compound, reduces 3,4dihydroxyphenylalanine-induced dyskinesia in Parkinsonian macaques. Mov. Disord. 34, 708-716. doi: 10.1002/mds.27565

Jong, Y. I., Harmon, S. K., and O’Malley, K. L. (2018). Intracellular GPCRs play key roles in synaptic plasticity. ACS Chem. Neurosci. 9, 2162-2172. doi: 10.1021/ acschemneuro.7b00516

Jong, Y. J., Kumar, V., and O’Malley, K. L. (2009). Intracellular metabotropic glutamate receptor 5 (mGluR5) activates signaling cascades distinct from cell surface counterparts. J. Biol. Chem. 284, 35827-35838. doi: 10.1074/jbc.M109. 046276

Jurado-Coronel, J. C., Avila-Rodriguez, M., Capani, F., Gonzalez, J., Moran, V. E., and Barreto, G. E. (2016). Targeting the nicotinic acetylcholine receptors (nachrs) in astrocytes as a potential therapeutic target in parkinson's disease. Curr. Pharm. Des. 22, 1305-1311. doi: 10.2174/138161282210160304112133

Jurado-Coronel, J. C., Loaiza, A. E., Diaz, J. E., Cabezas, R., Ashraf, G. M., Sahebkar, A., et al. (2019). (E)-Nicotinaldehyde O-cinnamyloxime, a nicotine analog, attenuates neuronal cells death against rotenone-induced neurotoxicity. Mol. Neurobiol. 56, 1221-1232. doi: 10.1007/s12035-018-1163-0

Kaiser, S., and Wonnacott, S. (2000). alpha-bungarotoxin-sensitive nicotinic receptors indirectly modulate $[(3) \mathrm{H}]$ dopamine release in rat striatal slices via glutamate release. Mol. Pharmacol. 58, 312-318. doi: 10.1124/mol.58.2.312

Kalaitzakis, M. E., Graeber, M. B., Gentleman, S. M., and Pearce, R. K. (2008). Striatal beta-amyloid deposition in Parkinson disease with dementia. J. Neuropathol. Exp. Neurol. 67, 155-161.

Kawamata, J., and Shimohama, S. (2011). Stimulating nicotinic receptors trigger multiple pathways attenuating cytotoxicity in models of Alzheimer's and Parkinson's diseases. J. Alzheimers. Dis. 24(Suppl. 2), 95-109. doi: 10.3233/JAD2011-110173 
Kawamata, J., Suzuki, S., and Shimohama, S. (2011). Enhancement of nicotinic receptors alleviates cytotoxicity in neurological disease models. Ther. Adv. Chronic. Dis. 2, 197-208. doi: 10.1177/2040622310397691

Kawamata, J., Suzuki, S., and Shimohama, S. (2012). alpha7 nicotinic acetylcholine receptor mediated neuroprotection in Parkinson's disease. Curr. Drug. Targets 13, 623-630. doi: 10.2174/138945012800399026

Keane, P. C., Kurzawa, M., Blain, P. G., and Morris, C. M. (2011). Mitochondrial dysfunction in Parkinson's disease. Parkinsons. Dis. 2011:716871. doi: 10.4061/ 2011/716871

Kellis, D. M., Kaigler, K. F., Witherspoon, E., Fadel, J. R., and Wilson, M. A. (2020). Cholinergic neurotransmission in the basolateral amygdala during cued fear extinction. Neurobiol. Stress 13:100279. doi: 10.1016/j.ynstr.2020. 100279

Kihara, T., Shimohama, S., Sawada, H., Honda, K., Nakamizo, T., Shibasaki, H., et al. (2001). alpha 7 nicotinic receptor transduces signals to phosphatidylinositol 3-kinase to block A beta-amyloid-induced neurotoxicity. J. Biol. Chem. 276, 13541-13546. doi: 10.1074/jbc.M008035200

Kim, M. J., Park, M., Kim, D. W., Shin, M. J., Son, O., Jo, H. S., et al. (2015). Transduced PEP-1-PON1 proteins regulate microglial activation and dopaminergic neuronal death in a Parkinson's disease model. Biomaterials 64, 45-56. doi: 10.1016/j.biomaterials.2015.06.015

Kim, R., Yoo, D., Jung, Y. J., Han, K., and Lee, J. Y. (2020). Smoking cessation, weight change, and risk of parkinson's disease: analysis of national cohort data. J. Clin. Neurol. 16, 455-460. doi: 10.3988/jcn.2020.16.3.455

Kim, T., Capps, R. A., Hamade, K. C., Barnett, W. H., Todorov, D. I., Latash, E. M., et al. (2019). The functional role of striatal cholinergic interneurons in reinforcement learning from computational perspective. Front. Neural. Circuits 13:10. doi: 10.3389 /fncir.2019.00010

Kline, E. M., Houser, M. C., Herrick, M. K., Seibler, P., Klein, C., West, A., et al. (2020). Genetic and environmental factors in parkinson's disease converge on immune function and inflammation. Mov. Disord. 2020:28411. doi: 10.1002/ mds. 28411

Koh, Y. Y., Jang, S. J., and Lim, D. Y. (2003). Cotinine inhibits catecholamine release evoked by cholinergic stimulation from the rat adrenal medulla. Arch. Pharm. Res. 26, 747-755.

Kondabolu, K., Roberts, E. A., Bucklin, M., McCarthy, M. M., Kopell, N., and Han, X. (2016). Striatal cholinergic interneurons generate beta and gamma oscillations in the corticostriatal circuit and produce motor deficits. Proc. Natl. Acad. Sci. U S A 113, E3159-E3168. doi: 10.1073/pnas.1605658113

Koziorowski, D., Figura, M., Milanowski, L. M., Szlufik, S., Alster, P., Madetko, N., et al. (2021). Mechanisms of neurodegeneration in various forms of parkinsonism-similarities and differences. Cells 10:656. doi: 10.3390/ cells10030656

Kreitzer, A. C., and Malenka, R. C. (2008). Striatal plasticity and basal ganglia circuit function. Neuron 60, 543-554. doi: 10.1016/j.neuron.2008.11.005

Kroker, K. S., Rast, G., and Rosenbrock, H. (2011). Differential effects of subtypespecific nicotinic acetylcholine receptor agonists on early and late hippocampal LTP. Eur. J. Pharmacol. 671, 26-32. doi: 10.1016/j.ejphar.2011.09.167

Kruse, A. C., Kobilka, B. K., Gautam, D., Sexton, P. M., Christopoulos, A., and Wess, J. (2014). Muscarinic acetylcholine receptors: novel opportunities for drug development. Nat. Rev. Drug Discov. 13, 549-560. doi: 10.1038/nrd4295

Kucinski, A., and Sarter, M. (2015). Modeling Parkinson's disease falls associated with brainstem cholinergic systems decline. Behav. Neurosci. 129, 96-104. doi: 10.1037/bne0000048

Kwon, K. Y., Lee, E. J., Lee, M., Ju, H., and Im, K. (2021). Impact of motor subtype on non-motor symptoms and fall-related features in patients with early Parkinson's disease. Geriatr. Gerontol. Int. 21, 416-420. doi: 10.1111/ggi. 14156

Kyaw, W. T., Nagai, M., Kaneta, M., Kubo, M., Nishikawa, N., Tsujii, T., et al. (2013). Effect of nicotine on the pharmacokinetics of levodopa. Clin. Neuropharmacol. 36, 46-51. doi: 10.1097/WNF.0b013e31827fd9cd

Langmead, C. J., Austin, N. E., Branch, C. L., Brown, J. T., Buchanan, K. A., Davies, C. H., et al. (2008a). Characterization of a CNS penetrant, selective M1 muscarinic receptor agonist, 77-LH-28-1. Br. J. Pharmacol. 154, 1104-1115. doi: $10.1038 /$ bjp.2008.152

Langmead, C. J., Watson, J., and Reavill, C. (2008b). Muscarinic acetylcholine receptors as CNS drug targets. Pharmacol. Ther. 117, 232-243. doi: 10.1016/j. pharmthera.2007.09.009
Lanskey, J. H., McColgan, P., Schrag, A. E., Acosta-Cabronero, J., Rees, G., Morris, H. R., et al. (2018). Can neuroimaging predict dementia in Parkinson's disease? Brain 141, 2545-2560. doi: 10.1093/brain/awy211

Lee, J., Kim, C. H., Simon, D. K., Aminova, L. R., Andreyev, A. Y., Kushnareva, Y.E., et al. (2005). Mitochondrial cyclic AMP response element-binding protein (CREB) mediates mitochondrial gene expression and neuronal survival. J. Biol. Chem. 280, 40398-40401.

Lee, J. A., Kim, J. H., Woo, S. Y., Son, H. J., Han, S. H., Jang, B. K., et al. (2015). A novel compound VSC2 has anti-inflammatory and antioxidant properties in microglia and in Parkinson's disease animal model. Br. J. Pharmacol. 172, 1087-1100. doi: 10.1111/bph.12973

Leinninger, G. M., Backus, C., Uhler, M. D., Lentz, S. I., and Feldman, E. L. (2004). Phosphatidylinositol 3-kinase and Akt effectors mediate insulin-like growth factor-I neuroprotection in dorsal root ganglia neurons. FASEB J. 18, 1544-1546. doi: 10.1096/fj.04-1581fje

Lenka, N., Vijayasarathy, C., Mullick, J., and Avadhani, N. G. (1998). Structural organization and transcription regulation of nuclear genes encoding the mammalian cytochrome c oxidase complex. Prog. Nucleic Acid Res. Mol. Biol. $61,309-344$.

L'Episcopo, F., Tirolo, C., Testa, N., Caniglia, S., Morale, M. C., Serapide, M. F., et al. (2014). Wnt/beta-catenin signaling is required to rescue midbrain dopaminergic progenitors and promote neurorepair in ageing mouse model of Parkinson's disease. Stem Cells 32, 2147-2163. doi: 10.1002/stem.1708

Lester, D. B., Rogers, T. D., and Blaha, C. D. (2010). Acetylcholine-dopamine interactions in the pathophysiology and treatment of CNS disorders. CNS Neurosci. Ther. 16, 137-162. doi: 10.1111/j.1755-5949.2010.00142.x

Lester, H. A., Xiao, C., Srinivasan, R., Son, C. D., Miwa, J., Pantoja, R., et al. (2009). Nicotine is a selective pharmacological chaperone of acetylcholine receptor number and stoichiometry. Implications for drug discovery. AAPS $J$ 11, 167-177. doi: 10.1208/s12248-009-9090-7

Leverenz, J. B., Quinn, J. F., Zabetian, C., Zhang, J., Montine, K. S., and Montine, T. J. (2009). Cognitive impairment and dementia in patients with Parkinson disease. Curr. Top. Med. Chem. 9, 903-912.

Lieberman, A., Lockhart, T. E., Olson, M. C., Smith Hussain, V. A., Frames, C. W., Sadreddin, A., et al. (2019). Nicotine bitartrate reduces falls and freezing of gait in parkinson disease: a reanalysis. Front. Neurol. 10:424. doi: 10.3389/fneur. 2019.00424

Lim, S. A., Kang, U. J., and McGehee, D. S. (2014). Striatal cholinergic interneuron regulation and circuit effects. Front. Synaptic. Neurosci. 6:22. doi: 10.3389/fnsyn. 2014.00022

Lindqvist, D., Kaufman, E., Brundin, L., Hall, S., Surova, Y., and Hansson, O. (2012). Non-motor symptoms in patients with Parkinson's disease - correlations with inflammatory cytokines in serum. PLoS One 7:e47387.

Linert, W., Bridge, M. H., Huber, M., Bjugstad, K. B., Grossman, S., and Arendash, G. W. (1999). In vitro and in vivo studies investigating possible antioxidant actions of nicotine: relevance to Parkinson's and Alzheimer's diseases. Biochim. Biophys. Acta 1454, 143-152.

Liu, C. (2020). Targeting the cholinergic system in Parkinson's disease. Acta Pharmacol. Sin. 41, 453-463. doi: 10.1038/s41401-020-0380-z

Liu, Q. Q., Ding, S. K., Zhang, H., and Shang, Y. Z. (2021). The molecular mechanism of scutellaria baicalensis georgi stems and leaves flavonoids in promoting neurogenesis and improving memory impairment by the PI3KAKT-CREB Signaling Pathway in Rats. Comb. Chem. High Throughput Screen 2021:6152320. doi: 10.2174/1386207324666210506152320

Liu, X. K., Wang, G., and Chen, S. D. (2010). Modulation of the activity of dopaminergic neurons by SK channels: a potential target for the treatment of Parkinson's disease? Neurosci. Bull. 26, 265-271. doi: 10.1007/s12264-0101217-4

Liu, Y., Hao, S., Yang, B., Fan, Y., Qin, X., Chen, Y., et al. (2017). Wnt/betacatenin signaling plays an essential role in alpha7 nicotinic receptor-mediated neuroprotection of dopaminergic neurons in a mouse Parkinson's disease model. Biochem. Pharmacol. 140, 115-123. doi: 10.1016/j.bcp.2017.05.017

Livingstone, P. D., and Wonnacott, S. (2009). Nicotinic acetylcholine receptors and the ascending dopamine pathways. Biochem. Pharmacol. 78, 744-755.

Lohle, M., Hermann, W., Hausbrand, D., Wolz, M., Mende, J., Beuthien-Baumann, B., et al. (2019). Putaminal dopamine turnover in de novo parkinson's disease predicts later neuropsychiatric fluctuations but not other major health outcomes. J. Parkinsons. Dis. 9, 693-704. doi: 10.3233/JPD- 191672 
Lopes, E. F., Roberts, B. M., Siddorn, R. E., Clements, M. A., and Cragg, S. J. (2019). Inhibition of nigrostriatal dopamine release by striatal GABAA and GABAB Receptors. J. Neurosci. 39, 1058-1065. doi: 10.1523/JNEUROSCI.2028-18.2018

Lu, J., Cheng, Y., Xie, X., Woodson, K., Bonifacio, J., Disney, E., et al. (2021). Whole-brain mapping of direct inputs to dopamine D1 and D2 Receptorexpressing medium spiny neurons in the posterior dorsomedial striatum. eNeuro 8:2020. doi: 10.1523/ENEURO.0348-20.2020

$\mathrm{Lu}, \mathrm{J}$., and $\mathrm{Wu}, \mathrm{W}$. (2021). Cholinergic modulation of the immune system - A novel therapeutic target for myocardial inflammation. Int. Immunopharmacol. 93:107391. doi: 10.1016/j.intimp.2021.107391

Lu, X., Cui, Z., Liu, S., and Yin, F. (2018). MiRNAs participate in the diagnosis, pathogenesis and therapy of Parkinson's disease. Histol. Histopathol. 33, 447453. doi: 10.14670/HH-11-944

Lu, X., Kim-Han, J. S., Harmon, S., Sakiyama-Elbert, S. E., and O'Malley, K. L. (2014). The Parkinsonian mimetic, 6-OHDA, impairs axonal transport in dopaminergic axons. Mol. Neurodegener. 9:17. doi: 10.1186/1750-1326-9-17

Luo, R., Janssen, M. J., Partridge, J. G., and Vicini, S. (2013). Direct and GABA-mediated indirect effects of nicotinic ACh receptor agonists on striatal neurones. J. Physiol. 591, 203-217. doi: 10.1113/jphysiol.2012.241786

Lykhmus, O., Gergalova, G., Koval, L., Zhmak, M., Komisarenko, S., and Skok, M. (2014). Mitochondria express several nicotinic acetylcholine receptor subtypes to control various pathways of apoptosis induction. Int. J. Biochem. Cell. Biol. 53, 246-252. doi: 10.1016/j.biocel.2014.05.030

Maggio, R., Riva, M., Vaglini, F., Fornai, F., Molteni, R., Armogida, M., et al. (1998). Nicotine prevents experimental parkinsonism in rodents and induces striatal increase of neurotrophic factors. J. Neurochem. 71, 2439-2446. doi: 10.1046/j.1471-4159.1998.71062439.x

Maillet, A., Krack, P., Lhommee, E., Metereau, E., Klinger, H., Favre, E., et al. (2016). The prominent role of serotonergic degeneration in apathy, anxiety and depression in de novo Parkinson's disease. Brain 139(Pt 9), 2486-2502. doi: 10.1093/brain/aww162

Majdi, A., Kamari, F., Sadigh-Eteghad, S., and Gjedde, A. (2018). Molecular insights into memory-enhancing metabolites of nicotine in brain: a systematic review. Front. Neurosci. 12:1002. doi: 10.3389/fnins.2018.01002

Mallet, N., Leblois, A., Maurice, N., and Beurrier, C. (2019). Striatal cholinergic interneurons: how to elucidate their function in health and disease. Front. Pharmacol. 10:1488. doi: 10.3389/fphar.2019.01488

Mappin-Kasirer, B., Pan, H., Lewington, S., Kizza, J., Gray, R., Clarke, R., et al. (2020). Tobacco smoking and the risk of Parkinson disease: A 65-year follow-up of 30,000 male British doctors. Neurology 94, e2132-e2138. doi: 10.1212/WNL. 0000000000009437

Marchetti, B. (2018). Wnt/beta-catenin signaling pathway governs a full program for dopaminergic neuron survival, neurorescue and regeneration in the mptp mouse model of parkinson's disease. Int. J. Mol. Sci. 19:19123743. doi: 10.3390/ ijms 19123743

Marchi, M., Risso, F., Viola, C., Cavazzani, P., and Raiteri, M. (2002). Direct evidence that release-stimulating alpha $7^{*}$ nicotinic cholinergic receptors are localized on human and rat brain glutamatergic axon terminals. J. Neurochem. 80, 1071-1078. doi: 10.1046/j.0022-3042.2002.00805.x

Marshall, D. L., Redfern, P. H., and Wonnacott, S. (1997). Presynaptic nicotinic modulation of dopamine release in the three ascending pathways studied by in vivo microdialysis: comparison of naive and chronic nicotine-treated rats. J. Neurochem. 68, 1511-1519. doi: 10.1046/j.1471-4159.1997.68041511.x

Martel, A. C., and Apicella, P. (2021). Temporal processing in the striatum: Interplay between midbrain dopamine neurons and striatal cholinergic interneurons. Eur. J. Neurosci. 53, 2090-2099. doi: 10.1111/ejn.14741

Martin, Z. S., Neugebauer, V., Dineley, K. T., Kayed, R., Zhang, W., Reese, L. C., et al. (2012). alpha-Synuclein oligomers oppose long-term potentiation and impair memory through a calcineurin-dependent mechanism: relevance to human synucleopathic diseases. J. Neurochem. 120, 440-452. doi: 10.1111/j. 1471-4159.2011.07576.x

Martinez-Banaclocha, M. (2021). Proteomic Complexity in Parkinson's Disease: A Redox Signaling Perspective of the Pathophysiology and Progression. Neuroscience 453, 287-300. doi: 10.1016/j.neuroscience.2020.11.006

Martin-Jimenez, C. A., Gaitan-Vaca, D. M., Echeverria, V., Gonzalez, J., and Barreto, G. E. (2017). Relationship between obesity, alzheimer's disease, and parkinson's disease: an astrocentric view. Mol. Neurobiol. 54, 7096-7115. doi: 10.1007/s12035-016-0193-8
Mashimo, M., Fujii, T., Ono, S., Moriwaki, Y., Misawa, H., and Kawashima, K. (2020). Minireview: Divergent roles of alpha7 nicotinic acetylcholine receptors expressed on antigen-presenting cells and CD4(+) T cells in the regulation of T cell differentiation. Int. Immunopharmacol. 82:106306. doi: 10.1016/j.intimp. 2020.106306

Mathur, B. N., and Lovinger, D. M. (2012). Serotonergic action on dorsal striatal function. Parkinsonism Relat. Disord. 18(Suppl. 1), S129-S131. doi: 10.1016/ S1353-8020(11)70040-2

Maurice, N., Liberge, M., Jaouen, F., Ztaou, S., Hanini, M., Camon, J., et al. (2015). Striatal Cholinergic interneurons control motor behavior and basal ganglia function in experimental parkinsonism. Cell Rep. 13, 657-666. doi: 10.1016/j. celrep.2015.09.034

McCarthy, M. M., Moore-Kochlacs, C., Gu, X., Boyden, E. S., Han, X., and Kopell, N. (2011). Striatal origin of the pathologic beta oscillations in Parkinson's disease. Proc. Natl. Acad. Sci. U S A 108, 11620-11625. doi: 10.1073/pnas. 1107748108

McKinley, J. W., Shi, Z., Kawikova, I., Hur, M., Bamford, I. J., Sudarsana Devi, S. P., et al. (2019). Dopamine deficiency reduces striatal cholinergic interneuron function in models of parkinson's disease. Neuron 105:e1056. doi: 10.1016/j. neuron.2019.06.013

Mehra, S., Sahay, S., and Maji, S. K. (2019). alpha-Synuclein misfolding and aggregation: Implications in Parkinson's disease pathogenesis. Biochim. Biophys. Acta Proteins Proteom. 1867, 890-908. doi: 10.1016/j.bbapap.2019. 03.001

Mendonca, I. P., Duarte-Silva, E., Chaves-Filho, A. J. M., Andrade, da Costa, B., and Peixoto, C. A. (2020). Neurobiological findings underlying depressive behavior in Parkinson's disease: A review. Int. Immunopharmacol. 83:106434. doi: 10.1016/j.intimp.2020.106434

Mendoza, C., Perez-Urrutia, N., Alvarez-Ricartes, N., Barreto, G. E., Perez-Ordas, R., Iarkov, A., et al. (2018). Cotinine plus krill oil decreased depressive behavior, and increased astrocytes survival in the hippocampus of mice subjected to restraint stress. Front. Neurosci. 12:952. doi: 10.3389/fnins.2018.00952

Mesulam, M. M., Mash, D., Hersh, L., Bothwell, M., and Geula, C. (1992). Cholinergic innervation of the human striatum, globus pallidus, subthalamic nucleus, substantia nigra, and red nucleus. J. Comp. Neurol. 323, 252-268. doi: 10.1002/cne.903230209

Mesulam, M. M., Mufson, E. J., Levey, A. I., and Wainer, B. H. (1983). Cholinergic innervation of cortex by the basal forebrain: cytochemistry and cortical connections of the septal area, diagonal band nuclei, nucleus basalis (substantia innominata), and hypothalamus in the rhesus monkey. J. Comp. Neurol. 214, 170-197. doi: 10.1002/cne. 902140206

Mihailescu, S., and Drucker-Colin, R. (2000). Nicotine and brain disorders. Acta Pharmacol. Sin. 21, 97-104.

Miklossy, J., Steele, J. C., Yu, S., McCall, S., Sandberg, G., McGeer, E. G., et al. (2008). Enduring involvement of tau, beta-amyloid, alpha-synuclein, ubiquitin and TDP-43 pathology in the amyotrophic lateral sclerosis/parkinsonismdementia complex of Guam (ALS/PDC). Acta Neuropathol. 116, 625-637.

Millar, N. S. (2003). Assembly and subunit diversity of nicotinic acetylcholine receptors. Biochem. Soc. Trans. 31(Pt 4), 869-874. doi: 10.1042/bst0310869

Millar, N. S., and Gotti, C. (2009). Diversity of vertebrate nicotinic acetylcholine receptors. Neuropharmacology 56, 237-246. doi: 10.1016/j.neuropharm.2008. 07.041

Moran, V. E. (2012). Cotinine: beyond that expected. more than a biomarker of tobacco consumption. Front. Pharmacol. 3, 173.

Morelli, M., Carta, A. R., Kachroo, A., and Schwarzschild, M. A. (2010). Pathophysiological roles for purines: adenosine, caffeine and urate. Prog. Brain Res. 183, 183-208. doi: 10.1016/S0079-6123(10)83010-9

Moreno, E., Hoffmann, H., Gonzalez-Sepulveda, M., Navarro, G., Casado, V., Cortes, A., et al. (2011). Dopamine D1-histamine H3 receptor heteromers provide a selective link to MAPK signaling in GABAergic neurons of the direct striatal pathway. J. Biol. Chem. 286, 5846-5854. doi: 10.1074/jbc.M110.161489

Morioka, N., Hisaoka-Nakashima, K., and Nakata, Y. (2018). "Regulation by Nicotinic Acetylcholine Receptors of Microglial Glutamate Transporters: Role of Microglia in Neuroprotection," in Nicotinic Acetylcholine Receptor Signaling in Neuroprotection, eds A. Akaike, S. Shimohama, and Y. Misu (Singapore: Springer), $73-88$.

Morioka, N., Tokuhara, M., Nakamura, Y., Idenoshita, Y., Harano, S., Zhang, F. F., et al. (2014). Primary cultures of rat cortical microglia treated with nicotine 
increases in the expression of excitatory amino acid transporter 1 (GLAST) via the activation of the alpha7 nicotinic acetylcholine receptor. Neuroscience 258, 374-384. doi: 10.1016/j.neuroscience.2013.11.044

Morishima, S., Anisuzzaman, A. S. M., Uwada, J., Yoshiki, H., and Muramatsu, I. (2013). Comparison of subcellular distribution and functions between exogenous and endogenous M1 muscarinic acetylcholine receptors. Life Sci. 93, 17-23. doi: 10.1016/j.lfs.2013.05.013

Mudo, G., Belluardo, N., and Fuxe, K. (2007). Nicotinic receptor agonists as neuroprotective/neurotrophic drugs. Progress in molecular mechanisms. J. Neural. Transm. 114, 135-147. doi: 10.1007/s00702-006-0561-z

Munoz-Manchado, A. B., Bengtsson Gonzales, C., Zeisel, A., Munguba, H., Bekkouche, B., Skene, N. G., et al. (2018). Diversity of interneurons in the dorsal striatum revealed by single-cell RNA Sequencing and PatchSeq. Cell Rep. 217:e2177. doi: 10.1016/j.celrep.2018.07.053

Muramatsu, I., Masuoka, T., Uwada, J., Yoshiki, H., Yazama, T., Lee, K.-S., et al. (2018). "A New Aspect of Cholinergic Transmission in the Central Nervous System," in Nicotinic Acetylcholine Receptor Signaling in Neuroprotection, eds A. Akaike, S. Shimohama, and Y. Misu (Singapore: Springer), 45-58.

Myslivecek, J. (2021). Two players in the field: hierarchical model of interaction between the dopamine and acetylcholine signaling systems in the striatum. Biomedicines 9:25. doi: 10.3390/biomedicines9010025

Myslivecek, J., Farar, V., and Valuskova, P. (2017). M(4) muscarinic receptors and locomotor activity regulation. Physiol. Res. 66(Suppl. 4), S443-S455. doi: 10.33549 /physiolres.933796

Nees, F. (2015). The nicotinic cholinergic system function in the human brain. Neuropharmacology 96, 289-301. doi: 10.1016/j.neuropharm.2014.10.021

O'Callaghan, J. P., and Miller, D. B. (2019). Neuroinflammation disorders exacerbated by environmental stressors. Metabolism 100S:153951. doi: 10.1016/ j.metabol.2019.153951

Olanow, C. W., and Tatton, W. G. (1999). Etiology and pathogenesis of Parkinson's disease. Annu. Rev. Neurosci. 22, 123-144. doi: 10.1146/annurev.neuro.22. 1.123

Oldan, J. D., Jewells, V. L., Pieper, B., and Wong, T. Z. (2021). Complete evaluation of dementia: PET and MRI Correlation and diagnosis for the neuroradiologist. AJNR Am. J. Neuroradiol. 2021:7079. doi: 10.3174/ajnr.A7079

Oldenburg, I. A., and Ding, J. B. (2011). Cholinergic modulation of synaptic integration and dendritic excitability in the striatum. Curr. Opin. Neurobiol. 21, 425-432. doi: 10.1016/j.conb.2011.04.004

O’Leary, K., Parameswaran, N., McIntosh, J. M., and Quik, M. (2008). Cotinine selectively activates a subpopulation of alpha3/alpha6beta2 nicotinic receptors in monkey striatum. J. Pharmacol. Exp. Ther. 325, 646-654. doi: 10.1124/jpet. 108.136838

Oliveros-Matus, P., Perez-Urrutia, N., Alvarez-Ricartes, N., Echeverria, F., Barreto, G. E., Elliott, J., et al. (2020). Cotinine enhances fear extinction and astrocyte survival by mechanisms involving the nicotinic acetylcholine receptors signaling. Front. Pharmacol. 11:303. doi: 10.3389/fphar.2020.00303

Oorschot, D. E. (1996). Total number of neurons in the neostriatal, pallidal, subthalamic, and substantia nigral nuclei of the rat basal ganglia: a stereological study using the cavalieri and optical disector methods. J. Comp. Neurol. 580-599. doi: 10.1002/(SICI)1096-9861(19960318)366:4<580::AID-CNE3<3.0. $\mathrm{CO} ; 2-0$

Osada, O., and Iwasaki, A. (2017). A case of successful treatment with donepezil of olfactory hallucination in parkinson disease. Rinsho Shinkeigaku 57, 29-32. doi: 10.5692/clinicalneurol.cn-000913

Owens-Walton, C., Jakabek, D., Power, B. D., Walterfang, M., Hall, S., van Westen, D., et al. (2021). Structural and functional neuroimaging changes associated with cognitive impairment and dementia in Parkinson's disease. Psychiatry Res. Neuroimag. 312:111273. doi: 10.1016/j.pscychresns.2021.111273

Pakhotin, P., and Bracci, E. (2007). Cholinergic interneurons control the excitatory input to the striatum. J. Neurosci. 27, 391-400. doi: 10.1523/JNEUROSCI.370906.2007

Palermo, G., Frosini, D., Corsi, A., Giuntini, M., Mazzucchi, S., Del Prete, E., et al. (2019a). Freezing of gait and dementia in parkinsonism: a retrospective case-control study. Brain Behav. 9:e01247. doi: 10.1002/brb3.1247

Palermo, G., Tommasini, L., Aghakhanyan, G., Frosini, D., Giuntini, M., Tognoni, G., et al. (2019b). Clinical correlates of cerebral amyloid deposition in parkinson's disease dementia: evidence from a PET Study. J. Alzheimers Dis. 70, 597-609. doi: 10.3233/JAD- 190323
Papke, R. L., and Lindstrom, J. M. (2020). Nicotinic acetylcholine receptors: Conventional and unconventional ligands and signaling. Neuropharmacology 168:108021. doi: 10.1016/j.neuropharm.2020.108021

Parain, K., Hapdey, C., Rousselet, E., Marchand, V., Dumery, B., and Hirsch, E. C. (2003). Cigarette smoke and nicotine protect dopaminergic neurons against the 1-methyl-4-phenyl-1,2,3,6-tetrahydropyridine Parkinsonian toxin. Brain Res. 984, 224-232.

Parain, K., Marchand, V., Dumery, B., and Hirsch, E. (2001). Nicotine, but not cotinine, partially protects dopaminergic neurons against MPTP-induced degeneration in mice. Brain Res. 890, 347-350.

Parent, M., Wallman, M. J., Gagnon, D., and Parent, A. (2011). Serotonin innervation of basal ganglia in monkeys and humans. J. Chem. Neuroanat. 41, 256-265. doi: 10.1016/j.jchemneu.2011.04.005

Park, H. J., Lee, P. H., Ahn, Y. W., Choi, Y. J., Lee, G., Lee, D. Y., et al. (2007). Neuroprotective effect of nicotine on dopaminergic neurons by antiinflammatory action. Eur. J. Neurosci. 26, 79-89. doi: 10.1111/j.1460-9568.2007. 05636.x

Patel, S., Grizzell, J. A., Holmes, R., Zeitlin, R., Solomon, R., Sutton, T. L., et al. (2014). Cotinine halts the advance of Alzheimer's disease-like pathology and associated depressive-like behavior in Tg6799 mice. Front. Aging Neurosci. 6:162. doi: 10.3389/fnagi.2014.00162

Patt, S., Gertz, H. J., Gerhard, L., and Cervos-Navarro, J. (1991). Pathological changes in dendrites of substantia nigra neurons in Parkinson's disease: a Golgi study. Histol. Histopathol. 6, 373-380.

Pavlou, M. A. S., and Outeiro, T. F. (2017). Epigenetics in Parkinson's Disease. Adv. Exp. Med. Biol. 978, 363-390. doi: 10.1007/978-3-319-53889-1_19

Perez, M. J., Jara, C., and Quintanilla, R. A. (2018). Contribution of Tau Pathology to Mitochondrial Impairment in Neurodegeneration. Front. Neurosci. 12:441. doi: $10.3389 /$ fnins.2018.00441

Perier, C., and Vila, M. (2012). Mitochondrial biology and Parkinson's disease. Cold Spring Harb. Perspect. Med. 2:a009332. doi: 10.1101/cshperspect.a009332

Phelps, P. E., Houser, C. R., and Vaughn, J. E. (1985). Immunocytochemical localization of choline acetyltransferase within the rat neostriatum: a correlated light and electron microscopic study of cholinergic neurons and synapses. J. Comp. Neurol. 238, 286-307. doi: 10.1002/cne.902380305

Picciotto, M. R., Caldarone, B. J., King, S. L., and Zachariou, V. (2000). Nicotinic receptors in the brain. Links between molecular biology and behavior. Neuropsychopharmacology 22, 451-465.

Picciotto, M. R., Higley, M. J., and Mineur, Y. S. (2012). Acetylcholine as a neuromodulator: cholinergic signaling shapes nervous system function and behavior. Neuron 76, 116-129. doi: 10.1016/j.neuron.2012.08.036

Pillai, S., and Chellappan, S. (2012). alpha7 nicotinic acetylcholine receptor subunit in angiogenesis and epithelial to mesenchymal transition. Curr. Drug Targets 13, 671-679.

Pimlott, S. L., Piggott, M., Owens, J., Greally, E., Court, J. A., Jaros, E., et al. (2004). Nicotinic acetylcholine receptor distribution in Alzheimer's disease, dementia with Lewy bodies, Parkinson's disease, and vascular dementia: in vitro binding study using 5-[(125)i]-a-85380. Neuropsychopharmacology 29, 108-116. doi: 10.1038/sj.npp.1300302

Pisani, A., Bonsi, P., Centonze, D., Calabresi, P., and Bernardi, G. (2000). Activation of D2-like dopamine receptors reduces synaptic inputs to striatal cholinergic interneurons. J. Neurosci. 20:RC69.

Poewe, W., Seppi, K., Tanner, C. M., Halliday, G. M., Brundin, P., Volkmann, J., et al. (2017). Parkinson disease. Nat. Rev. Dis. Primers 3:17013. doi: 10.1038/ nrdp. 2017.13

Pogocki, D., Ruman, T., Danilczuk, M., Danilczuk, M., Celuch, M., and WalajtysRode, E. (2007). Application of nicotine enantiomers, derivatives and analogues in therapy of neurodegenerative disorders. Eur. J. Pharmacol. 563, 18-39.

Pohanka, M. (2021). Pharmacological Influencing of The Cholinergic Antiinflammatory pathway in infectious diseases and inflammatory pathologies. Mini. Rev. Med. Chem. 21, 660-669. doi: 10.2174/1389557520666201117111715

Prots, I., Grosch, J., Brazdis, R. M., Simmnacher, K., Veber, V., Havlicek, S., et al. (2018). alpha-Synuclein oligomers induce early axonal dysfunction in human iPSC-based models of synucleinopathies. Proc. Natl. Acad. Sci. U S A 115, 7813-7818. doi: 10.1073/pnas.1713129115

Prots, I., Veber, V., Brey, S., Campioni, S., Buder, K., Riek, R., et al. (2013). alphaSynuclein oligomers impair neuronal microtubule-kinesin interplay. J. Biol. Chem. 288, 21742-21754. doi: 10.1074/jbc.M113.451815 
Przuntek, H., and Muller, T. (1999). Clinical efficacy of budipine in Parkinson's disease. J. Neural. Transm. Suppl. 56, 75-82. doi: 10.1007/978-3-70916360-3_3

Quik, M. (2004). Smoking, nicotine and Parkinson's disease. Trends Neurosci. 27, 561-568. doi: 10.1016/j.tins.2004.06.008

Quik, M., Bordia, T., Huang, L., and Perez, X. (2011). Targeting nicotinic receptors for Parkinson's disease therapy. CNS Neurol. Disord Drug Targets 10, 651-658.

Quik, M., Bordia, T., and O’Leary, K. (2007). Nicotinic receptors as CNS targets for Parkinson's disease. Biochem, Pharmacol. 74, 1224-1234. doi: 10.1016/j.bcp. 2007.06.015

Quik, M., Bordia, T., Zhang, D., and Perez, X. A. (2015a). Nicotine and Nicotinic Receptor Drugs: Potential for Parkinson's Disease and Drug-Induced Movement Disorders. Int. Rev. Neurobiol. 124, 247-271. doi: 10.1016/bs.irn. 2015.07.005

Quik, M., Campos, C., and Grady, S. R. (2013a). Multiple CNS nicotinic receptors mediate L-dopa-induced dyskinesias: studies with parkinsonian nicotinic receptor knockout mice. Biochem. Pharmacol. 86, 1153-1162. doi: 10.1016/j. bcp.2013.06.027

Quik, M., Huang, L. Z., Parameswaran, N., Bordia, T., Campos, C., and Perez, X. A. (2009). Multiple roles for nicotine in Parkinson's disease. Biochem. Pharmacol. 78, 677-685. doi: 10.1016/j.bcp.2009.05.003

Quik, M., and Kulak, J. M. (2002). Nicotine and nicotinic receptors; relevance to Parkinson's disease. Neurotoxicology 23, 581-594.

Quik, M., Mallela, A., Ly, J., and Zhang, D. (2013b). Nicotine reduces established levodopa-induced dyskinesias in a monkey model of Parkinson's disease. Mov. Disord 28, 1398-1406. doi: 10.1002/mds. 25594

Quik, M., and McIntosh, J. M. (2006). Striatal alpha6* nicotinic acetylcholine receptors: potential targets for Parkinson's disease therapy. J. Pharmacol. Exp. Ther. 316, 481-489. doi: 10.1124/jpet.105.094375

Quik, M., Parameswaran, N., McCallum, S. E., Bordia, T., Bao, S., McCormack, A., et al. (2006). Chronic oral nicotine treatment protects against striatal degeneration in MPTP-treated primates. J. Neurochem. 98, 1866-1875. doi: 10.1111/j.1471-4159.2006.04078.x

Quik, M., Park, K. M., Hrachova, M., Mallela, A., Huang, L. Z., McIntosh, J. M., et al. (2012). Role for alpha6 nicotinic receptors in 1-dopa-induced dyskinesias in parkinsonian mice. Neuropharmacology 63, 450-459. doi: 10 . 1016/j.neuropharm.2012.04.029

Quik, M., and Wonnacott, S. (2011). alpha6beta2* and alpha4beta2* nicotinic acetylcholine receptors as drug targets for Parkinson's disease. Pharmacol. Rev. 63, 938-966. doi: 10.1124/pr.110.003269

Quik, M., Zhang, D., McGregor, M., and Bordia, T. (2015b). Alpha7 nicotinic receptors as therapeutic targets for Parkinson's disease. Biochem. Pharmacol. 97, 399-407. doi: 10.1016/j.bcp.2015.06.014

Quirion, R., Aubert, I., Robitaille, Y., Gauthier, S., Araujo, D. M., and Chabot, J. G. (1990). Neurochemical deficits in pathological brain aging: specificity and possible relevance for treatment strategies. Clin. Neuropharmacol. 13(Suppl. 3), S73-S80.

Rajmohan, R., and Reddy, P. H. (2017). Amyloid-beta and phosphorylated tau accumulations cause abnormalities at synapses of alzheimer's disease neurons. J. Alzheimers. Dis. 57, 975-999. doi: 10.3233/JAD160612

Reader, T. A., and Dewar, K. M. (1999). Effects of denervation and hyperinnervation on dopamine and serotonin systems in the rat neostriatum: implications for human Parkinson's disease. Neurochem. Int. 34, 1-21. doi: 10.1016/s0197-0186(98)00048-5

Rehani, K., Scott, D. A., Renaud, D., Hamza, H., Williams, L. R., Wang, H., et al. (2008). Cotinine-induced convergence of the cholinergic and PI3 kinasedependent anti-inflammatory pathways in innate immune cells. Biochim. Biophys. Acta 1783, 375-382.

Rehman, S., and Dimri, M. (2020). Biochemistry, G Protein Coupled Receptors. Treasure Island, FL: StatPearls.

Reich, S. G., and Savitt, J. M. (2019). Parkinson's Disease. Med. Clin. North Am. 103, 337-350. doi: 10.1016/j.mcna.2018.10.014

Renouf, S., Ffytche, D., Pinto, R., Murray, J., and Lawrence, V. (2018). Visual hallucinations in dementia and Parkinson's disease: a qualitative exploration of patient and caregiver experiences. Int. J. Geriatr. Psychiatry 33, 1327-1334. doi: $10.1002 /$ gps.4929
Requejo-Aguilar, R., and Bolanos, J. P. (2016). Mitochondrial control of cell bioenergetics in Parkinson's disease. Free Radic. Biol. Med. 100, 123-137. doi: 10.1016/j.freeradbiomed.2016.04.012

Resende, R. R., and Adhikari, A. (2009). Cholinergic receptor pathways involved in apoptosis, cell proliferation and neuronal differentiation. Cell Commun. Signal. 7:20. doi: 10.1186/1478-811X-7-20

Riveles, K., Huang, L. Z., and Quik, M. (2008). Cigarette smoke, nicotine and cotinine protect against 6-hydroxydopamine-induced toxicity in SH-SY5Y cells. Neurotoxicology 29, 421-427.

Rizzi, G., and Tan, K. R. (2017). Dopamine and Acetylcholine, a Circuit Point of View in Parkinson's Disease. Front. Neural. Circuits 11:110. doi: 10.3389/fncir. 2017.00110

Robinson, L., Platt, B., and Riedel, G. (2011). Involvement of the cholinergic system in conditioning and perceptual memory. Behav. Brain Res. 221, 443-465. doi: 10.1016/j.bbr.2011.01.055

Rodriguez-Sabate, C., Rodriguez, M., and Morales, I. (2021). Studying the functional connectivity of the primary motor cortex with the binarized cross recurrence plot: The influence of Parkinson's disease. PLoS One 16:e0252565. doi: 10.1371/journal.pone.0252565

Roselli, F., Pisciotta, N. M., Pennelli, M., Aniello, M. S., Gigante, A., De Caro, M. F., et al. (2010). Midbrain SERT in degenerative parkinsonisms: a 123I-FP-CIT SPECT study. Mov. Disord. 25, 1853-1859. doi: 10.1002/mds.23179

Ross, H. F., Hughes, T. A., Boyd, J. L., Biggins, C. A., Madeley, P., Mindham, R. H., et al. (1996). The evolution and profile of dementia in Parkinson's disease. Adv. Neurol. 69, 343-347.

Roth, B. L. (2019). Molecular pharmacology of metabotropic receptors targeted by neuropsychiatric drugs. Nat. Struct. Mol. Biol. 26, 535-544. doi: 10.1038/ s41594-019-0252-8

Sadigh-Eteghad, S., Vatandoust, S. M., Mahmoudi, J., Rahigh Aghsan, S., and Majdi, A. (2020). Cotinine ameliorates memory and learning impairment in senescent mice. Brain Res. Bull. 164, 65-74. doi: 10.1016/j.brainresbull.2020. 08.010

Saitgareeva, A. R., Bulygin, K. V., Gareev, I. F., Beylerli, O. A., and Akhmadeeva, L. R. (2020). The role of microglia in the development of neurodegeneration. Neurol. Sci. 41, 3609-3615. doi: 10.1007/s10072-020-04468-5

Salminen, O., Seppa, T., Gaddnas, H., and Ahtee, L. (1999). The effects of acute nicotine on the metabolism of dopamine and the expression of Fos protein in striatal and limbic brain areas of rats during chronic nicotine infusion and its withdrawal. J. Neurosci. 19, 8145-8151.

Samudra, N., Patel, N., Womack, K. B., Khemani, P., and Chitnis, S. (2016). Psychosis in parkinson disease: a review of etiology, phenomenology, and management. Drugs Aging 33, 855-863. doi: 10.1007/s40266-016-0416-8

Sanjari Moghaddam, H., Zare-Shahabadi, A., Rahmani, F., and Rezaei, N. (2017). Neurotransmission systems in Parkinson's disease. Rev. Neurosci. 28, 509-536. doi: 10.1515/revneuro-2016-0068

Santiago, L. J., and Abrol, R. (2019). Understanding G Protein selectivity of muscarinic acetylcholine receptors using computational methods. Int. J. Mol. Sci. 20:20215290. doi: 10.3390/ijms20215290

Sastry, B. V. (1995). Neuropharmacology of nicotine: effects on the autoregulation of acetylcholine release by substance $\mathrm{P}$ and methionine enkephalin in rodent cerebral slices and toxicological implications. Clin. Exp. Pharmacol. Physiol. 22, 288-290.

Sato, K. Z., Fujii, T., Watanabe, Y., Yamada, S., Ando, T., Kazuko, F., et al. (1999). Diversity of mRNA expression for muscarinic acetylcholine receptor subtypes and neuronal nicotinic acetylcholine receptor subunits in human mononuclear leukocytes and leukemic cell lines. Neurosci. Lett. 266, 17-20. doi: 10.1016/ s0304-3940(99)00259-1

Sayas, C. L., and Avila, J. (2021). GSK-3 and tau: a key duet in alzheimer's disease. Cells 10:721. doi: 10.3390/cells10040721

Schapira, A. H. (2011). Monoamine oxidase B inhibitors for the treatment of Parkinson's disease: a review of symptomatic and potential disease-modifying effects. CNS Drugs 25, 1061-1071. doi: 10.2165/11596310-000000000-00000

Schapira, A. H., and Jenner, P. (2011). Etiology and pathogenesis of Parkinson's disease. Mov. Disord 26, 1049-1055. doi: 10.1002/mds. 23732

Schulz-Schaeffer, W. J. (2010). The synaptic pathology of alpha-synuclein aggregation in dementia with Lewy bodies, Parkinson's disease and Parkinson's disease dementia. Acta Neuropathol. 120, 131-143. doi: 10.1007/s00401-0100711-0 
Schulz-Schaeffer, W. J. (2015). Is cell death primary or secondary in the pathophysiology of idiopathic parkinson's disease? Biomolecules 5, 1467-1479. doi: 10.3390/biom5031467

Scott, L., Dawson, V. L., and Dawson, T. M. (2017). Trumping neurodegeneration: Targeting common pathways regulated by autosomal recessive Parkinson's disease genes. Exp. Neurol. 298, 191-201. doi: 10.1016/j.expneurol.2017.04.008

Searles Nielsen, S., Gallagher, L. G., Lundin, J. I., Longstreth, W. T. Jr., SmithWeller, T., Franklin, G. M., et al. (2012). Environmental tobacco smoke and Parkinson's disease. Mov. Disord. 27, 293-296. doi: 10.1002/mds.24012

Shamoto-Nagai, M., Hisaka, S., Naoi, M., and Maruyama, W. (2018). Modification of alpha-synuclein by lipid peroxidation products derived from polyunsaturated fatty acids promotes toxic oligomerization: its relevance to Parkinson disease. J. Clin. Biochem. Nutr. 62, 207-212. doi: 10.3164/jcbn. $18-25$

Sharma, P. K., Wells, L., Rizzo, G., Elson, J. L., Passchier, J., Rabiner, E. A., et al. (2020). DREADD activation of pedunculopontine cholinergic neurons reverses motor deficits and restores striatal dopamine signaling in parkinsonian rats. Neurotherapeutics 17, 1120-1141. doi: 10.1007/s13311-019-00830-4

Shimohama, S., and Kawamata, J. (2018). "Roles of Nicotinic Acetylcholine Receptors in the Pathology and Treatment of Alzheimer's and Parkinson's Diseases," in Nicotinic Acetylcholine Receptor Signaling in Neuroprotection, eds A. Akaike, S. Shimohama, and Y. Misu (Singapore: Springer), 137-158.

Shin, N. Y., Bang, M., Yoo, S. W., Kim, J. S., Yun, E., Yoon, U., et al. (2021). Cortical thickness from mri to predict conversion from mild cognitive impairment to dementia in parkinson disease: a machine learning-based model. Radiology 2021:203383. doi: 10.1148/radiol.2021203383

Siciliano, C. A., McIntosh, J. M., Jones, S. R., and Ferris, M. J. (2017). alpha6beta2 subunit containing nicotinic acetylcholine receptors exert opposing actions on rapid dopamine signaling in the nucleus accumbens of rats with highversus low-response to novelty. Neuropharmacology 126, 281-291. doi: 10.1016/ j.neuropharm.2017.06.028

Sil'kis, I. G. (2003). [The influence of neuromodulators on the synaptic plasticity in dopaminergic structures of the midbrain (hypothetical mechanism)]. Zh Vyssh Nerv Deiat Im I P Pavlova 53, 464-479.

Singh, J., Singh, P., and Malik, V. (2017). Sensitivity analysis of discharge patterns of subthalamic nucleus in the model of basal ganglia in Parkinson disease. J. Integr. Neurosci. 16, 441-452. doi: 10.3233/JIN- 170027

Skok, M., and Lykhmus, O. (2016). The Role of alpha7 nicotinic acetylcholine receptors and alpha7-specific antibodies in neuroinflammation related to alzheimer disease. Curr. Pharm. Des. 22, 2035-2049. doi: 10.2174/ 1381612822666160127112914

Skok, M. V., Kalashnik, E. N., Koval, L. N., Tsetlin, V. I., Utkin, Y. N., Changeux, J. P., et al. (2003). Functional nicotinic acetylcholine receptors are expressed in B lymphocyte-derived cell lines. Mol. Pharmacol. 64, 885-889. doi: 10.1124/ mol.64.4.885

Snijders, A. H., Takakusaki, K., Debu, B., Lozano, A. M., Krishna, V., Fasano, A., et al. (2016). Physiology of freezing of gait. Ann. Neurol. 80, 644-659. doi: $10.1002 /$ ana. 24778

Soto-Otero, R., Mendez-Alvarez, E., Hermida-Ameijeiras, A., Lopez-Real, A. M., and Labandeira-Garcia, J. L. (2002). Effects of (-)-nicotine and (-)-cotinine on 6-hydroxydopamine-induced oxidative stress and neurotoxicity: relevance for Parkinson's disease. Biochem. Pharmacol. 64, 125-135. doi: 10.1016/s00062952(02)01070-5

Srinivasan, R., Pantoja, R., Moss, F. J., Mackey, E. D., Son, C. D., Miwa, J., et al. (2011). Nicotine up-regulates alpha4beta2 nicotinic receptors and ER exit sites via stoichiometry-dependent chaperoning. J. Gen. Physiol. 137, 59-79. doi: 10. 1085/jgp.201010532

Srivareerat, M., Tran, T. T., Salim, S., Aleisa, A. M., and Alkadhi, K. A. (2011). Chronic nicotine restores normal Abeta levels and prevents short-term memory and E-LTP impairment in Abeta rat model of Alzheimer's disease. Neurobiol. Aging 32, 834-844. doi: 10.1016/j.neurobiolaging.2009.04.015

Stein, J. F., and Aziz, T. Z. (2012). Basal ganglia output to the PPN, a commentary. Exp. Neurol. 233, 745-746. doi: 10.1016/j.expneurol.2011.11.023

Steinberg, R., Souilhac, J., Rodier, D., Alonso, R., Emonds-Alt, X., Le Fur, G., et al. (1998). Facilitation of striatal acetylcholine release by dopamine D1 receptor stimulation: involvement of enhanced nitric oxide production via neurokinin2 receptor activation. Neuroscience 84, 511-518. doi: 10.1016/s0306-4522(97) 00558-7
Stone, T. W. (2021). Relationships and interactions between ionotropic glutamate receptors and nicotinic receptors in the CNS. Neuroscience 2021:7. doi: 10.1016/ j.neuroscience.2021.06.007

Stoof, J. C., Drukarch, B., de Boer, P., and Westerink, B. H. (1992). In vitro and in vivo acetylcholine release from rat striatum as a functional paradigm of signal transduction via a D-2 dopamine receptor. Neurochem. Int. 20, 201S-205S. doi: 10.1016/0197-0186(92)90239-n

Subramaniam, S. R., and Chesselet, M. F. (2013). Mitochondrial dysfunction and oxidative stress in Parkinson's disease. Prog. Neurobiol. 10, 17-32. doi: 10.1016/ j.pneurobio.2013.04.004

Sudheer, P. S., Hall, J. E., Donev, R., Read, G., Rowbottom, A., and Williams, P. E. (2006). Nicotinic acetylcholine receptors on basophils and mast cells. Anaesthesia 61, 1170-1174. doi: 10.1111/j.1365-2044.2006.04870.x

Sulzer, D. (2007). Multiple hit hypotheses for dopamine neuron loss in Parkinson's disease. Trends Neurosci. 30, 244-250. doi: 10.1016/j.tins.2007.03.009

Sulzer, D., and Schmitz, Y. (2007). Parkinson's disease: return of an old prime suspect. Neuron 55, 8-10. doi: 10.1016/j.neuron.2007.06.023

Surmeier, D. J., and Graybiel, A. M. (2012). A feud that wasn't: acetylcholine evokes dopamine release in the striatum. Neuron 75, 1-3. doi: 10.1016/j.neuron.2012. 06.028

Sutachan, J. J., Casas, Z., Albarracin, S. L., Stab, B. R. II, Samudio, I., Gonzalez, J., et al. (2012). Cellular and molecular mechanisms of antioxidants in Parkinson's disease. Nutr. Neurosci. 15, 120-126. doi: 10.1179/1476830511Y.0000000033

Takahashi, M., and Yamada, T. (1999). Viral etiology for Parkinson's disease-a possible role of influenza A virus infection. JPN J. Infect. Dis. 52, 89-98.

Takahashi, T. (2020). Roles of nAChR and Wnt signaling in intestinal stem cell function and inflammation. Int. Immunopharmacol. 81:106260. doi: 10.1016/j. intimp.2020.106260

Tanaka, K., Miyake, Y., Fukushima, W., Sasaki, S., Kiyohara, C., Tsuboi, Y., et al. (2010). Active and passive smoking and risk of Parkinson's disease. Acta Neurol. Scand. 122, 377-382. doi: 10.1111/j.1600-0404.2010.01327.x

Tanimura, A., Pancani, T., Lim, S. A. O., Tubert, C., Melendez, A. E., Shen, W., et al. (2018). Striatal cholinergic interneurons and Parkinson's disease. Eur. J. Neurosci. 47, 1148-1158. doi: 10.1111/ejn.13638

Tata, A. M., Velluto, L., D’Angelo, C., and Reale, M. (2014). Cholinergic system dysfunction and neurodegenerative diseases: cause or effect? CNS Neurol. Disord. Drug Targets 13, 1294-1303. doi: 10.2174/ 1871527313666140917121132

Taverna, S., Ilijic, E., and Surmeier, D. J. (2008). Recurrent collateral connections of striatal medium spiny neurons are disrupted in models of Parkinson's disease. J. Neurosci. 28, 5504-5512. doi: 10.1523/JNEUROSCI.5493-07.2008

Tepper, J. M., Abercrombie, E. D., and Bolam, J. P. (2007). Basal ganglia macrocircuits. Prog. Brain. Res. 160, 3-7. doi: 10.1016/S0079-6123(06)60001-0

Terenzi, M. G., Rees, H., and Roberts, M. H. (1992). The pontine parabrachial region mediates some of the descending inhibitory effects of stimulating the anterior pretectal nucleus. Brain Res. 594, 205-214. doi: 10.1016/0006-8993(92) 91127-z

Terry, A. V. Jr., Buccafusco, J. J., Schade, R. F., Vandenhuerk, L., Callahan, P. M., Beck, W. D., et al. (2012). The nicotine metabolite, cotinine, attenuates glutamate (n.d.) antagonist-related effects on the performance of the five choice serial reaction time task (5C-SRTT) in rats. Biochem. Pharmacol. 83, 941-951.

Terry, A. V. Jr., Callahan, P. M., and Bertrand, D. (2015). R-(+) and s-(-) isomers of cotinine augment cholinergic responses in vitro and in vivo. J. Pharmacol. Exp. Ther. 352, 405-418.

Terry, A. V. Jr., Hernandez, C. M., Hohnadel, E. J., Bouchard, K. P., and Buccafusco, J. J. (2005). Cotinine, a neuroactive metabolite of nicotine: potential for treating disorders of impaired cognition. CNS Drug Rev. 11, 229-252.

Thomas, B., and Beal, M. F. (2007). Parkinson's disease. Hum. Mol. Genet. 2, R183-R194. doi: 10.1093/hmg/ddm159

Thomas, R. L., Langmead, C. J., Wood, M. D., and Challiss, R. A. (2009). Contrasting effects of allosteric and orthosteric agonists on $\mathrm{ml}$ muscarinic acetylcholine receptor internalization and down-regulation. J. Pharmacol. Exp. Ther. 331, 1086-1095. doi: 10.1124/jpet.109.160242

Thomopoulos, C., Lombardi, C., and Parati, G. (2013). Cotinine and blood pressure levels: variability omitted once again. Hypertension 61:e41. doi: 10. 1161/HYPERTENSIONAHA.111.00812

Threlfell, S., Clements, M. A., Khodai, T., Pienaar, I. S., Exley, R., Wess, J., et al. (2010). Striatal muscarinic receptors promote activity dependence of dopamine 
transmission via distinct receptor subtypes on cholinergic interneurons in ventral versus dorsal striatum. J. Neurosci. 30, 3398-3408. doi: 10.1523/ JNEUROSCI.5620-09.2010

Threlfell, S., and Cragg, S. J. (2011). Dopamine signaling in dorsal versus ventral striatum: the dynamic role of cholinergic interneurons. Front. Syst. Neurosci. 5:11. doi: 10.3389/fnsys.2011.00011

Threlfell, S., Lalic, T., Platt, N. J., Jennings, K. A., Deisseroth, K., and Cragg, S. J. (2012). Striatal dopamine release is triggered by synchronized activity in cholinergic interneurons. Neuron 75, 58-64. doi: 10.1016/j.neuron.2012.04.038

Titova, N., and Chaudhuri, K. R. (2018). Non-motor Parkinson disease: new concepts and personalised management. Med. J. Aust. 208, 404-409.

Tiwari, M. N., Agarwal, S., Bhatnagar, P., Singhal, N. K., Tiwari, S. K., Kumar, P., et al. (2013). Nicotine-encapsulated poly(lactic-co-glycolic) acid nanoparticles improve neuroprotective efficacy against MPTP-induced parkinsonism. Free Radic. Biol. Med. 65, 704-718. doi: 10.1016/j.freeradbiomed.2013.07.042

Tiwari, M. N., Agarwal, S., Bhatnagar, P., Singhal, N. K., Tiwari, S. K., Kumar, P., et al. (2015). Nicotine-encapsulated poly(lactic-co-glycolic) acid nanoparticles improve neuroprotective efficacy against MPTP-induced parkinsonism. Free Radic. Biol. Med. 65, 704-718.

Tobin, A. B., and Budd, D. C. (2003). The anti-apoptotic response of the Gq/11coupled muscarinic receptor family. Biochem. Soc. Trans. 31(Pt 6), 1182-1185. doi: 10.1042/bst0311182

Tompkins, M. M., Basgall, E. J., Zamrini, E., and Hill, W. D. (1997). Apoptoticlike changes in Lewy-body-associated disorders and normal aging in substantia nigral neurons. Am. J. Pathol. 150, 119-131.

Toulorge, D., Guerreiro, S., Hild, A., Maskos, U., Hirsch, E. C., and Michel, P. P. (2011). Neuroprotection of midbrain dopamine neurons by nicotine is gated by cytoplasmic Ca2+. FASEB J. 25, 2563-2573. doi: 10.1096/fj.11-182824

Tozzi, A., de Iure, A., Di Filippo, M., Tantucci, M., Costa, C., Borsini, F., et al. (2011). The distinct role of medium spiny neurons and cholinergic interneurons in the $\mathrm{D}(2) / \mathrm{A}(2) \mathrm{A}$ receptor interaction in the striatum: implications for Parkinson's disease. J. Neurosci. 31, 1850-1862. doi: 10.1523/JNEUROSCI. 4082-10.2011

Tripathy, D., Chakraborty, J., and Mohanakumar, K. P. (2015). Antagonistic pleiotropic effects of nitric oxide in the pathophysiology of Parkinson's disease. Free Radic Res. 49, 1129-1139. doi: 10.3109/10715762.2015.1045505

Uspenska, K., Lykhmus, O., Gergalova, G., Chernyshov, V., Arias, H. R., Komisarenko, S., et al. (2017). Nicotine facilitates nicotinic acetylcholine receptor targeting to mitochondria but makes them less susceptible to selective ligands. Neurosci. Lett. 656, 43-50. doi: 10.1016/j.neulet.2017.07.009

Uwada, J., Yoshiki, H., Masuoka, T., Nishio, M., and Muramatsu, I. (2014). Intracellular localization of the M1 muscarinic acetylcholine receptor through clathrin-dependent constitutive internalization is mediated by a C-terminal tryptophan-based motif. J. Cell Sci. 127(Pt 14), 3131-3140. doi: 10.1242/jcs. 148478

Vainio, P. J., Viluksela, M., and Tuominen, R. K. (1998). Nicotine-like effects of cotinine on protein kinase $\mathrm{C}$ activity and noradrenaline release in bovine adrenal chromaffin cells. J. Auton. Pharmacol. 18, 245-250.

Vallee, A., Vallee, J. N., and Lecarpentier, Y. (2021). Parkinson's Disease: Potential Actions of Lithium by Targeting the WNT/beta-Catenin Pathway, Oxidative Stress, Inflammation and Glutamatergic Pathway. Cells 10:230. doi: 10.3390/ cells 10020230

Van Beek, A. H., and Claassen, J. A. (2011). The cerebrovascular role of the cholinergic neural system in Alzheimer's disease. Behav. Brain Res. 221, 537542. doi: 10.1016/j.bbr.2009.12.047

van Nuland, A. J. M., den Ouden, H. E. M., Zach, H., Dirkx, M. F. M., van Asten, J. J. A., Scheenen, T. W. J., et al. (2020). GABAergic changes in the thalamocortical circuit in Parkinson's disease. Hum. Brain Mapp. 41, 10171029. doi: 10.1002/hbm.24857

Vanhauwaert, R., and Verstreken, P. (2015). Flies with Parkinson's disease. Exp. Neurol. 274, 42-51. doi: 10.1016/j.expneurol.2015.02.020

Venkateshappa, C., Harish, G., Mythri, R. B., Mahadevan, A., Bharath, M. M., and Shankar, S. K. (2012). Increased oxidative damage and decreased antioxidant function in aging human substantia nigra compared to striatum: implications for Parkinson's disease. Neurochem. Res. 37, 358-369. doi: 10.1007/s11064-0110619-7

Videira, P. A. Q., and Castro-Caldas, M. (2018). Linking Glycation and Glycosylation With Inflammation and Mitochondrial Dysfunction in
Parkinson's Disease. Front. Neurosci. 12:381. doi: 10.3389/fnins.2018. 00381

Walker, L., Stefanis, L., and Attems, J. (2019). Clinical and neuropathological differences between Parkinson's disease, Parkinson's disease dementia and dementia with Lewy bodies - current issues and future directions. J. Neurochem. 150, 467-474. doi: 10.1111/jnc. 14698

Wang, J. Y., Chen, B. K., Wang, Y. S., Tsai, Y. T., Chen, W. C., Chang, W. C., et al. (2012). Involvement of store-operated calcium signaling in EGF-mediated COX-2 gene activation in cancer cells. Cell Signal. 24, 162-169. doi: 10.1016/j. cellsig.2011.08.017

Wang, M. Y., Meng, M., Yang, C. C., Zhang, L., Li, Y. L., Zhang, L., et al. (2020a). Cornel iridoid glycoside improves cognitive impairment induced by chronic cerebral hypoperfusion via activating PI3K/Akt/GSK-3beta/CREB pathway in rats. Behav. Brain Res. 379:112319. doi: 10.1016/j.bbr.2019.112319

Wang, X., Qiao, Y., Dai, Z., Sui, N., Shen, F., Zhang, J., et al. (2019). Medium spiny neurons of the anterior dorsomedial striatum mediate reversal learning in a cell-type-dependent manner. Brain Struct. Funct. 224, 419-434. doi: 10.1007/ s00429-018-1780-4

Wang, Y., Wang, Y., Zhou, M., Jiang, D., and Deng, X. (2020b). Association of transferrin G258A and transferrin receptor A82G polymorphisms with the risk of Parkinson disease in certain area. Medicine 99:e23432. doi: 10.1097/MD. 0000000000023432

Wang, Y., Yang, Z., and Le, W. (2017). Tiny But Mighty: Promising Roles of MicroRNAs in the Diagnosis and Treatment of Parkinson's Disease. Neurosci. Bull. 33, 543-551. doi: 10.1007/s12264-017-0160-z

Wang, Y. Q., Qu, D. H., and Wang, K. (2016). Therapeutic approaches to Alzheimer's disease through stimulating of non-amyloidogenic processing of amyloid precursor protein. Eur. Rev. Med. Pharmacol. Sci. 20, 2389-2403.

Wayner, M. J., Armstrong, D. L., and Phelix, C. F. (1996). Nicotine blocks angiotensin II inhibition of LTP in the dentate gyrus. Peptides 17, 1127-1133. doi: 10.1016/s0196-9781(96)00179-9

Wess, J., Eglen, R. M., and Gautam, D. (2007). Muscarinic acetylcholine receptors: mutant mice provide new insights for drug development. Nat. Rev. Drug Discov. 6, 721-733. doi: 10.1038/nrd2379

Wichmann, T. (2018). Pathophysiologic Basis of Movement Disorders. Prog. Neurol. Surg. 33, 13-24. doi: 10.1159/000480718

Wichmann, T. (2019). Changing views of the pathophysiology of Parkinsonism. Mov. Disord. 34, 1130-1143. doi: 10.1002/mds.27741

Wilson, M. A., and Fadel, J. R. (2017). Cholinergic regulation of fear learning and extinction. J. Neurosci. Res. 95, 836-852. doi: 10.1002/jnr.23840

Wirdefeldt, K., Adami, H. O., Cole, P., Trichopoulos, D., and Mandel, J. (2011). Epidemiology and etiology of Parkinson's disease: a review of the evidence. Eur. J. Epidemiol. 26(Suppl. 1), S1-S58. doi: 10.1007/s10654-011-9581-6

Wu, J., and Lukas, R. J. (2011). Naturally-expressed nicotinic acetylcholine receptor subtypes. Biochem. Pharmacol. 82, 800-807. doi: 10.1016/j.bcp.2011. 07.067

Wysocka, A., Palasz, E., Steczkowska, M., and Niewiadomska, G. (2020). Dangerous Liaisons: Tau Interaction with Muscarinic Receptors. Curr. Alzheimer Res. 17, 224-237. doi: 10.2174/1567205017666200424134311

Yamamoto, S., Nishiyama, S., Kawamata, M., Ohba, H., Wakuda, T., Takei, N., et al. (2011). Muscarinic receptor occupancy and cognitive impairment: a PET study with $[11 \mathrm{C}](+) 3-\mathrm{MPB}$ and scopolamine in conscious monkeys. Neuropsychopharmacology 36, 1455-1465. doi: 10.1038/npp.2011.31

Yan, Y., Beckley, N. A., Kim, V. J., and Drenan, R. M. (2019). Differential Nicotinic Modulation of Glutamatergic and GABAergic VTA Microcircuits. eNeuro 6:2019. doi: 10.1523/ENEURO.0298-19.2019

Yan, Z., Song, W. J., and Surmeier, J. (1997). D2 dopamine receptors reduce $\mathrm{N}$-type $\mathrm{Ca} 2+$ currents in rat neostriatal cholinergic interneurons through a membrane-delimited, protein-kinase-C-insensitive pathway. J. Neurophysiol. 77, 1003-1015. doi: 10.1152/jn.1997.77.2.1003

Ye, B. S., Jeon, S., Ham, J. H., Lee, J. J., Lee, J. M., Lee, H. S., et al. (2017). Dementia-Predicting Cognitive Risk Score and Its Correlation with Cortical Thickness in Parkinson Disease. Dement. Geriatr. Cogn. Disord. 44, 203-212. doi: 10.1159/000479057

Yim, S. H., and Hee, S. S. (1995). Genotoxicity of nicotine and cotinine in the bacterial luminescence test. Mutat. Res. 335, 275-283.

Yogev-Falach, M., Amit, T., Bar-Am, O., and Youdim, M. B. (2003). The importance of propargylamine moiety in the anti-Parkinson drug rasagiline 
and its derivatives in MAPK-dependent amyloid precursor protein processing. FASEB J. 17, 2325-2327. doi: 10.1096/fj.03-0078fje

Yoo, H. S., Chung, S. J., Lee, Y. H., Ye, B. S., Sohn, Y. H., and Lee, P. H. (2019). Olfactory anosognosia is a predictor of cognitive decline and dementia conversion in Parkinson's disease. J. Neurol. 266, 1601-1610. doi: 10.1007/ s00415-019-09297-x

Zdanowski, R., Krzyzowska, M., Ujazdowska, D., Lewicka, A., and Lewicki, S. (2015). Role of alpha7 nicotinic receptor in the immune system and intracellular signaling pathways. Cent. Eur. J. Immunol. 40, 373-379. doi: 10.5114/ceji.2015. 54602

Zeng, X. S., Geng, W. S., Jia, J. J., Chen, L., and Zhang, P. P. (2018). Cellular and Molecular Basis of Neurodegeneration in Parkinson Disease. Front. Aging Neurosci. 10:109. doi: 10.3389/fnagi.2018.00109

Zevin, S., Jacob, P., Geppetti, P., and Benowitz, N. L. (2000). Clinical pharmacology of oral cotinine. Drug Alcohol. Depend 60, 13-18.

Zhai, S., Shen, W., Graves, S. M., and Surmeier, D. J. (2019). Dopaminergic modulation of striatal function and Parkinson's disease. J. Neural. Transm. 126, 411-422. doi: 10.1007/s00702-019-01997-y

Zhang, D., Mallela, A., Sohn, D., Carroll, F. I., Bencherif, M., Letchworth, S., et al. (2013). Nicotinic receptor agonists reduce L-DOPA-induced dyskinesias in a monkey model of Parkinson's disease. J. Pharmacol. Exp. Ther. 347, 225-234. doi: 10.1124/jpet.113.207639

Zhang, T., Chen, D., and Lee, T. H. (2019). Phosphorylation Signaling in APP Processing in Alzheimer's Disease. Int. J. Mol. Sci. 21:209. doi: 10.3390/ ijms 21010209

Zhao, J., Yu, S., Zheng, Y., Yang, H., and Zhang, J. (2017). Oxidative Modification and Its Implications for the Neurodegeneration of Parkinson's Disease. Mol. Neurobiol. 54, 1404-1418. doi: 10.1007/s12035-016-9743-3

Zheng, B., Liao, Z., Locascio, J. J., Lesniak, K. A., Roderick, S. S., Watt, M. L., et al. (2010). PGC-1alpha, a potential therapeutic target for early intervention in Parkinson's disease. Sci. Transl. Med. 2:59. doi: 10.1126/scitranslmed. 3001059

Zhou, F. M., Wilson, C., and Dani, J. A. (2003). Muscarinic and nicotinic cholinergic mechanisms in the mesostriatal dopamine systems. Neuroscientist 9, 23-36.
Zhu, Z., Yin, J., Guan, J., Hu, B., Niu, X., Jin, D., et al. (2014). Lithium stimulates human bone marrow derived mesenchymal stem cell proliferation through GSK-3beta-dependent beta-catenin/Wnt pathway activation. FEBS J. 281, 5371-5389. doi: 10.1111/febs.13081

Zoccolella, S., Martino, D., Defazio, G., Lamberti, P., and Livrea, P. (2006). Hyperhomocysteinemia in movement disorders: Current evidence and hypotheses. Curr. Vasc. Pharmacol. 4, 237-243. doi: 10.2174/157016106777 698414

Zou, J., Chen, Z., Liang, C., Fu, Y., Wei, X., Lu, J., et al. (2018). Trefoil Factor 3, Cholinesterase and Homocysteine: Potential Predictors for Parkinson's Disease Dementia and Vascular Parkinsonism Dementia in Advanced Stage. Aging Dis. 9, 51-65. doi: 10.14336/AD.2017.0416

Ztaou, S., and Amalric, M. (2019). Contribution of cholinergic interneurons to striatal pathophysiology in Parkinson's disease. Neurochem. Int. 126, 1-10. doi: 10.1016/j.neuint.2019.02.019

Zuchner, T., Perez-Polo, J. R., and Schliebs, R. (2004). Beta-secretase BACE1 is differentially controlled through muscarinic acetylcholine receptor signaling. J. Neurosci. Res. 77, 250-257. doi: 10.1002/jnr.20152

Conflict of Interest: The authors declare that the research was conducted in the absence of any commercial or financial relationships that could be construed as a potential conflict of interest.

Publisher's Note: All claims expressed in this article are solely those of the authors and do not necessarily represent those of their affiliated organizations, or those of the publisher, the editors and the reviewers. Any product that may be evaluated in this article, or claim that may be made by its manufacturer, is not guaranteed or endorsed by the publisher.

Copyright $\odot 2021$ Iarkov, Mendoza and Echeverria. This is an open-access article distributed under the terms of the Creative Commons Attribution License (CC BY). The use, distribution or reproduction in other forums is permitted, provided the original author(s) and the copyright owner(s) are credited and that the original publication in this journal is cited, in accordance with accepted academic practice. No use, distribution or reproduction is permitted which does not comply with these terms. 